Pontifícia U Miversidade $C_{\text {atólica }}$

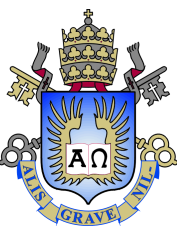

Flávio Araújo Lim-Apo

\title{
Alocação de colaboradores qualificados em missões de fiscalização de uma agência reguladora
}

Dissertação de Mestrado

Dissertação apresentada como requisito parcial para obtenção do grau de Mestre pelo Programa de Pós-graduação em Engenharia de Produção, do Departamento de Engenharia Industrial da PUCRio.

Orientador : Prof. Silvio Hamacher

Coorientador: Prof. Silvia Araujo dos Reis 
Flávio Araújo Lim-Apo

\title{
Alocação de colaboradores qualificados em missões de fiscalização de uma agência \\ reguladora
}

Dissertação apresentada como requisito parcial para obtenção do grau de Mestre pelo Programa de Pós-graduação em Engenharia de Produção da PUC-Rio. Aprovada pela Comissão Examinadora abaixo:

\author{
Prof. Silvio Hamacher \\ Orientador \\ Departamento de Engenharia Industrial - PUC-Rio
}

Prof. Silvia Araujo dos Reis

Co-orientadora

UnB

Prof. Rafael Martinelli Pinto

Departamento de Engenharia Industrial - PUC-Rio

Prof. Janaina Figueira Marchesi

PUC-Rio

Prof. Victor Rafael Rezende Celestino 
Todos os direitos reservados. A reprodução, total ou parcial do trabalho, é proibida sem a autorização da universidade, do autor e do orientador.

Flávio Araújo Lim-Apo

Graduado em Administração pela Universidade de Brasília em 2017. É pesquisador do Instituto Tecgraf (PUC-Rio), atuando na Gerência de Sistemas de Apoio à Decisão e Supply Chain

Ficha Catalográfica

Lim-Apo, Flävio Araújo
Alocação de colaboradores qualificados em missões de
fiscalização de uma agência reguladora / Flávio Araújo Lim-Apo;
orientador: Prof. Silvio Hamacher, co-orientadora: Prof. Silva Araujo
dos Reis. - Rio de Janeiro PUC, Depto. Engenharia Industrial, 2021.
91 f. : il. color. ; $30 \mathrm{~cm}$
Dissertação (mestrado)-Pontifícia Universidade Católica do Rio
de Janeiro, Departamento de Engenharia Industrial, 2021.
Inclui bibliografia
1. Engenharia Industrial - Teses. 2. Alocação de colaboradore
qualificados. 3. MILP. 4. Safety oversight. 5. Julia. I. Hamacher
Silvio. II. Pontifícia Universidade Católica do Rio de Janeiro
Departamento de Engenharia Industrial. III.Título.

CDD: 658.5 
Dedico este trabalho aos meus pais, André e Karine, pelo suporte e os valiosos ensinamentos para meu desenvolvimento pessoal e profissional. 


\section{Agradecimentos}

Aos meus pais André e Karine por apoiarem a realização do mestrado.

Ao orientador Silvio Hamacher, pelo auxílio, suporte e oportunidades, muito obrigado.

À coorientadora Silvia Reis, pelos ensinamentos durante a graduação que me estimularam de continuar pesquisando sobre Pesquisa Operacional.

À Janaína, por acompanhar a pesquisa e ter apresentado pontos de melhoria.

Aos professores do DEI/PUC-Rio pela qualidade do ensino e pelas oportunidades de pesquisa.

Aos professores Silvio Hamacher, Rafael Martinelli, Silvia Reis e Victor Celestino por terem ministrado disciplinas de Pesquisa Operacional, no mestrado e na graduação. Vocês me mostraram o potencial da otimização. Muito do que sei hoje é fruto do que foi ministrado nas disciplinas de vocês.

Aos colegas de turma, pelo companheirismo durante o mestrado.

A todos que de alguma forma auxiliaram a realização dessa pesquisa.

Também gostaria de agradecer pela bolsa de estudos da CAPES que recebi durante o mestrado. Por fim, gostaria de registrar o agradecimento pelo suporte da equipe do DEI.

O presente trabalho foi realizado com apoio da Coordenação de Aperfeiçoamento de Pessoal de Nível Superior - Brasil (CAPES) - Código de Financiamento 001. 


\section{Resumo}

Lim-Apo, Flávio Araújo; Hamacher, Silvio; Reis, Silvia Araujo dos. Alocação de colaboradores qualificados em missões de fiscalização de uma agência reguladora. Rio de Janeiro, 2021. 91p. Dissertação de Mestrado - Departamento de Engenharia Industrial, Pontifícia Universidade Católica do Rio de Janeiro.

As atividades de transporte aéreo devem ser fiscalizadas para garantir a adequação dos níveis de segurança e procedimentos operacionais, no Brasil essa atividade é realizada pela Agência Nacional de Aviação Civil (ANAC). Diversos aeroportos devem ser fiscalizados e em cada um deles uma inspeção diferente pode ser necessária. Os inspetores estão alocados em centros da ANAC em diferentes estados e é importante que o custo dessa atividade de inspeção seja minimizado, respeitando as regras existentes. Nesse sentido, essa dissertação de mestrado propõe dois modelos matemáticos para alocação de agentes qualificados para a realização de missões de fiscalização no território brasileiro. O objetivo é a definição de quais colaboradores formarão cada equipe de fiscalização, minimizando o custo de deslocamento dos agentes. O modelo proposto nesse trabalho é multi-período, para o planejamento operacional quinzenal, com a definição do período que as atividades devem ocorrer, da equipe de inspetores multi-habilitados em atividades de inspeção, multi-origens e multi-destinos. A modelagem é feita no LINGO e em Julia com a utilização do pacote JuMP e dos solvers Gurobi e CPLEX. O Modelo 1 propõe uma reformulação de artigos da literatura e possui tempo de solução entre 2 e 25 vezes menor. O Modelo 2 leva em consideração aspectos não considerados até então no Modelo 1, além disso, dada a quantidade de variáveis de decisão, foi utilizada para resolução do modelo heurística baseada na geração de colunas com programação dinâmica, proposta pelo autor, capaz de reduzir em até $95 \%$ a quantidade de variáveis de decisão. A heurística permitiu a obtenção de solução inteira em instâncias que não a obtiveram com o modelo completo.

\section{Palavras-chave}

Alocação de colaboradores qualificados; MILP; Safety oversight; Julia. 


\section{Abstract}

Lim-Apo, Flávio Araújo; Hamacher, Silvio (Advisor); Reis, Silvia Araujo dos (Co-Advisor). Allocation of skilled workforce on inspection missions of a regulatory agency. Rio de Janeiro, 2021. 91p. Dissertação de Mestrado - Departamento de Engenharia Industrial, Pontifícia Universidade Católica do Rio de Janeiro.

Air transport activities must be inspected to ensure the adequacy of safety levels and operating procedures, in Brazil this activity is carried out by the National Civil Aviation Agency (ANAC). Several airports must be inspected and at each airport a different inspection may be required. The inspectors are located in ANAC centers in different states and it is important that the cost of this inspection activity is minimized, respecting the existing rules. In this sense, this master's thesis proposes two mathematical models for the allocation of qualified workforce to carry out inspection missions in the Brazilian territory. The objective is to define which employees will form in each inspection team, minimizing the cost of displacement of agents. The model proposed in this work is multi-period, for fortnightly operational planning, with the definition of the period that the activities must occur, of a team of multiskilled inspectors in inspection activities, multi-sources and multi-destinations. Modeling is done in LINGO and Julia using the JuMP package and the solvers Gurobi and CPLEX. Model 1 proposes a reformulation of articles in the literature and has a solution time between 2 and 25 times shorter. The second model takes into account aspects not considered so far in Model 1, in addition, given the amount of decision variables, it was used to solve the heuristic model based on the generation of columns with dynamic programming, proposed by the author, capable of reducing by up to $95 \%$ the amount of decision variables. The heuristic allowed obtaining an integer solution in instances that did not have a solution with the complete model.

\section{Keywords}

Skilled workforce scheduling; MILP; Safety oversight; Julia. 


\section{Sumário}

1 Introdução $\quad 13$

$\begin{array}{lll}1.1 & \text { Objetivos } & 14\end{array}$

1.2 Organização da dissertação 15

2 Referencial teórico $\quad 17$

$\begin{array}{lll}2.1 & \text { Safety Oversight System } & 17\end{array}$

2.2 Alocação de colaboradores em atividades qualificadas 18

2.3 Revisão sistemática da literatura 22

2.3.1 Planejamento e formulação do problema 23

$\begin{array}{lll}2.3 .2 & \text { Pesquisa e coleta de dados } & 23\end{array}$

2.3.3 Apresentação dos resultados $\quad 25$

$\begin{array}{ll}2.3 .4 & \text { Dados estatísticos }\end{array}$

$\begin{array}{ll}2.3 .5 & \text { Classificação dos artigos }\end{array}$

2.3.6 Síntese dos achados $\quad 30$

2.3.6.1 Alocação com aprendizagem e retrabalho 32

2.3.6.2 Dependência entre atividades 33

2.3.6.3 Satisfação dos colaboradores 33

2.3.6.4 Alocação com incertezas $\quad 33$

2.3.7 Síntese do referencial teórico 34

3 Descrição do problema $\quad 35$

$\begin{array}{lll}3.1 & \text { ANAC } & 35\end{array}$

$\begin{array}{lll}3.2 & \text { Aplicações na ANAC } & 35\end{array}$

$\begin{array}{lll}3.3 & \text { Premissas } & 38\end{array}$

4 Metodologia $\quad 42$

4.1 Descrição geral dos métodos 42

4.2 Modelo 1 - Modelo para Alocação de Inspetores (MAI) 43

4.2.1 Conjuntos 43

$\begin{array}{lll}4.2 .2 & \text { Subconjuntos } & 43\end{array}$

4.2.3 Parâmetros 44

4.2.4 Variáveis de decisão 44

4.2.5 Equações 44

4.2.6 Função objetivo 44

4.2.7 Restrições 45

4.3 Modelo 2 - Modelo para Alocação de Inspetores Multi-período (MAIM)

4.3.1 Conjuntos 45

$\begin{array}{lll}4.3 .2 & \text { Subconjuntos } & 46\end{array}$

4.3.3 Parâmetros 46

4.3.4 Variáveis de decisão 46

$\begin{array}{lll}4.3 .5 & \text { Equações } & 47\end{array}$

4.3.6 Função objetivo 48

$\begin{array}{lll}4.3 .7 & \text { Restrições } & 48\end{array}$ 
$\begin{array}{lll}4.4 & \text { Redução de variáveis } & 49\end{array}$

$5 \quad$ Resultados e discussões $\quad 55$

5.1 Implementação dos modelos 55

5.2 Instâncias 55

5.3 Pré-processamento de dados 57

5.4 Modelo 1 - MAI 57

$\begin{array}{lll}5.4 .1 & \text { Execução } & 57\end{array}$

5.4.2 Benefícios e limitações do MAI 58

$\begin{array}{lll}5.5 & \text { Modelo } 2 \text { - MAIM } & 60\end{array}$

$\begin{array}{lll}5.5 .1 & \text { Execução } & 60\end{array}$

6 Conclusões $\quad 65$

6.1 Sugestões para trabalhos futuros 66

$\begin{array}{ll}\text { Bibliografia } & 68\end{array}$

$\begin{array}{lll}\text { A Classificação dos artigos selecionados da RSL } & 76\end{array}$

B Planilha com os dados após pré-processamento $\quad 79$

C Mapa com alocação dos inspetores no território brasileiro 80

D Programação dinâmica para criação de colunas $\quad 81$

E Heurística - processo de seleção de variáveis 84

$\begin{array}{llr}\text { F } & \text { Total de variáveis do MAIM } & 86\end{array}$

$\begin{array}{lll}\text { G } & \text { Identificação das alocações } & 87\end{array}$

H Informações das instâncias $r$ 


\section{Lista de figuras}

Figura 2.1 Termos de pesquisa utilizados na base Scopus 24

Figura 2.2 Processo de busca e filtros realizados na RSL 26

Figura 2.3 Nuvem de palavras-chaves indicadas pelos autores 28

Figura 2.4 Relação entre palavras-chaves dos artigos gerada pelo bibliometrix 30

Figura 3.1 Exemplo da alocação de inspetores com 9 períodos 39

Figura 4.1 Fluxograma de solução e da heurística 3 etapas $\quad 51$

Figura 4.2 Fluxograma de solução e da heurística 2 etapas $\quad 52$

Figura 4.3 Detalhamento da heurística 3 etapas 53

Figura 5.1 Exemplo de solução viável 59

Figura 5.2 Exemplo de solução inviável a partir da solução do MAI 59

Figura 5.3 Valor da função objetivo em relação ao tempo da instância A3 63

$\begin{array}{lll}\text { Figura B.1 Planilha com os dados após pré-processamento } & 79\end{array}$

Figura C.1 Mapa com os arcos possíveis e possível solução 80

Figura D.1 Matriz da programação dinâmica 82

Figura D.2 Código da programação dinâmica implementado em Julia 83

$\begin{array}{lll}\text { Figura G.1 Parte da solução do MAIM } & 88\end{array}$

$\begin{array}{lll}\text { Figura G.2 Parte da solução do MAIM } & 88\end{array}$ 


\section{Lista de tabelas}

$\begin{array}{lll}\text { Tabela 2.1 } & \text { Artigos mais citados } & 26\end{array}$

Tabela 2.2 $\quad$ Pesquisas mais citadas pelos artigos selecionados 27

Tabela 2.3 Publicações por journal 27

Tabela 2.4 Frequência das palavras-chaves mais utilizadas $\quad 29$

$\begin{array}{lll}\text { Tabela 2.5 } & \text { Publicações por ano } & 29\end{array}$

Tabela 2.6 Classificação, software e solver utilizados nos trabalhos identificados 31

Tabela 2.7 Identificação dos trabalhos que utilizaram multiperíodos, multi-origens e multi-destinos 31

Tabela 2.8 Identificação dos trabalhos que utilizaram skills e tamanho das equipes 32

Tabela 3.1 Descrição dos trabalhos realizados na ANAC 37

Tabela 5.1 Características das instâncias utilizadas $\quad 57$

Tabela 5.2 Tempo de solução em segundos das instâncias utilizadas 58

Tabela 5.3 Tempo de solução do Modelo $2 \quad 61$

Tabela 5.4 Best bound e GAP estimados 61

Tabela 5.5 Redução de variáveis com a geração de colunas 64

Tabela A.1 Dados coletados dos artigos selecionados e modelos $\begin{array}{ll}\text { propostos } & 76\end{array}$

$\begin{array}{lll}\text { Tabela A.2 Dados coletados dos artigos selecionados } & 77\end{array}$

$\begin{array}{lll}\text { Tabela F.1 Variáveis do MAIM } & 86\end{array}$

$\begin{array}{lll}\text { Tabela H.1 } & \text { Atividades e inspetores disponíveis } & 89\end{array}$

$\begin{array}{lll}\text { Tabela H.2 Inspeções por destino } & 90\end{array}$

$\begin{array}{lll}\text { Tabela H.3 Inspeções por colaborador } & 91\end{array}$

Tabela H.4 Origem do colaborador que atenderá a inspeção $\quad 91$

Tabela H.5 Quantidade de destinos que cada inspetor irá visitar 91 


\section{Lista de Abreviaturas}

ANAC - Agência Nacional de Aviação Civil

$\mathrm{BB}-$ Best Bound

FAA - Federal Aviation Administration

LP - Linear programming

NLP - Nonlinear Programming

MAI - Modelo para Alocação de Inspetores

MAIM - Modelo para Alocação de Inspetores Multi-Período

MI - Melhor (solução) Inteira

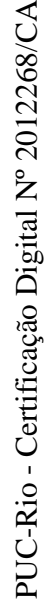

MILP - Mixed-Integer Linear Programming

MINLP - Mixed Integer Nonlinear Programming

NURAC - Núcleo Regional de Aviação Civil

PSO-BR - Programa Brasileiro para a Segurança Operacional da Aviação Civil

RSL - Revisão Sistemática da Literatura

SIA - Superintendência de Infraestrutura Aeroportuária

SFI - Superintendência de Ação Fiscal

SPO - Superintendência de Padrões Operacionais 


\section{1 \\ Introdução}

Em 2019, antes da pandemia do Sars-CoV-2, o transporte de passageiros estava em crescimento, 119,4 milhões de pessoas foram transportadas neste ano no Brasil, um aumento de 1,4\% no número de passageiros em relação ao ano anterior (ANAC, 2020b).

O Sars-CoV-2 em 2020 impactou todos os países, embora tenha ocorrido uma redução significativa no número de pessoas transportadas e no número de voos realizados, a aviação assumiu um papel muito importante com o transporte de equipamento médico (ANAC, 2020a, 2021). Em 2021, além do transporte de itens hospitalares, como respiradores e equipamentos de proteção individual, o transporte aéreo tem sido o principal meio de transporte de vacinas para a Covid-19.

Dada a importância desse modal, seja para o transporte de pessoas ou de cargas, é preciso que exista segurança na realização dos voos. Existem regulamentos para os aeroportos, companhias aéreas, aviões e equipes que devem ser seguidos para garantir a correta execução de atividades e processos.

A atividade de fiscalização de uma agência reguladora de transporte aéreo é fundamental para garantir segurança e conformidade às atividades de transporte dos passageiros. A fiscalização busca garantir que as atividades estejam observando as regulamentações existentes. A fiscalização ocorre em todo o território brasileiro e o planejamento e alocação dos colaboradores não são atividades triviais, dada a existência de restrições operacionais para a realização da inspeção.

Dias (2019) afirma que existem poucas aplicações de Pesquisa Operacional no Brasil no setor público com a aplicação de ferramentas de otimização. Considerando a complexidade do problema, a alocação de colaboradores em atividade de inspeção possui um alto custo de execução, levando-se em consideração os custos de deslocamento e de acomodação dos inspetores. Além do que, dadas as diversas habilitações e missões que devem ser realizadas, o problema de alocação demanda muito tempo para a alocação manual dos colaboradores nessas atividades. 
A utilização de uma ferramenta de apoio à decisão pode proporcionar melhorias na alocação dos inspetores, uma vez que é possível obter melhor resultado com um menor custo para esta alocação, atendendo às restrições existentes e em um tempo de solução menor do que o atual.

O estudo desenvolveu-se na Agência Nacional de Aviação Civil (ANAC), agência reguladora fundada em 2005 que apresenta como uma de suas finalidades garantir a segurança técnica do setor aéreo. É responsável pela regulação e fiscalização das atividades de aviação civil e de infraestrutura aeronáutica e aeroportuária. (BRASIL, 2005)

Existem trabalhos aplicados na ANAC por Freitas Júnior (2017), Silva (2018), Pinheiro (2018), Reis e Celestino (2018), ANAC (2019a), Lopes (2019), Couto (2020) e Silva Junior (2021) que realizam a alocação de inspetores; todavia, existem pontos de melhoria nos modelos realizados para a utilização da solução no auxílio da tomada de decisão. São pontos de melhoria: a consideração de tempos e custos diferentes para os arcos de ida e de volta; multi-períodos e inclusão de ajuda de custo ao colaborador que estiver em serviço. As considerações feitas nos trabalhos citados estão detalhadas no Referencial Teórico.

\section{1 \\ Objetivos}

Este trabalho respondeu à seguinte pergunta de pesquisa: como realizar a alocação dos agentes em atividades de fiscalização com o objetivo de minimizar o custo da operação e do transporte - respeitando as exigências das atividades, habilitações, localização das demandas e dos colaboradores?

Dessa forma, essa dissertação teve como objetivo geral a elaboração de um modelo matemático de apoio à decisão para o planejamento operacional de alocação de agentes em atividades de fiscalização, considerando as restrições de capacitações necessárias, formação de equipes, duração de cada demanda, tempo disponível de cada inspetor. Além das restrições fundamentais do modelo, outras restrições opcionais com viés qualitativo foram acrescentadas para entregar maior satisfação aos agentes.

Nesse sentido, foram definidos objetivos específicos para o alcance do objetivo principal:

i. identificar as características específicas do problema para a alocação de colaboradores em atividades de inspeção;

ii. fazer análise exploratória de dados nas bases de colaboradores, habilitações e missões; 
iii. melhorar a performance do modelo operacional;

iv. incluir novas funcionalidades em relação ao modelo atual;

v. comparar os resultados do modelo com modelos existentes.

A dissertação traz benefícios para a academia e para o mundo organizacional, uma vez que foi realizada revisão do referencial teórico e, com isso, uma base de conteúdo foi elaborada. Do ponto de vista organizacional, o modelo proposto poderá ser utilizado pela organização em estudo. Não existe limitação para que outras organizações também façam a implementação e assim possam reduzir custos e tempo de alocação de colaboradores em processos semelhantes.

A alocação dos inspetores, quando realizada de forma manual, pode consumir muito tempo; e ainda não garante que a alocação tenha um custo ótimo, ou próximo do ótimo, e nem garante que a solução respeite todas as restrições do problema.

Além dos trabalhos citados, não foram encontrados outros artigos que abordassem a alocação de colaboradores de inspeção em múltiplas origens com múltiplos destinos utilizando modelagem matemática. Trabalhos encontrados do setor aéreo abordam planejamento de manutenção, mas não incluem atividades de inspeção. A dissertação é de natureza quantitativa e utilizou como instrumentos de pesquisa a revisão sistemática de literatura, elaboração de modelo matemático e implementação de heurística.

\section{2}

\section{Organização da dissertação}

A dissertação está organizada em 6 capítulos, iniciando-se pela introdução, seguida pelos seguintes:

O Capítulo 2 apresenta a revisão da literatura em relação às atividades de alocação de inspetores em missões, e inclui modelos matemáticos da literatura e técnicas de solução de problemas de alocação de colaboradores. Após a revisão inicial da literatura, são descritas as etapas e resultados da Revisão Sistemática da Literatura.

O Capítulo 3 contém a contextualização, descrição do problema e análise exploratória dos dados que são utilizados. As informações obtidas dos dados iniciais permitem melhor compreensão do problema e da metodologia utilizada.

O Capítulo 4 apresenta a metodologia e ferramentas de otimização empregadas, também são descritos os indicadores de mensuração do resultado do modelo matemático. 
No Capítulo 5 discorre-se sobre o resultado encontrado com a elaboração do modelo matemático. As melhorias encontradas em relação à alocação atual dos colaboradores foram correlacionadas neste capítulo, além disso, mostrouse os resultados dos indicadores utilizados para mensuração da qualidade da alocação do modelo.

Por fim, no Capítulo 6 são apresentadas as considerações finais da dissertação, contribuições e sugestões para estudos futuros, levando em consideração as limitações e dificuldades encontradas na dissertação. 


\section{2 \\ Referencial teórico}

Nesse capítulo, apresentou-se a revisão da literatura dos problemas relacionados à Safety Oversight System, alocação de colaboradores capacitados e revisão sistemática da literatura.

\section{1}

\section{Safety Oversight System}

O transporte aéreo de passageiros é regulamentado e segue procedimentos para manter a segurança operacional. ICAO (2006) apresenta Safety Oversight System como um meio para garantir a implementação eficaz das normas e práticas recomendadas relacionadas à segurança e procedimentos.

No Brasil, de acordo com o Programa Brasileiro para a Segurança Operacional da Aviação Civil (PSO-BR), é apresentada a definição de Segurança Operacional (ANAC, 2019b).

\footnotetext{
O Estado brasileiro adotou a definição de Segurança Operacional como sendo o estado no qual o risco de lesões às pessoas ou danos aos bens se reduz e se mantém em um nível aceitável, ou abaixo deste, por meio de um processo contínuo de identificação de perigos e gestão de riscos. Neste contexto, faz-se necessário um monitoramento contínuo dos riscos e das ameaças presentes no ambiente operacional da aviação, de modo que as ações preventivas possam ser adotadas de maneira eficiente. Para tanto, é preciso compreender o panorama atual de acidentes e incidentes aeronáuticos, de modo que se possa prospectar cenários futuros (análise de tendências), concentrando os esforços nas áreas mais sensíveis (ANAC, 2019b).
}

Hansen e McAndrews (2005) informam dificuldades existentes em verificar o sistema de Safety Oversight System da FAA (Federal Aviation Administration), agência americana de transporte aéreo equivalente à ANAC no Brasil. Os autores afirmam que tal dificuldade não é restrita ao transporte aéreo, visto encontradas em agências de outros modais. 
Com as definições da ICAO (2006) e da ANAC (2019b), é possível compreender que Safety Oversight System são um conjunto de métodos e ferramentas que buscam garantir a segurança da aviação em geral. Nesse sentido, de acordo com Araújo (2015), o objetivo do inspetor é melhorar a qualidade do serviço das aeronaves, passageiros e de carga, garantindo a segurança, regularidade e eficiência dos voos.

\section{2}

\section{Alocação de colaboradores em atividades qualificadas}

Uma das formas de verificar se as atividades seguem os regulamentos é a execução de inspeções. Assim, colaboradores habilitados para realizar atividades de inspeção devem ser alocados nas missões.

Os problemas de alocação exigem que a demanda seja atendida com recursos considerados limitados. De acordo com Paraskevopoulos et al. (2017), possíveis recursos são colaboradores qualificados, enfermeiros, operadores, veículos, máquinas e equipamentos. Segundo estes autores, esse tipo de problema aplica-se em eventos de instalação, manutenção, reparo, Home and health care e em problemas de alocação em aeroportos.

$\mathrm{Na}$ literatura, são diversos os problemas de personnel scheduling, no entanto cada modelo possui uma característica que pode diferenciar a sua finalidade dos demais. Van Den Bergh et al. (2013) realizaram pesquisa de revisão de literatura com aplicação de alocação de colaboradores em 291 artigos e identificaram características que podem ou não estarem presentes, são elas:

i. contratação de colaboradores em tempo integral ou parcial, e casuais;

ii. exigência ou não na alocação de colaboradores qualificados;

iii. alocação individual ou em equipes;

iv. as alocações podem ocorrer por atividade, por grupo, por sequência ou ordem temporal;

v. em alguns casos é permitido que cada colaborador realize mais de uma atividade no mesmo instante, assim como podem ser estabelecidos tempos de início rígidos ou não;

vi. flexibilização na quantidade de colaboradores alocados, sendo permitido alocar uma quantidade menor do que a necessária, todavia, penalizando a função objetivo; 
vii. em alguns artigos, foi permitido que colaboradores não qualificados fossem alocados em atividades qualificadas, todavia, essa alocação é penalizada na função objetivo.

Paraskevopoulos et al. (2017) catalogaram 49 artigos e observaram três aspectos: qualificação do recurso, requisitos da operação, e objetivos para identificar a taxonomia do problema de alocação de recursos. As qualificações do recurso em um problema de alocação de colaboradores não estão associadas somente à possibilidade do colaborador possuir ou não tal qualificação, mas também ao nível de qualificação que ele dispõe. Os requisitos da operação estão associados às regras que devem ser seguidas para a alocação, os problemas podem ser temporais, de precedência, multi-períodos e de importância. Por fim, cada variação de problema pode possuir um objetivo específico, e os objetivos identificados pelos autores foram redução de atrasos, distância, balanceamento de trabalho ou maximização de prioridades.

As restrições de alocação de colaboradores qualificados podem ser soft e hard. As restrições do tipo hard devem obrigatoriamente ser seguidas, enquanto que as soft permitem uma flexibilização - normalmente associada a uma penalização na função objetivo. Paraskevopoulos et al. (2017) identificaram artigos com esse tipo de restrição na alocação em janelas de tempo e em regras de precedência.

Para a realização do planejamento da alocação de colaboradores que realizam inspeções, é preciso levar em consideração que os inspetores podem ter diversos tipos de competências e devem atuar em conjunto para a realização das atividades.

Anwar et al. (2013) mostram pesquisa para a alocação de pessoas qualificadas em um projeto de software. No estudo foram detalhados os requisitos necessários para a alocação considerando não somente a qualificação dos colaboradores, como também a expertise sobre o problema. Nessa pesquisa é possível identificar a necessidade de compreender os aspectos específicos para que a solução atenda o problema real.

A atividade de inspeção reúne especificidades a serem consideradas para realizar a alocação dos inspetores nas atividades. Chaker et al. (2019) realizaram survey para avaliar quais aspectos relevantes devem ser considerados na alocação de colaboradores, especificamente em atividades de inspeção para que os objetivos do cliente sejam atendidos com a redução de custo para realizar essa atividade. 
Chaker et al. (2019), por meio de entrevistas, identificaram 5 aspectos que devem ser levados em consideração no planejamento da alocação dos colaboradores para que as necessidades e objetivos da alocação sejam alcançados, assim:

i. necessidade - deve haver uma demanda para a implementação de um sistema de alocação. Tal demanda pode decorrer: da demora da alocação, dos resultados com custo maior do que o ótimo, ou ainda da impossibilidade do processo manual apresentar uma alocação viável de ser realizada;

ii. restrições - deve-se compreender as restrições e regras de negócio que a alocação deve seguir, alocando os colaboradores somente nas atividades em que estes sejam habilitados;

iii. objetivo - identificar o objetivo pretendido pela organização, seja minimizar os custos respeitando as regras existentes, equiparar a quantidade de horas e/ou de viagens realizadas por cada colaborador, ou ainda alocar o colaborador em atividades que ele tenha preferência em realizar;

iv. expectativas - com a implementação de uma ferramenta de otimização, almeja-se que os erros humanos sejam minimizados e que haja uma melhora da solução em relação à alocação manual. Além disso, comumente espera-se que exista uma plataforma que permita a visualização da alocação dos colaboradores;

v. informações adicionais - embora em alguns casos diversos inspetores possam realizar determinada inspeção, eventualmente, a depender do tipo do problema, é ideal que seja designado um colaborador com maior experiência para proceder a missão. Nessa etapa, devem ser levantados itens que dependem das exigências e especificidades da alocação.

Kuo et al. (2014) descrevem tipos de habilitações dos colaboradores e níveis que podem ser exigidos para as atividades; os autores classificam as habilitações em dois níveis, as habilitações que podem ser avaliadas em um nível de qualificação do colaborador, como nenhuma, mínimo ou avançado, e as habilitações que o colaborador possui ou não possui. As habilitações que são em níveis permitem que um colaborador com um nível mínimo de qualificação realize a atividade; de outro lado, algumas tarefas críticas não permitem que pessoas com um nível baixo de habilitação as realize.

Em um problema de alocação de pessoas qualificadas, é possível que existam algumas com poucas qualificações e outras com muitas. Gomar et al. (2002) abordam a relação das habilitações de cada colaborador com o impacto no número de pessoas a serem contratadas. $\mathrm{O}$ estudo foi realizado no 
setor construtivo e concluiu-se que ter entre 10 e $20 \%$ de colaboradores multicapacitados gerou redução no custo de contratação. É custoso e eventualmente inviável que a organização capacite os colaboradores em todas as habilitações possíveis. Dessa forma, deve existir um trade-off para a definição das habilitações necessárias para cada colaborador.

Além das aplicações realizadas na ANAC por Freitas Júnior (2017), Silva (2018), Pinheiro (2018), Reis e Celestino (2018), ANAC (2019a), Lopes (2019), Couto (2020) e Silva Junior (2021), não foram encontrados artigos que abordem a utilização de modelagem matemática para a alocação de atividades de inspeção, todavia, Wan e Bard (2007) propuseram um modelo matemático para a alocação de pessoal em atividades que exigem qualificações dos colaboradores. Os autores utilizaram geração de colunas para reduzir a complexidade do modelo matemático.

Relacionado ao setor de transporte aéreo, Kuo et al. (2014) apresentam modelo matemático para a alocação de colaboradores qualificados de uma empresa aérea para a realização de atividades de embarque e desembarque dos passageiros, considerando que existem atividades executadas em locais diferentes e que cada colaborador pode ser capacitado ou não para realizar as referidas atividades. Na modelagem, foi considerada a existência de múltiplas atividades em múltiplos locais, todavia, o modelo não leva em consideração a origem do colaborador.

A pesquisa apresentada por Kuo et al. (2014) busca resolver o problema de alocação de colaboradores que atendem os passageiros, para o check-in e embarque, de uma companhia aérea; embora existam múltiplos locais onde o colaborador possa ser alocado, o ambiente é restrito ao aeroporto, e há um baixo tempo de deslocamento entre os locais que os colaboradores podem atuar.

Para o planejamento estratégico da realização de atividades de inspeção podem existir incertezas que devem ser levadas em consideração, nesse sentido, Campbell (2011) elaborou um modelo matemático estocástico em duas etapas para a alocação de colaboradores qualificados em atividades com demanda aleatória.

Por fim, Gopalan (2014) apresenta um modelo utilizando grafos para a resolução de um problema de facility location para a definição de locais utilizados como base para a manutenção de aviões. A abordagem utilizada pode ser adaptada para definição dos centros que devem ser utilizados e quais inspetores devem estar em cada centro. 
O problema de alocação de colaboradores é complexo, Firat e Hurkens (2012) abordam técnicas de solução e a complexidade do problema de alocação de colaboradores com habilitações. Cuevas et al. (2016) apresentam modelo matemático para minimizar as pessoas alocadas, dada uma variação na demanda de serviço ao decorrer do dia, considerando a qualificação dos colaboradores.

\section{3}

\section{Revisão sistemática da literatura}

A alocação de colaboradores qualificados em atividades de inspeção abrange especificidades e características a serem analisadas. Para Moher et al. (2015), é essencial a utilização de um protocolo para a realização da RSL, uma vez que a documentação do que foi planejado e do que foi realizado confere transparência ao processo e ainda reduz arbitrariedades. Dessa forma, foi realizada revisão sistemática da leitura (RSL) utilizando os oito passos apresentados por Thomé et al. (2016).

Os passos apresentados por Thomé et al. (2016) são divididos em oito etapas, apresentadas abaixo:

i. planejamento e formulação do problema - Nessa etapa é realizada a definição de escopo da pesquisa, conceitualização do tópico que será abordado, definição das perguntas de pesquisa, definição das categorias para caraterização dos dados e definição do protocolo que será utilizado;

ii. pesquisa na literatura - Seleção da base para pesquisa, palavras-chaves, análise de resumos e de texto para a definição dos termos de pesquisa;

iii. coleta de dados - Coleta e estruturação dos artigos que serão encontrados;

iv. avaliação da qualidade - Deve-se verificar se não existe algum tipo de viés nos artigos que foram encontrados;

v. análise e síntese de dados - Verificação de possíveis informações faltantes, descrição e sínteses dos dados encontrados;

vi. interpretação - Interpretação dos dados analisados;

vii. apresentação dos resultados - Preparação da apresentação dos dados;

viii. atualização da revisão - Quando identificada a necessidade de atualização da revisão sistemática, é preciso reiniciar o processo apresentado. 
No fluxo das etapas apresentadas, existe uma retroalimentação na etapa (ii) e nas etapas (iii) e (iv), assim como nas etapas (vii) e (viii) que retornam ao início da revisão sistemática da leitura.

\subsection{1}

\section{Planejamento e formulação do problema}

A primeira etapa da RSL é a definição do escopo da pesquisa, da pergunta de pesquisa e do objetivo.

Considerando o contexto de alocação de colaboradores qualificados em atividades nos modais de trasporte com a utilização de modelos matemáticos, a RSL tem como objetivo identificar aplicações deste tipo de problema e compreender as principais características.

A realização da RSL é necessária uma vez que os modelos clássicos de alocação de colaboradores não incorporam características específicas existentes em atividades de alocação de inspetores em atividades qualificadas.

Nesse sentido, formulou-se a seguinte pergunta de pesquisa da RSL: "quais foram as aplicações de modelos matemáticos para a alocação de colaboradores em atividades envolvidas pelo Safety Oversight System nos modais de transportes?"

Após filtro e seleção dos artigos, foi feita classificação dos artigos em relação ao contexto da aplicação, classe do modelo matemático, quantidade de períodos, origens, destinos, identificação de habilidades e tamanho da equipe que será alocada. Além disso, foram catalogados a linguagem de implementação, solver utilizada para a modelagem matemática e algoritmos adicionais que tenham sido desenvolvidos nos artigos.

\subsection{2}

\section{Pesquisa e coleta de dados}

Para a realização da RSL, optou-se pela consulta dos artigos disponíveis na base de dados Scopus.

Foi realizada busca inicial na literatura por artigos que abordassem modelagem matemática, otimização, modelos LP, MILP e MINLP, alocação de colaboradores qualificados, Safety Oversight System, technician routing, e que fossem aplicados nos modais de transporte. Após essa busca prévia, foram definidos os termos de busca dos artigos. Os termos da pesquisa são apresentados na Figura 2.1. Os artigos selecionados na pesquisa continham pelo menos um dos termos do "tipo de problema" e do "método de solução", 
além do tipo de publicação, devendo ser um artigo em inglês e publicado a partir de 2011. Esclareça-se que foram selecionados apenas artigos publicados a partir de 2011, uma vez que existiam escassas pesquisas sobre o tema nos anos anteriores.

Tipo do problema

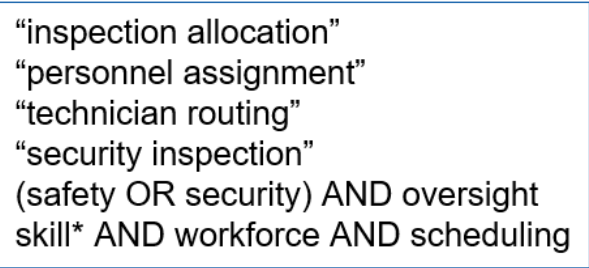

Método de solução

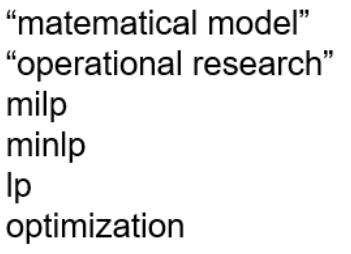

Publicação

$\mathrm{ANO}(>=2011)$

\begin{tabular}{|l|}
\hline Inglês \\
\hline Artigo
\end{tabular}

Figura 2.1: Termos de pesquisa utilizados na base Scopus

Conforme apresentado na Figura 2.1, foi definido um amplo período de busca, dado que foram encontradas poucas publicações sobre esse tema, assim, o filtro encontra as publicações a partir de 2011.

Para a interpretação dos resultados da RSL, os artigos foram classificados e 9 tipos de informações foram catalogados. A descrição de cada informação é definida a seguir:

1. classificação da modelagem matemática - o problema matemático pode ser classificado em Programação Linear (LP), Programação Linear Inteira Mista (MILP), Programação Não Linear (NPL) e Programação Não Linear Inteira Mista (MINLP);

2. identificação do software em que o modelo matemático foi implementado;

3. identificação do solver utilizado para a resolução do modelo matemático;

4. identificação de heurística, meta-heurística ou de algoritmo auxiliar desenvolvido para auxiliar na resolução do problema, podendo ser utilizado junto com o modelo matemático, como a geração de colunas ou decomposição;

5. classificação do modelo como multi-período ou não, ou seja, se é definido o período ou intervalo em que a atividade inicia e termina ou se é realizada a alocação do colaborador sem a especificação do período em que a atividade deve ser realizada; 
6. classificação do modelo como multi-origens, ou seja, se existe mais de um local onde os colaboradores estão alocados na origem. São classificados como multi-origens nos casos em que os colaboradores podem estar distribuídos em mais de uma central, seja em cidades diferentes ou em locais diferentes dentro do mesma localidade;

7. classificação do modelo como multi-destino, ou seja, se existe mais de um local onde os colaboradores podem ser alocados - nessa categoria o destino é definido como locais diferentes, como cidades diferentes, ou locais diferentes dentro da mesma localização, desde que o tempo de deslocamento possa ser diferente;

8. identificação se o modelo matemático considera a habilitação dos colaboradores para a realização da atividade. As habilitações podem indicar se o colaborador é habilitado ou não para realizar a atividade ou ainda indicar o nível da habilidade/experiência - caso o nível seja baixo, normalmente é atribuída penalização na função objetivo. Dependendo do tipo de problema abordado, pode ser permitido que colaboradores não qualificados realizem determinadas atividades. Todavia, quando isso ocorre, pode ser atribuída penalização ou probabilidade de retrabalho nessa atividade;

9. identificação se a alocação dos colaboradores é realizada em atividades que demandem mais de uma pessoa, se a alocação é realizada apenas em grupos, ou se o modelo permite que ambos os casos ocorram.

Foi realizada avaliação da qualidade, uma vez que foram selecionados artigos a partir da base Scopus. E, como dito anteriormente, selecionados artigos publicados a partir de 2011.

\subsection{3}

\section{Apresentação dos resultados}

Conforme apresentado por Thomé et al. (2016), a etapa de pesquisa na literatura exige uma retroalimentação até que exista confiabilidade da pesquisa, desse modo, foram realizadas diversas combinações de palavraschaves até a obtenção da combinação que melhor compreendesse o escopo da pesquisa, a Figura 2.1 apresenta a seleção realizada.

A partir das palavras-chaves apresentadas na base de dados Scopus, foram recuperados inicialmente 72 artigos. Após leitura do título, dispensouse 35 artigos - por terem o método de solução com o uso exclusivo de heurísticas e meta-heurísticas, ou por não abordarem o problema de alocação de colaboradores. 
Após o filtro inicial, selecionou-se 37 artigos para a segunda fase, para leitura do resumo. Nessa etapa foram removidos mais 19 artigos - dos quais sete não apresentaram modelo matemático, seis enfocavam na alocação para manufatura, dois não estavam relacionados ao tema de pesquisa e um abordava a predição do tempo e não a alocação dos colaboradores. Ao final, os 18 artigos restantes foram lidos e classificados. Esse processo é apresentado na Figura 2.2.

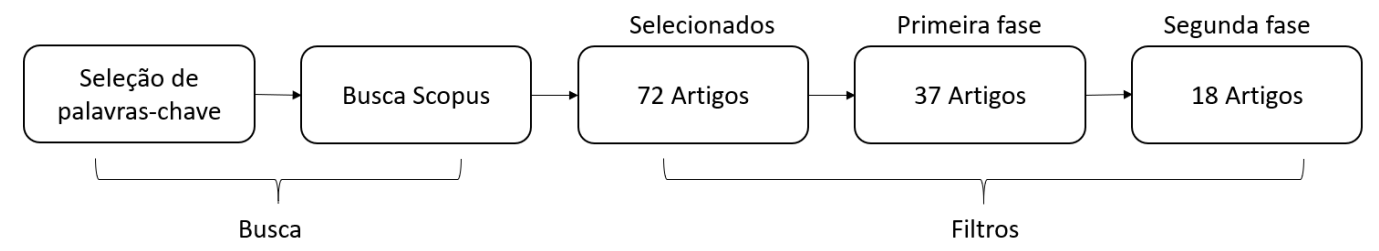

Figura 2.2: Processo de busca e filtros realizados na RSL

\subsection{4}

\section{Dados estatísticos}

As informações bibliográficas dos artigos foram selecionadas e analisadas. Por meio do pacote bibliometrix do software $R$ consolidou-se parte das informações estatísticas dos artigos selecionados (ARIA; CUCCURULLO, 2017). Os artigos com pelo menos 4 citações são apresentados na Tabela 2.1.

Tabela 2.1: Artigos mais citados

\begin{tabular}{cc} 
Artigo & Citações \\
\hline Maghsoudlou et al. $(2017)$ & 38 \\
Safaei et al. $(2012)$ & 15 \\
Lazzerini e Pistolesi (2018) & 11 \\
Zabihi et al. $(2019)$ & 9 \\
Karam et al. $(2017)$ & 9 \\
Pour et al. $(2017)$ & 8 \\
Qin et al. $(2016)$ & 7 \\
Pereira et al. $(2020)$ & 4 \\
Kiermaier et al. $(2020)$ & 4 \\
Dahmen et al. $(2020)$ & 4 \\
Kiermaier et al. $(2020)$ & 4
\end{tabular}

Em relação ao país do autor correspondente, o Irã possui 4 artigos, Alemanha 3 artigos, Canadá 2 artigos, Brasil, China, Hong Kong, Itália e Estados Unidos da América possuem 1 artigo, em 4 artigos não foi informado o país do autor correspondente.

A Tabela 2.2 apresenta as referências mais citadas pelos artigos filtrados, os demais artigos tiveram somente uma citação. 
Tabela 2.2: Pesquisas mais citadas pelos artigos selecionados

\begin{tabular}{cc} 
Artigos & Citações \\
\hline Castillo-Salazar et al. $(2016)$ & 3 \\
Kovacs et al. $(2012)$ & 3 \\
Hosseinian e Baradaran (2019) & 3 \\
Anzanello e Fogliatto (2011) & 2 \\
Heimerl e Kolisch (2010) & 2 \\
Nembhard e Uzumeri (2000) & 2 \\
Restrepo et al. (2016) & 2 \\
Valls et al. $(2009)$ & 2 \\
Zamorano e Stolletz (2017) & 2
\end{tabular}

Tabela 2.3: Publicações por journal

\begin{tabular}{lc}
\hline Journal & Publicações \\
\hline Computers and Industrial Engineering & 4 \\
IFAC-PapersOnLine & 2 \\
Academia Revista Latinoamericana de Administracion & 1 \\
Applied Soft Computing Journal & 1 \\
Computers and Operations Research & 1 \\
Engineering, Construction and Architectural Management & 1 \\
EURO Journal on Transportation and Logistics & 1 \\
European Journal of Operational Research & 1 \\
IEEE Transactions on Systems, Man, and Cybernetics: Systems & 1 \\
International Journal of Production Research & 1 \\
Journal of Optimization in Industrial Engineering & 1 \\
Journal of Scheduling & 1 \\
Mathematical Problems in Engineering & 1 \\
Omega (United Kingdom) & 1 \\
\hline Total & 18
\end{tabular}

O Journal Computers and Industrial Engineering publicou 4 artigos e o IFAC-PapersOnLine 2 artigos, os demais artigos foram publicados em outros 12 journal, conforme exposto na Tabela 2.3.

A Figura 2.3 apresenta uma nuvem de palavras contendo as palavraschaves encontradas nos artigos; a Tabela 2.4 contém as palavras-chaves mais utilizadas.

A Figura 2.4 apresenta uma funcionalidade do pacote bibliometrix, a possibilidade de identificar visualmente a relação entre palavras-chaves (ARIA; CUCCURULLO, 2017). Os principais termos são são: "integer programming" - relacionado ao fato do modelo matemático utilizado para a alocação dos colaboradores ser inteiro; "scheduling" - classe do problema abordado; e, "mul- 


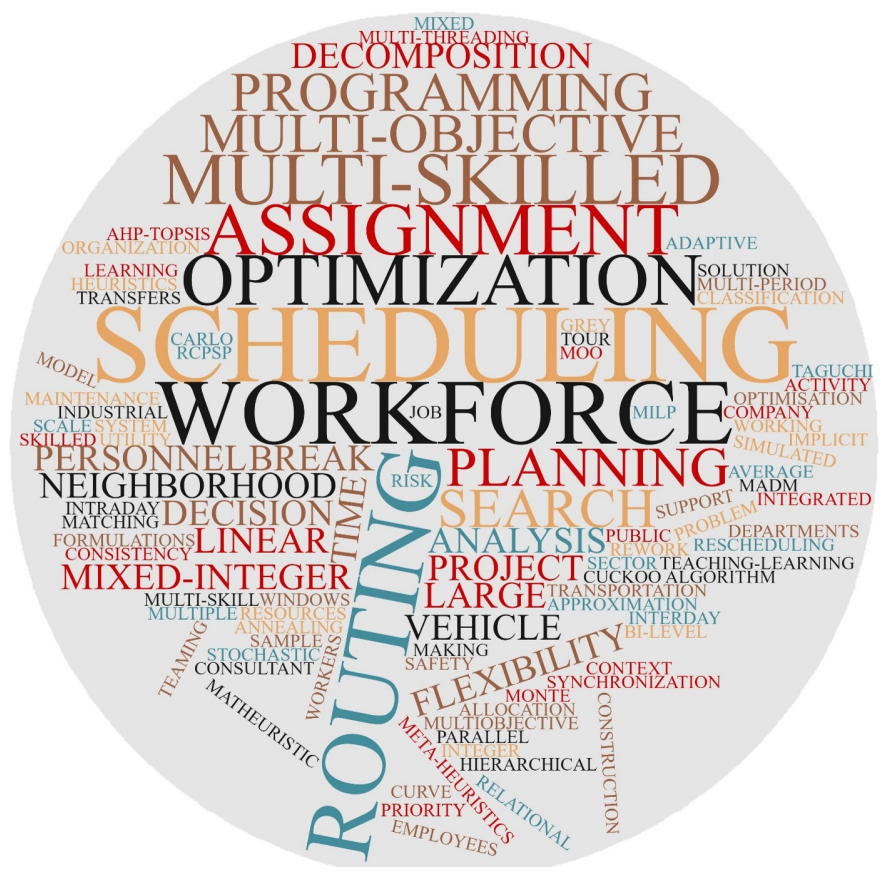

Figura 2.3: Nuvem de palavras-chaves indicadas pelos autores

tiobjective optimization". Os problemas multiobjetivos normalmente buscam minimizar o custo de alocação levando em consideração a satisfação dos colaboradores (DOAN et al., 2019; ANOSHKINA; MEISEL, 2019) ou para evitar retrabalho das atividades (MAGHSOUDLOU et al., 2017).

A quantidade de publicações em cada ano, a partir de 2012, é apresentada na Tabela 2.5. É possível observar que 2019 foi o ano com a maior quantidade de publicações - 6 artigos, com 4 e 2 artigos, respectivamente, em 2020 e 2021 embora 2021 ainda não tenha terminado, já existem 2 artigos. Isso demonstra o aumento de pesquisas com o tema nos últimos anos.

\subsection{5}

\section{Classificação dos artigos}

Em relação à classificação do modelo matemático, Li et al. (2019) e Zabihi et al. (2019) empregaram modelo de Programação Não Linear Inteira Mista (MINLP), todos os demais artigos apresentaram modelo de Programação Linear Inteira Mista (MILP). Considerando que existe um aumento na complexidade de solução de um problema não linear, é esperado que existam mais abordagens com modelos lineares do que não lineares para a alocação de colaboradores. 
Tabela 2.4: Frequência das palavras-chaves mais utilizadas

\begin{tabular}{ll}
\hline Paravra-chave & Frequência \\
\hline scheduling & 15 \\
workforce & 6 \\
optimization & 6 \\
routing & 6 \\
workforce scheduling & 4 \\
assignment & 4 \\
multi-skilled & 4 \\
multi-objective & 3 \\
planning & 3 \\
programming & 3 \\
search & 3
\end{tabular}

Tabela 2.5: Publicações por ano

\begin{tabular}{cc}
\hline Ano & Publicações \\
\hline 2021 & 2 \\
2020 & 4 \\
2019 & 6 \\
2018 & 1 \\
2017 & 3 \\
2016 & 1 \\
2012 & 1 \\
\hline Total & 18
\end{tabular}

Dos 18 artigos analisados, 10 indicaram o software para a implementação do modelo de otimização, Python 3 foi utilizado por Lyu e Yu (2021) e Pereira et al. (2020); Java por Anoshkina e Meisel (2020) e Kiermaier et al. (2020); Lingo por Qin et al. (2016) e Safaei et al. (2012); Li et al. (2019) utilizaram o MATLAB; Doan et al. (2019) utilizaram o CPLEX Studio; Hosseinian e Baradaran (2019) implementaram com o software GAMS; e, Solano Charris et al. (2019) utilizaram o Excel.

O CPLEX foi o solver mais utilizado para a resolução dos problemas, tendo sido utilizado em 11 dos trabalhos, seguido pelo LINGO, com duas utilizações, e o Gurobi e o solver do Excel com uma utilização. Essas informações estão consolidadas na Tabela 2.6.

Apenas Doan et al. (2019) e Lazzerini e Pistolesi (2018) não elaboraram o modelo com a utilização de multi-período, assim, são definidas quais atividades cada colaborador deverá executar, todavia, não é estabelecido o período em que cada atividade deverá ser realizada. Os demais trabalhos identificam o período em que as atividades devem ser executadas. 


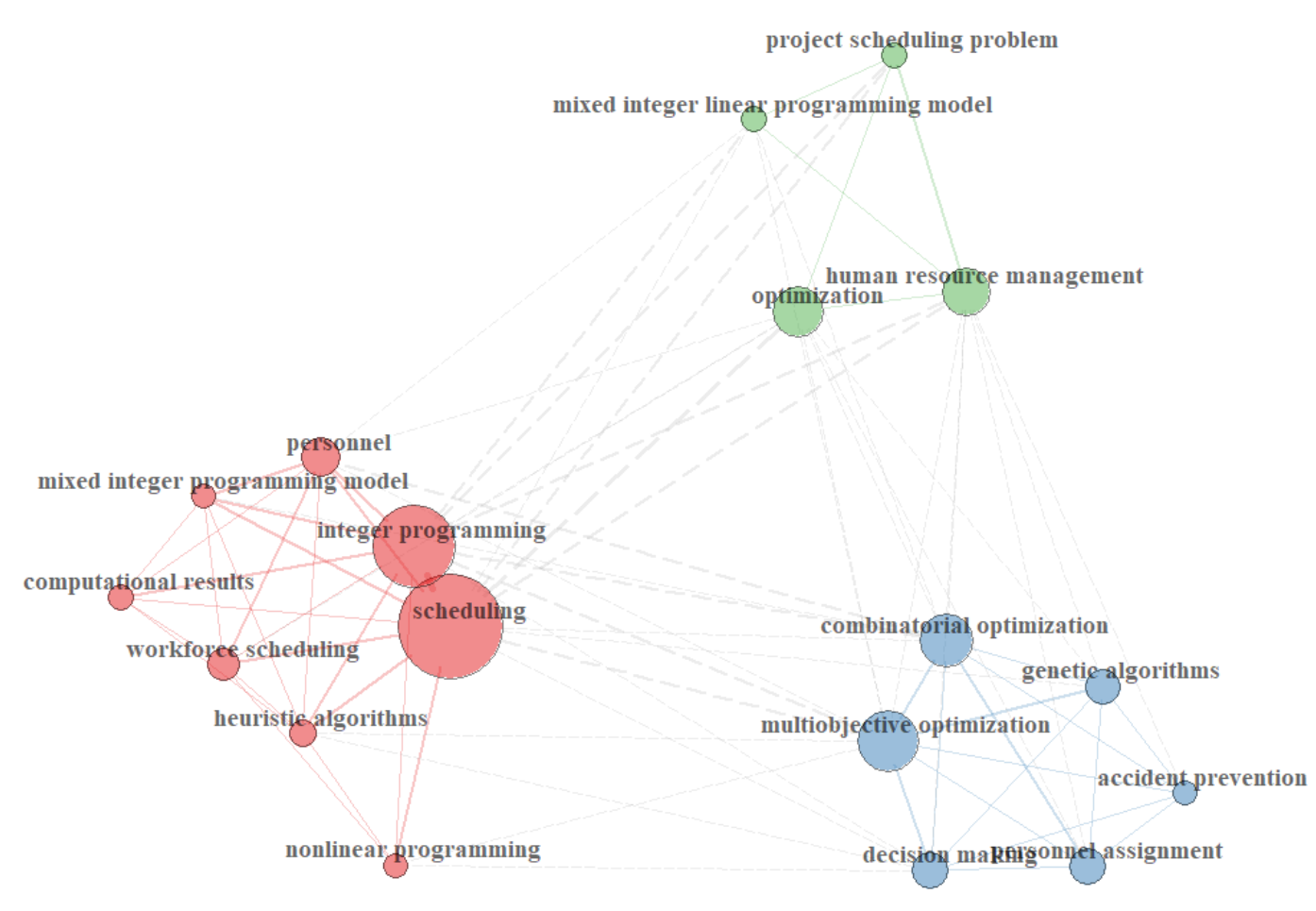

Figura 2.4: Relação entre palavras-chaves dos artigos gerada pelo bibliometrix

Os trabalhos de Lyu e Yu (2021) e Dahmen et al. (2020) consideram que os colaboradores podem estar alocados em mais de uma origem, os demais artigos levam em consideração que existe apenas uma origem. Apenas Zabihi et al. (2019) consideram a existência de apenas um destino, nos demais trabalhos as atividades são realizadas em locais diferentes. Na Tabela 2.7 identifica-se se o trabalho é multi-períodos, multi-origens e multi-destinos.

A Tabela 2.8 indica se os trabalhos consideram as habilitações dos colaboradores. Solano Charris et al. (2019) e Lazzerini e Pistolesi (2018) não consideram as habilitações dos colaboradores, os demais autores fazem essa consideração. Dos 18 artigos, 11 consideram que podem ser atividades com um ou mais colaboradores, seis consideram que as atividades possuem apenas uma pessoa e apenas um artigo considera que essa alocação deve ser realizada em grupo.

\subsection{6}

\section{Síntese dos achados}

Os artigos analisados abordam a alocação de colaboradores qualificados em atividades e apresentam características específicas para cada tipo de problema. Dentre os principais achados foram observados artigos em que os colaboradores adquirem conhecimento durante os períodos (LI et al., 2019; 
Tabela 2.6: Classificação, software e solver utilizados nos trabalhos identificados

\begin{tabular}{lccc}
\hline Autores & Classificação & Software & Solver \\
\hline Guastaroba et al. $(2021)$ & MILP & - & CPLEX \\
Lyu e Yu $(2021)$ & MILP & Python 3 & Gurobi \\
Anoshkina e Meisel $(2020)$ & MILP & JAVA & CPLEX \\
Pereira et al. $(2020)$ & MILP & Python 3 & CPLEX \\
Kiermaier et al. $(2020)$ & MILP & JAVA & CPLEX \\
Dahmen et al. $(2020)$ & MILP & - & CPLEX \\
Li et al. $(2019)$ & MINLP & MATLAB & CPLEX \\
Zabihi et al. (2019) & MINLP & - & - \\
Doan et al. $(2019)$ & MILP & CPLEX Studio & CPLEX \\
Anoshkina e Meisel $(2019)$ & MILP & - & CPLEX \\
Hosseinian e Baradaran $(2019)$ & MILP & GAMS & - \\
Solano Charris et al. $(2019)$ & MILP & Excel & Solver \\
Lazzerini e Pistolesi $(2018)$ & MILP & - & - \\
Pour et al. (2017) & MILP & - & CPLEX \\
Karam et al. (2017) & MILP & - & CPLEX \\
Maghsoudlou et al. $(2017)$ & MILP & - & - \\
Qin et al. (2016) & MILP & LINGO & LINGO e CPLEX \\
Safaei et al. $(2012)$ & MILP & LINGO & LINGO
\end{tabular}

Tabela 2.7: Identificação dos trabalhos que utilizaram multi-períodos, multiorigens e multi-destinos

\begin{tabular}{lccc}
\hline Autores & Multi-Períodos & Multi-Origens & Multi-Destinos \\
\hline Guastaroba et al. (2021) & $\checkmark$ & $\checkmark$ & $\checkmark$ \\
Lyu e Yu (2021) & $\checkmark$ & & $\checkmark$ \\
Anoshkina e Meisel (2020) & $\checkmark$ & $\checkmark$ & $\checkmark$ \\
Pereira et al. (2020) & $\checkmark$ & $\checkmark$ \\
Kiermaier et al. (2020) & $\checkmark$ & $\checkmark$ \\
Dahmen et al. (2020) & $\checkmark$ & & \\
Li et al. (2019) & $\checkmark$ & & $\checkmark$ \\
Zabihi et al. (2019) & $\checkmark$ & $\checkmark$ \\
Doan et al. (2019) & & $\checkmark$ \\
Anoshkina e Meisel (2019) & $\checkmark$ & $\checkmark$ \\
Hosseinian e Baradaran (2019) & $\checkmark$ & $\checkmark$ \\
Solano Charris et al. (2019) & $\checkmark$ & $\checkmark$ \\
Lazzerini e Pistolesi (2018) & & & $\checkmark$ \\
Pour et al. (2017) & $\checkmark$ & $\checkmark$ \\
Karam et al. (2017) & $\checkmark$ & $\checkmark$ \\
Maghsoudlou et al. (2017) & $\checkmark$ & & $\checkmark$ \\
Qin et al. (2016) & $\checkmark$ & \\
Safaei et al. (2012) & $\checkmark$ & & $\checkmark$
\end{tabular}


Tabela 2.8: Identificação dos trabalhos que utilizaram skills e tamanho das equipes

\begin{tabular}{|c|c|c|}
\hline Autores & skills & Individual/Grupos \\
\hline Guastaroba et al. (2021) & $\checkmark$ & Ambos \\
\hline Lyu e Yu (2021) & $\checkmark$ & Individual \\
\hline Anoshkina e Meisel (2020) & $\checkmark$ & Ambos \\
\hline Pereira et al. (2020) & $\checkmark$ & Grupos \\
\hline Kiermaier et al. (2020) & $\checkmark$ & Individual \\
\hline Dahmen et al. (2020) & $\checkmark$ & Individual \\
\hline Li et al. (2019) & $\checkmark$ & Ambos \\
\hline Zabihi et al. (2019) & $\checkmark$ & Ambos \\
\hline Doan et al. (2019) & $\checkmark$ & Ambos \\
\hline Anoshkina e Meisel (2019) & $\checkmark$ & Ambos \\
\hline Hosseinian e Baradaran (2019) & $\checkmark$ & Ambos \\
\hline Solano Charris et al. (2019) & & Ambos \\
\hline Lazzerini e Pistolesi (2018) & & Individual \\
\hline Pour et al. (2017) & $\checkmark$ & Individual \\
\hline Karam et al. (2017) & $\checkmark$ & Ambos \\
\hline Maghsoudlou et al. (2017) & $\checkmark$ & Ambos \\
\hline Qin et al. (2016) & $\checkmark$ & Individual \\
\hline Safaei et al. (2012) & $\checkmark$ & Ambos \\
\hline
\end{tabular}

ZABIHI et al., 2019; KARAM et al., 2017; QIN et al., 2016); alocações que são dependentes (PEREIRA et al., 2020); casos em que além da redução dos custos é levada em consideração a satisfação dos colaboradores (DOAN et al., 2019; ANOSHKINA; MEISEL, 2019); por fim, também foi identificada a consideração de incerteza no processo de alocação (DAHMEN et al., 2020; POUR et al., 2017).

A tabela completa com a classificação dos artigos selecionados na segunda etapa da RSL está disponível no Apêndice A.

Ainda que exista demanda para a utilização de tal ferramenta, na RSL não foi encontrado modelo para planejamento operacional quinzenal, com divisões por períodos, de alocação ótima de colaboradores multi-capacitados com o enfoque na inspeção, com a existência de múltiplas origens e destinos.

\subsubsection{1}

\section{Alocação com aprendizagem e retrabalho}

Embora Maghsoudlou et al. (2017) não considerem na modelagem matemática a possibilidade do colaborador adquirir experiência no decorrer dos períodos, é considerada a necessidade do retrabalho. É atribuído um nível de habilidade para cada colaborador, consequentemente, a partir de uma distribuição uniforme, é definido um intervalo de probabilidade de retrabalho da 
atividade. Assim, é levado em consideração o risco de alocar um colaborador menos qualificado para realizar determinada atividade - dado que ao realizar essa atividade existe uma maior probabilidade de que a atividade deverá ser refeita.

\subsubsection{2}

\section{Dependência entre atividades}

No problema apresentado por Pereira et al. (2020), é considerada a dependência entre atividades que devem ser respeitadas para a alocação e roteamento dos colaboradores em um problema de multi-período.

Anoshkina e Meisel (2020) consideram a dependência entre atividades de um modo alternativo, uma vez que permite a realocação dos colaboradores nas atividades planejadas em um dia. Os autores precisam identificar as atividades que já foram realizadas para não serem realizadas novamente.

\subsubsection{3}

\section{Satisfação dos colaboradores}

Em um problema de alocação de colaboradores, o principal objetivo é a redução de custos, ainda assim, existem pesquisas que ponderam a relação de custo com outros objetivos.

Lazzerini e Pistolesi (2018) têm como objetivo secundário a redução do risco da operação.

Doan et al. (2019) e Anoshkina e Meisel (2019) consideram que, para a alocação dos colaboradores, é preciso ponderar a satisfação dos colaboradores, mesmo que esse aspecto não seja o objetivo principal da função objetivo, é levado em consideração para a designação das atividades em que cada indivíduo será alocado.

\subsubsection{4}

\section{Alocação com incertezas}

Para a utilização de modelo determinístico para a alocação de pessoas, existe a premissa de que as informações são conhecidas a priori, não serão alteradas e não existe dúvida sobre a definição dos parâmetros. Entretanto, na vida real, isso nem sempre é verdade, ainda mais em modelos com abordagem estratégica de longo prazo. Dahmen et al. (2020) e Pour et al. (2017) avaliam no modelo matemático incertezas nos parâmetros. 
Pour et al. (2017) relatam modelagem estocástica para a alocação de pessoas onde existe incerteza na demanda futura. O modelo tem como objetivo a redução do custo de alocação, com a penalização dos casos em que não exista a quantidade de funcionários necessárias para atender à demanda incerta.

Dahmen et al. (2020) propõem modelo de dois estágios para a alocação de colaborador entre departamentos e multi-período. No momento inicial, é tomada a decisão de forma agregada e, no segundo estágio, os colaboradores são atribuídos às atividades.

\subsection{7}

\section{Síntese do referencial teórico}

A dissertação abordou a alocação de colaboradores qualificados em atividades de inspeção. Os artigos encontrados a partir da RSL se relacionam diretamente com o problema em estudo. Nesse tipo de problema, numerosos fatores podem influenciar e afetar a forma como a alocação é realizada. Conforme discutido, são determinantes, entre outros aspectos: a possibilidade de retrabalho, dependência entre atividades, objetivos não financeiros (como a satisfação dos colaboradores) e a consideração de incerteza no problema.

Araújo (2015) observa a importância da inspeção e a relaciona com o Safety Oversight System, como ferramenta para manter a segurança e regularidade dos voos.

As revisões de Paraskevopoulos et al. (2017) e Van Den Bergh et al. (2013) apresentaram aplicações em outras áreas com características semelhantes entre si, envolvendo a alocação de colaboradores, em sua grande maioria, com algum tipo de habilitação e/ou diferenciação.

Chaker et al. (2019), por sua vez, listaram aspectos a serem observados na alocação de inspetores em atividades de inspeção.

Essas informações delimitam as premissas dos modelos matemáticos elaborados. 


\section{3 \\ Descrição do problema}

\section{1}

\section{ANAC}

A Agência Nacional de Aviação Civil estabeleceu objetivos e indicadores estratégicos para o cumprimento das atividades. Um dos objetivos é garantir a segurança da aviação civil. Para tanto, é necessário o desenvolvimento e implementação de ações que elevem os níveis da Segurança Operacional (Safety) e de Segurança da Aviação Civil Contra Atos de Interferência Ilícita (Security), proporcionando assim o acesso a um transporte seguro e confiável (ANAC, 2020c). Existem indicadores para a mensuração da confiabilidade da inspeção de segurança e do nível de percepção de segurança.

Uma vez que a agência é responsável pela fiscalização nos aeroportos brasileiros BRASIL (2005), é necessária a alocação dos colaboradores localizados nos centros da ANAC distribuídos pelo país. Cada inspeção pode exigir que o colaborador tenha determinada habilitação, isso restringe as inspeções que cada colaborador pode executar. O inspetor é alocado em um centro da ANAC e pode se deslocar para qualquer destino onde exista uma missão para a qual ele esteja capacitado.

\section{2}

\section{Aplicações na ANAC}

No Brasil, foram realizadas pesquisas na ANAC que buscaram otimizar a alocação dos colaboradores nas atividades de inspeção, conforme descrito a seguir.

Freitas Júnior (2017) aplicou o modelo de designação clássico no problema de alocação de colaboradores. Considerou a oferta de colaboradores em cada centro e demanda em cada destino, todavia, nessa aplicação não foram levadas em consideração as habilitações de cada colaborador. A demanda foi simplificada - utilizada a demanda no destino e não a demanda de cada atividade de inspeção no destino, também não considerou-se a carga horária dos colaboradores. 
Silva (2018) elaborou dois modelos matemáticos, um para as inspeções programadas e outro para as inspeções demandadas. O primeiro modelo considera o planejamento anual de alocações, em que existe a definição das inspeções que irão ocorrer no próximo ano. Tem como objetivo minimizar o custo de alocação dos inspetores, levando em consideração a preferência de alocação. O plano de alocação dos colaboradores define as atividades que cada colaborador deverá realizar em cada mês.

O modelo para as inspeções demandadas apresentado por Silva (2018) atende às atividades de inspeção que não estavam planejadas no plano anual da agência. Dessa forma, esse modelo pode ser rodado diariamente ou semanalmente, a depender da demanda de atividades, e possui as mesmas premissas do modelo anterior, não leva em consideração períodos, pois essas atividades serão realizadas em um curto horizonte de tempo.

Embora Silva (2018) tenha apresentado os modelos matemáticos para a alocação, dada a complexidade de solução do problema, o autor elaborou heurística no Excel utilizando o VBA para obter a alocação dos colaboradores nas atividades de inspeção. Para Couto (2020), a aplicação em VBA possui limitações, uma vez que é desenvolvido em software limitado, e não com a utilização de linguagem de programação tradicional, o que torna a solução do problema não escalável.

O modelo proposto por Reis e Celestino (2018) apresenta a demanda anual e agrupa a oferta das missões de inspeções por grupo de colaboradores habilitados para tal atividade, desse modo, a demanda de cada agrupamento de habilitações deve ser realizada pelos inspetores com habilitação para aquele tipo de atividade.

Pinheiro (2018) mostra modelo matemático para minimizar o custo de deslocamento. Contém premissas semelhantes ao apresentado em Reis e Celestino (2018) e, como no primeiro modelo apresentado por Silva (2018), é utilizada a demanda anual de missões de inspeções para designação das alocações para o ano. A implementação é feita utilizando o software LINGO e o pacote OpenSolver do Excel para validação do modelo. O planejamento é realizado tendo-se por base a oferta dos inspetores e demanda das inspeções anual, todavia, a proposta não leva em consideração o período em que a atividade será realizada e os colaboradores com o mesmo conjunto de habilitações são agrupados. 
ANAC (2019a) apresenta formulação que considera a habilitação em si, diferentemente dos modelos anteriores que agrupavam as missões semelhantes. Além disso, existem variações dos modelos que, em alguns casos, podem ser lineares ou binários; com ou sem transbordo, tempo de arco, um ou dois períodos e alterações na demanda.

Lopes (2019) analisa a sensibilidade do modelo apresentado por Pinheiro (2018), especialmente nos casos em que a solução é degenerada - a autora utiliza uma instância simplificada para realizar as análises.

Pinheiro (2018), Reis e Celestino (2018) e ANAC (2019a) implementam modelo matemático utilizando o software LINGO. Couto (2020) apresenta comparativo entre o tempo de solução para a implementação na literatura e a utilização do software AIMMS com o solver CPLEX. Para a comparação do tempo de solução, a autora utilizou três instâncias, alterando a quantidade de dias disponíveis para os inspetores; nas duas com maior disponibilidade, o desempenho dos dois solvers chegaram ao ótimo, sem diferença significativa no tempo de solução. Enquanto que, na instância com menor disponibilidade de dias, o melhor resultado foi obtido usando o AIMMS com CPLEX, uma vez que alcançou um GAP de otimalidade menor em menos tempo.

Couto (2020) mostra o resultado comparativo entre a utilização de ferramentas de solução. Silva Junior (2021) expõe o problema de alocação dos inspetores com a utilização de heurística, assim como Silva (2018). No total foram utilizados cinco algoritmos, sendo: Busca Tabu, Algoritmo Genético, Simulated Annealing e dois Métodos de Hibridização. Esses resultados são comparados com a solução ótima do problema encontrada a partir de adaptação do modelo apresentado em ANAC (2019a).

A consolidação das informações coletadas nesses artigos está disponível na Tabela 3.1. Os modelos propostos nesta dissertação levam em consideração a carga horária, um modelo sem período e outro com, ambos multi-origens e multi-destinos com skills, a alocação pode ser individual ou em grupos e serão utilizadas 9 instâncias.

Tabela 3.1: Descrição dos trabalhos realizados na ANAC

\begin{tabular}{|c|c|c|c|c|c|c|c|c|c|}
\hline Autores & Implementação & Solver & Carga Horária & Períodos & Multi-Origens & Multi-Destinos & Skills & Alocação & Instâncias \\
\hline Freitas Júnior (2017) & Excel & OpenSolver & & 1 & $\checkmark$ & $\checkmark$ & & Individual & 1 \\
\hline Silva (2018) - 1 & Excel & Heurística & $\checkmark$ & 12 & $\checkmark$ & $\checkmark$ & $\checkmark$ & Ambos & 1 \\
\hline Silva (2018) - 2 & Excel & Heurística & $\checkmark$ & 1 & $\checkmark$ & $\checkmark$ & $\checkmark$ & Ambos & 1 \\
\hline Pinheiro (2018) & Lingo & Lingo & & 1 & $\checkmark$ & $\checkmark$ & $\checkmark$ & Individual & 1 \\
\hline Reis e Celestino (2018) & Lingo & Lingo & $\checkmark$ & 1 & $\checkmark$ & $\checkmark$ & $\checkmark$ & Individual & 1 \\
\hline $\operatorname{ANAC}(2019 \mathrm{a})$ & Lingo & Lingo & $\checkmark$ & $1 / 2^{1}$ & $\checkmark$ & $\checkmark$ & $\checkmark$ & Ambos & $58 / 80^{2}$ \\
\hline Lopes (2019) & Excel & Solver & & 1 & $\checkmark$ & $\checkmark$ & & Individual & 1 \\
\hline Couto (2020) & Lingo/AIMMS & Lingo/CPLEX, Cbc & $\checkmark$ & 1 & $\checkmark$ & $\checkmark$ & $\checkmark$ & Ambos & 3 \\
\hline Silva Junior (2021) & Lingo/- & Lingo/Heurística & $\checkmark$ & 1 & $\checkmark$ & $\checkmark$ & $\checkmark$ & Individual & 20 \\
\hline Lim-Apo (2021) - 1 & Lingo/Julia & Lingo/CPLEX e Gurobi & $\checkmark$ & 1 & $\checkmark$ & $\checkmark$ & $\checkmark$ & Ambos & 9 \\
\hline Lim-Apo (2021) - 2 & Julia & Gurobi & $\checkmark$ & 7,14 e 21 & $\checkmark$ & $\checkmark$ & $\checkmark$ & Ambos & 9 \\
\hline
\end{tabular}


Nas duas últimas linhas da Tabela 3.1, estão os modelos propostos nesta dissertação. O Modelo 1 é implementado no LINGO e em Julia. No LINGO o Modelo 1 é solucionado com o solver interno do LINGO, enquanto em Julia é utilizado o pacote JuMP com os Cplex e Gurobi. Já o Modelo 2, é implementado em Julia utilizando o solver Gurobi. Ambos modelos propostos levam em consideração a carga horária dos colaboradores, são multi-origens e multi-destinos, consideram as skills dos inspetores e permitem tanto a alocação individual quanto em grupo. A diferença entre as proposições é que o Modelo 1 não determina o período em que a atividade deve ser realizada, informando as atividades que cada inspetor deverá realizar, enquanto o Modelo 2 determina o período em que os inspetores deverão realizar as atividades que lhe foram atribuídas.

\section{3 \\ Premissas}

Os modelos propostos neste trabalho podem ser aplicados quando já existe a definição das atividades que devem ocorrer no próximo mês ou na próxima quinzena e é necessário alocar os colaboradores disponíveis nas missões existentes - considerando as restrições de operação existentes.

Assim, foram consideradas as missões de inspeção nos aeroportos. Um planejamento anual é realizado para determinar quando cada atividade de inspeção deve ser realizada, mas no decorrer do ano novas inspeções podem ser realizadas.

As inspeções podem verificar aspectos do aeroporto, dos aviões, dos pilotos e comissários e da área de manutenção das aeronaves. No total, existem cerca de 693 tipos de atividades a serem realizadas, e cada uma exige um tipo de habilitação do colaborador. As inspeções programadas ocorrem com regularidade, seja, trimestral, semestral ou anual; as inspeções exigem um determinado número de inspetores, podendo ser de um inspetor até quatro, e podem levar de meio dia até cinco dias para finalização.

Além disso, cada inspetor possui uma quantidade máxima de horas que poderá realizar as atividades por mês. Quando o colaborador desloca-se até um destino, é permitida a realização de mais de uma missão, todavia, uma de cada vez. Em cada período, o colaborador pode realizar apenas uma atividade.

Assim, as informações disponíveis são: os colaboradores e suas habilitações, missões programadas, destinos, local base do colaborador, custo de transporte, limitações na carga horária, equipe necessária para cada atividade, horizonte de planejamento, tempo das atividades, tempo de deslocamento entre cada origem e destino, disponibilidade dos colaboradores. 
Todos os anos a ANAC realiza o planejamento das atividades de inspeção a serem realizadas no ano seguinte - com a definição do mês em que cada missão irá ocorrer em cada destino, essas são as atividades fixas. Existem dois tipos de missões demandadas durante o ano e devem ser incluídas nos planejamento mensal. O primeiro tipo de missão envolve atividades que podem ser demandadas pelas companhias aéreas; e o segundo tipo, são as missões realizadas a partir de alguma denúncia ou de forma aleatória para a fiscalização de alguma atividade.

A Figura 3.1 apresenta um exemplo simplificado da alocação com quatro inspetores, localizados respectivamente no Distrito Federal, São Paulo, Rio de Janeiro e São Paulo; as missões acontecem nos aeroportos $\mathrm{SBIZ}^{3}, \mathrm{SBGO}^{4}$ e SBRJ $^{5}$; os colaboradores possuem no total 4 missões de inspeção, com duração de dois períodos e todos possuem as habilitações necessárias para realizar as atividades de inspeção.

\begin{tabular}{|c|c|c|c|c|c|c|c|c|c|c|}
\hline$P \backslash T$ & ORIGEM & 1 & 2 & 3 & 4 & 5 & 6 & 7 & 8 & 9 \\
\hline P1 & DF & VI SBIZ & M1 & & VV DF & & VI SBGO & M2 & & VV DF \\
\hline P2 & $\mathrm{SP}$ & VISBIZ & M1 & & VV SP & & VI SBGO & M2 & & VV SP \\
\hline P3 & $\mathrm{RJ}$ & & & & VI SBRJ - M3 & & M4 & & VVRJ & \\
\hline P4 & SP & & & VI SBR & M3 & & M4 & & VV SP & \\
\hline
\end{tabular}

Figura 3.1: Exemplo da alocação de inspetores com 9 períodos

Em cada um dos períodos, cada colaborador pode ser alocado em uma atividade; o colaborador P1 no período um irá se deslocar do Distrito Federal para SBIZ, iniciando a atividade de inspeção M1 no período dois; enquanto isso, no período um, o colaborador P2 irá se deslocar de São Paulo para SBIZ para realizar a missão M1 em conjunto com o colaborador P1 no período dois. Após a realização da missão M1, que dura dois períodos - um dia - os colaboradores voltam no período quatro respectivamente para o Distrito Federal e São Paulo.

Os tempos da viagem de ida e de volta podem variar dependendo do arco da viagem, além disso, cada missão tem uma duração e uma quantidade de inspetores necessários.

Existem casos em que a cidade de residência do inspetor é a localidade do aeroporto onde deverá ser realizada a atividade, nesses casos, é permitido que ele realize o deslocamento no mesmo período em que a atividade é iniciada. Esse exemplo é apresentado na Figura 3.1, onde o inspetor P3, que está alocado no

\footnotetext{
${ }^{3}$ Aeroporto de Imperatriz - Prefeito Renato Moreira - Maranhão

${ }^{4}$ Aeroporto Internacional de Goiânia - Goiás

${ }^{5}$ Aeroporto do Rio de Janeiro - Santos Dumont - Rio de Janeiro
} 
Rio de Janeiro, realiza no quarto período o transporte para o aeroporto SBRJ e inicia a atividade de inspeção da missão M3; enquanto isso, o colaborador P4 deve se deslocar no período anterior de São Paulo para SBRJ para iniciar a atividade da missão no quarto período, junto com o colaborador P3.

Considerando o problema existente, foram definidas premissas para o desenvolvimento da pesquisa e elaboração do modelo, sendo:

1. os dados utilizados no modelo são reais de três superintendências - Superintendência de Infraestrutura Aeroportuária (SIA), Superintendência de Ação Fiscal (SFI) e Superintendência de Padrões Operacionais (SPO). As características desses dados são apresentadas no Capítulo 4;

2. os modelos matemáticos têm como finalidade ser uma ferramenta de apoio à tomada de decisões no nível operacional, assim, realizam a alocação dos inspetores das atividades que ocorrerão na próxima quinzena ou mês - nesse sentido, é considerado que todas os dados são determinísticos;

3. a alocação seguirá a demanda das atividades já determinadas, não será proposto um modelo para determinar o mês em que cada missão planejada deve ser realizada.

Os colaboradores:

4. possuem uma lista de habilitações das atividades que podem realizar;

5. podem ser alocados somente nas atividades para as quais são capacitados;

6. podem realizar as missões em qualquer destino;

7. estão alocados em uma origem;

8. sofrem limitação na quantidade de períodos que podem ser alocados;

9. devem deslocar-se até o destino da missão para realizar a inspeção;

10. devem retornar ao destino após a realização da missão - é permitido que seja realizada mais de uma missão em uma viagem que o colaborador faça.

As missões:

11. ocorrem para um destino pré-estabelecido;

12. devem ser obrigatoriamente realizadas uma vez em algum período; 
13. têm duração estabelecida;

14. exigem uma determinada quantidade de colaboradores para sua realização;

15. podem ser atendidas com inspetores de origens distintas.

Para garantir o sigilo dos dados utilizados na pesquisa, as informações que permitiriam a identificação dos colaboradores, das habilitações existentes e quaisquer outras informações sigilosas foram anonimizadas - mantendo-se as características e aspectos do problema inicial. 


\section{4}

\section{Metodologia}

Foram desenvolvidos dois modelos matemáticos. O Modelo 1 é uma adaptação do modelo proposto por Reis e Celestino (2018) e ANAC (2019a) com a alteração na criação de variáveis e de restrições para redução no tempo de solução.

O Modelo 2 apresenta uma nova formulação do problema, com a inclusão do período em que as atividades devem ser realizadas, aumentando-se a complexidade do problema. Foram implementadas duas heurísticas para a redução no tempo de solução.

Os resultados obtidos pelos modelos foram comparados com os resultados encontrados por Reis e Celestino (2018), ANAC (2019a) e Couto (2020), que realizaram a implementação no Lingo e no AIMMS. Embora os modelos sejam semelhantes, existem diferenças na criação de variáveis e de restrições que diferenciam o modelo atual das implementações citadas.

\section{1}

\section{Descrição geral dos métodos}

Na metodologia aplicada, foi elaborado modelo matemático linear inteiro misto (MILP) no LINGO e em Julia, utilizou-se como base o pacote JuMP para a alocação dos colaboradores em atividades de inspeção.

O Modelo 1 foi implementado no Lingo para comparar o ganho no tempo de solução com os resultados da literatura. O Modelo 1 foi implementado em Julia, para comparação do tempo de solução da ferramenta com o Lingo. Por sua vez, o Modelo 2 foi implementado em Julia dada a possibilidade de programação para as heurísticas, além da possibilidade de selecionar o solver utilizado para a resolução do modelo do JuMP. 


\section{2}

\section{Modelo 1 - Modelo para Alocação de Inspetores (MAI)}

O Modelo 1 - Modelo para Alocação de Inspetores (MAI) - utiliza como base modelo apresentado por Reis e Celestino (2018) e ANAC (2019a). É realizada a alocação dos inspetores, todavia, não é determinado o período em que as atividades devem ser realizadas. O MAI leva em consideração as inspeções que cada colaborador pode realizar e também a disponibilidade de horas de cada inspetor.

Uma vez que o MAI não determina o período em que a atividade deva ser realizada, deve haver um pós-processamento para realizar a alocação dos inspetores, um exemplo será destacado no Capítulo 5.

A principal diferença do modelo da literatura e o MAI é que aqui são criadas somente as variáveis de alocação que podem ser realizadas. No modelo da literatura, todas as possíveis variáveis de alocação são criadas e são impostas restrições posteriormente de que tais alocações inviáveis não podem ser realizadas. Com essa alteração, o MAI possui menos variáveis e restrições para representar o mesmo problema.

De acordo com a taxonomia apresentada por Paraskevopoulos et al. (2017), o MAI apresenta que os colaboradores têm habilitações, e a função objetivo busca minimizar o custo de deslocamento.

\subsection{1}

\section{Conjuntos}

$M$ - Missões; $m \in M$

$O$ - Origens; $o \in O$

$D$ - Destinos; $d \in D$

$I$ - Inspetores; $i \in I$

\subsection{2}

\section{Subconjuntos}

$M I_{i} \subset M$ - Subconjunto de missões $m$ que o inspetor $i$ pode realizar

$D I_{i} \subset D$ - Subconjunto de destinos $d$ que o inspetor $i$ pode atender

$O I_{i} \subset O$ - Subconjunto de origem do inspetor $i$

$L M_{m} \subset D$ - Destino da missão $m$. 


\subsection{3}

\section{Parâmetros}

$D M_{m}$ - Duração da missão $m$

$E_{m}$ - Tamanho da equipe de inspetores necessários para missão $m$

$D P_{i}$ - Carga horária disponível do inspetor $i$

$C_{o, d}$ - Custo da viagem da origem o para o destino $d$

$T_{o, d}$ - Tempo da viagem da origem $o$ para o destino $d$

\subsection{4}

\section{Variáveis de decisão}

$A M_{i, m} \in M I_{i}$ - Define se o inspetor $i$ será alocado na missão $m$, variável binária.

$A G_{i, d} \in D I_{i^{-}}$Define se o inspetor $i$ será alocado no arco $\left(O I_{i}, d\right)$, variável binária.

\subsection{5}

\section{Equações}

$$
\operatorname{Min} \sum_{i, d \in D I_{i}} 2 \times C_{O I_{i}, d} \times A G_{i, d}
$$

Sujeito a:

$$
\begin{gathered}
\sum_{i \mid m \in M I_{i}} A M_{i, m}=E_{m} \quad \forall m \in M \\
\sum_{m \in M I_{i}} D M_{m} \times A M_{i, m}+\sum_{d \in D I_{i}} 2 \times T_{O I_{i}, d} \times A G_{i, d} \leq D P_{i} \quad \forall i \in I \\
A G_{i, L M_{m}} \geq A M_{i, m} \quad \forall i \in I, m \in M I_{i} \\
A M_{i, m} \in\{0,1\} \quad \forall i \in I, m \in M I_{i} \\
A G_{i, d} \in\{0,1\} \quad \forall i \in I, d \in D I_{i}
\end{gathered}
$$

\subsection{6}

\section{Função objetivo}

A função objetivo 4-1 minimiza o custo da alocação dos inspetores nas atividades, o custo total é considerado como duas vezes o custo do arco, considerando assim a viagem de ida e de volta. 


\subsection{7}

\section{Restrições}

Cada atividade pode exigir uma quantidade de colaboradores alocados para sua realização; a equação 4-2 garante que o número de inspetores necessários sejam alocados na atividade.

Cada inspetor possui um tempo de disponibilidade que deve ser respeitado. O tempo que o colaborador estiver em deslocamento de ida e volta mais o tempo em que estiver realizando as atividades deve ser menor ou igual à disponibilidade, o que é definido na restrição 4-3.

O inspetor apenas pode realizar a inspeção no destino se ele for alocado ao arco, assim a restrição 4-4 garante que o colaborador apenas pode ser alocado se foi feito o deslocamento.

As restrições 4-5 e 4-6 definem que as variáveis devem ser binárias.

\section{3}

\section{Modelo 2 - Modelo para Alocação de Inspetores Multi-período (MAIM)}

Diferentemente do MAI, o MAIM determina o período em que as atividades devem ser realizadas e considera um ajuda de custo enquanto o colaborador não retornar para sua base de origem.

Assim como o MAI, de acordo com a classificação proposta por Paraskevopoulos et al. (2017), o modelo apresenta a habilitação dos colaboradores, alocação multi-período e a função objetivo que minimiza o custo de deslocamento com ajuda de custo.

Com a inclusão do período, a quantidade de variáveis de deslocamento e de alocação crescem na mesma proporção da quantidade de períodos. Isso torna mais difícil a solução desse problema, motivo pelo qual são propostas as heurísticas.

\subsection{1}

\section{Conjuntos}

$M$ - Missões; $m \in M$

$O$ - Origens; $o \in O$

$D$ - Destinos; $d \in D$

$I$ - Inspetores; $i \in I$

$P$ - Períodos; $p \in P$ 


\subsection{2}

\section{Subconjuntos}

$M I_{i} \subset M$ - Subconjunto de missões $m$ que o inspetor pode realizar

$H_{i, p} \subset M$ - Subconjunto de missões $m$ que o inspetor $i$ pode realizar no período $p$

$H D_{i, p, d} \subset M$ - Subconjunto de missões $m$ que o inspetor $i$ pode realizar no período $p$ no destino $d$

$H T$ - Subconjunto das combinações de inspetor $i$, com períodos $p$ e missões $m$ - indica as missões para as quais os colaboradores são habilitados

$D I_{i} \subset D$ - Subconjunto de destinos $d$ que o inspetor $i$ pode ir

$O I_{i} \subset O$ - Subconjunto de origem do inspetor $i$

$A V I \subset O$ - Arcos de inspetores $i$, períodos $p$ e destinos de ida $d$ - viagem de ida

$A V V \subset O$ - Arcos de inspetores $i$, períodos $p$ - viagem de volta

$O M_{m} \subset D$ - Localidade da missão $m$

\subsection{3}

\section{Parâmetros}

$D M_{m}$ - Tempo de duração da missão $m$

$E_{m}$ - Tamanho da equipe de inspetores da missão $m$

$D P_{i}$ - Disponibilidade de trabalho do inspetor $i$

$C E$ - Custo da ajuda de custo do colaborador alocado

$C_{o, d}$ - Custo da viagem da origem o para o destino $d$

$T_{o, d}$ - Tempo da viagem da origem $o$ para o destino $d$

$|P|$ - Quantidade de períodos

\subsection{4}

\section{Variáveis de decisão}

$A M_{i, m, p} \in H T$ - Define se o inspetor $i$ será alocado na missão $m$ no período $p$ $R I_{i, p}$ - Define se o inspetor $i$ será alocado no período $p$ em alguma missão ou deslocamento

$V I_{i, d, p}$ - Define se o inspetor $i$ será alocado no arco $\left(O I_{i}, d\right)$ no período $p$ $V V_{i, d, p}$ - Define se o inspetor $i$ será alocado no arco $\left(d, O I_{i}\right)$ no período $p$ $R_{p, m}$ - Define se no período $p$ a missão $m$ será iniciada. 


\subsection{5}

\section{Equações}

$$
\begin{aligned}
\operatorname{Min} & \sum_{i, p, d \mid(i, p, O I i, d) \in A V I} C_{O I i, d} \times V I_{i, d, p}+\sum_{i, p, d \mid(i, p, d, O I i) \in A V V} C_{d, O I i} \times V V_{i, d, p}+ \\
& \sum_{i, p}\left(C E \times R I_{i, p}+\frac{p}{|P|} \times R I_{i, p}\right)
\end{aligned}
$$

Sujeito a:

$$
\sum_{i \in H_{i, p}} A M_{i, m, p}=E_{m} \times R_{p, m} \quad \forall m \in M, p \in P
$$

$\sum_{p p \in P \mid m \in H_{i, p p}, p p \geq p, p p<\left(p p+D M_{m}\right)} A M_{i, m, p p} \leq 1 \quad \forall i \in I, p \in P$

$$
\sum_{p} R_{p, m}=1 \quad \forall m \in M
$$

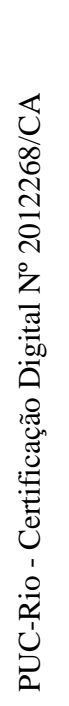

$$
\begin{aligned}
& \sum_{p p \in P \mid p p+T_{o, d} \leq p}\left(V I_{i, d, p p}-V V_{i, d, p p}\right) \geq A M_{i, m, p} \\
& \forall i \in I, p \in P, m \in M \mid(i, p, m) \in H T \\
& \sum_{p p \in P, d e \in D I_{i} \mid p p+T_{o, d}>p, p p \leq p}\left(V V_{i, d e, p p}\right)+V I_{i, d, p} \leq 1 \\
& \forall i \in I, p \in P, d \in D \mid(i, p, d) \in A V I \\
& \sum_{p p \in P \mid p p \geq\left(p+D M_{m}\right)} V V_{i, d, p p} \geq A M_{i, m, p} \\
& \forall i \in I, p \in P, m \in M \mid(i, p, m) \in H T \\
& V V_{i, d, p}-\sum_{m \in M, p p \in P \mid} \sum_{\left(i, p p, O M_{m}\right) \in H D_{i, p p, d}, p p \leq\left(p-D M_{m}\right)} A M_{i, m, p p} \leq 0 \\
& \forall i \in I, d \in D, p \in P \\
& \sum_{p p \in P, d \in D \mid p p \leq p}\left(V I_{i, d, p p}-V V_{i, d, p p}\right) \leq 1 \quad \forall i \in I, p \in P \mid(i, p) \in A V V \\
& \sum_{p p \in P, d \in D \mid p p \leq p}\left(V I_{i, d, p p}-V V_{i, d, p p}\right) \geq 0 \quad \forall i \in I, p \in P \mid(i, p) \in A V V \\
& \sum_{p \in P, d \in D \mid(i, p, d) \in D I_{i}}\left(T_{O I_{i}, d} \times V I_{i, d, p}+T_{d, O I_{i}} \times V V_{i, d, p}\right)+ \\
& \sum_{p \in P, d \in D \mid(i, p, d) \in M I_{i}} D M_{m} \times A M_{i, m, p} \leq D P_{i} \quad \forall i \in I
\end{aligned}
$$




$$
\begin{gathered}
\sum_{d \in D I_{i}} V I_{i, d, p} \leq R I_{i, p} \quad \forall i \in I, p \in P \\
R I_{i, p-1}-\sum_{d \in D I_{i}} V V_{i, d, p-1} \leq R I_{i, p} \quad \forall i \in I, p \in P \mid p \geq 2 \\
A M_{i, m, p} \in\{0,1\} \quad \forall i \in I, m \in M, p \in P \\
R I_{i, p} \in\{0,1\} \quad \forall i \in I, p \in P \\
V I_{i, d, p}, V V_{i, d, p} \in\{0,1\} \quad \forall i \in I, d \in D, p \in P \\
R_{p, m} \in\{0,1\} \quad \forall p \in P, m \in M
\end{gathered}
$$

\subsection{6}

\section{Função objetivo}

A função objetivo 4-7 minimiza o custo global da alocação dos inspetores nas atividades. É composta pelo custo de deslocamento do colaborador, no trajeto de ida e volta, com o custo de pernoite quando estiver realizando as missões no destino. O último termo faz com que exista uma pequena preferência na realização mais cedo das atividades, foi utilizado para reduzir a simetria do problema.

\subsection{7 Restrições}

As restrições são necessárias para garantir que as regras de negócios existentes sejam cumpridas.

As restrições 4-8 determinam que cada missão deve ser realizada exatamente pelo número de inspetores exigidos pela missão e que esse colaborador deve ser habilitado, além disso, todos os inspetores alocados para a missão $m$ ficam alocados no mesmo período $p$, garantindo, assim, que no período $p$ os inspetores que estarão naquela atividade estarão disponíveis para realização da inspeção.

A capacidade máxima de alocação de cada inspetor é limitada nas restrições 4-9, cada inspetor $i$ pode ser alocado em apenas uma missão $m$ por vez.

Cada missão $m$ deve ser realizada apenas uma vez e tem um período determinado de início, essa regra está prevista nas restrições 4-10. 
As restrições 4-11 delimitam que o inspetor $i$ somente pode realizar a missão $m$ se, antes, ele viajou até o destino da missão.

O colaborador somente pode iniciar uma nova viagem caso tenha retornado da viagem anterior, essa restrição é estabelecida nas equações 4-12.

O colaborador deve voltar para a origem somente após a missão que ele estiver alocado acabar, conforme restrições 4-13.

Ao realizar todas as missões no destino $d$, o inspetor $i$ deverá retornar para o local de origem, conforme apresentado em 4-14.

O saldo de viagens deve ser entre 0 e 1 , ou seja, a soma das viagens de ida menos as viagens de volta de todos os destinos deve ser 0 , indicando que o inspetor ainda não viajou, ou que viajou e já voltou; ou 1, indicando que o inspetor iniciou a viagem, mas que no período $p$ ainda não retornou. Isso é necessário para que o inspetor viaje para um novo destino apenas após voltar da viagem anterior. As restrições 4-15 fazem com que o saldo seja menor do que 1, enquanto as restrições 4-16 fazem com que esse valor seja maior do que 0 .

O tempo de alocação do colaborador em viagens de ida e volta e na realização das inspeções deve ser menor ou igual ao tempo disponível do inspetor. A limitação do tempo de atividades é feita nas restrições 4-17.

As equações 4-18 definem o início da alocação da pessoa em alguma atividade, enquanto a equação 4-19 define até qual período a pessoa estará realizando alguma atividade.

As equações 4-20, 4-21, 4-22 e 4-23 definem que as variáveis devem ser binárias.

\section{4}

\section{Redução de variáveis}

As heurísticas desenvolvidas pelo autor levam em consideração aspectos da geração de colunas, técnica de programação linear para a resolução de problemas quando existe um grande número de variáveis, o que ocorre nas instâncias utilizadas, considerando a quantidade de alocações de inspetores nas inspeções a serem realizadas (FORD; FULKERSON, 1958; GILMORE; GOMORY, 1691).

Considerando os tamanhos das instâncias apresentadas, o MAI é capaz de apresentar uma solução, entretanto, o MAIM, por ter uma modelagem mais complexa e considerar os períodos, não é capaz de encontrar uma solução recebendo todos os dados das combinações. Dessa forma, foi implementado procedimento baseado na geração de colunas, assim, o modelo será executado somente com as melhores combinações de alocação, reduzindo significativamente 
o número de combinações possíveis. Cada coluna representa um conjunto de variáveis de decisão, da alocação do inspetor na atividade de inspeção, o limite de variáveis em cada coluna é variável e o calculo utilizado é apresentado no Apêndice E.

O processo utilizado em otimizar em duas etapas possui semelhanças com o apresentado por Dahmen et al. (2020).

Os modelos matemáticos foram inclusos em um processo iterativo para a seleção de variáveis. A Figura 4.1 apresenta o workflow implementado para a heurística 3 etapas. As etapas são:

1. os dados disponibilizados em planilhas do Excel com as informações das missões, colaboradores, habilitações, origens, destinos e preços são préprocessados e são gerados arquivos .CSV e .XLSX que serão os dados de entrada do modelo;

2. antes dos dados serem inseridos no MAI Relaxado são geradas colunas, aleatórias inicialmente;

3. em seguida, o MAI Relaxado irá gerar novas colunas, com as combinações de alocação de inspetores nas missões;

4. é feita a definição do tamanho das colunas geradas no momento inicial e das que serão geradas posteriormente;

5. nessa etapa, é possível definir a quantidade de colunas que serão geradas, ou criar $n$ colunas, até que não exista uma nova coluna que seja vantajosa. Também é possível definir quantas colunas serão inseridas em cada rodada, o padrão é a cada rodada inserir uma coluna, contudo, para aproveitar o custo computacional do cálculo do preço sombra, é possível gerar mais de uma coluna;

6. para redução da dificuldade computacional, ao invés da utilização de um Modelo Inteiro para a identificação das alocações que serão inseridas em uma nova coluna, é utilizada programação dinâmica. A implementação da programação dinâmica é uma adaptação de um problema de alocação de itens em uma mochila, como apresentado por Dasgupta et al. (2006);

7. a partir do MAI é selecionada a menor quantidade de colunas que atendam o problema no menor custo identificado no problema inteiro;

8. é incluso o período nas variáveis, as colunas são desagrupadas e agrupadas novamente para iniciar a heurística 3 etapas com o MAIM Relaxado; 
9. com a heurística 3 etapas, é selecionado o menor número de colunas que solucione o problema ao menor custo;

10. as colunas selecionadas são desagrupadas e o MAIM é solucionado.

Esse processo tem como objetivo reduzir a quantidade de combinações possíveis, identificando as alocações que mais beneficiam o problema de otimização. Detalhamentos adicionais e premissas desse processo estão disponíveis no Apêndice E.

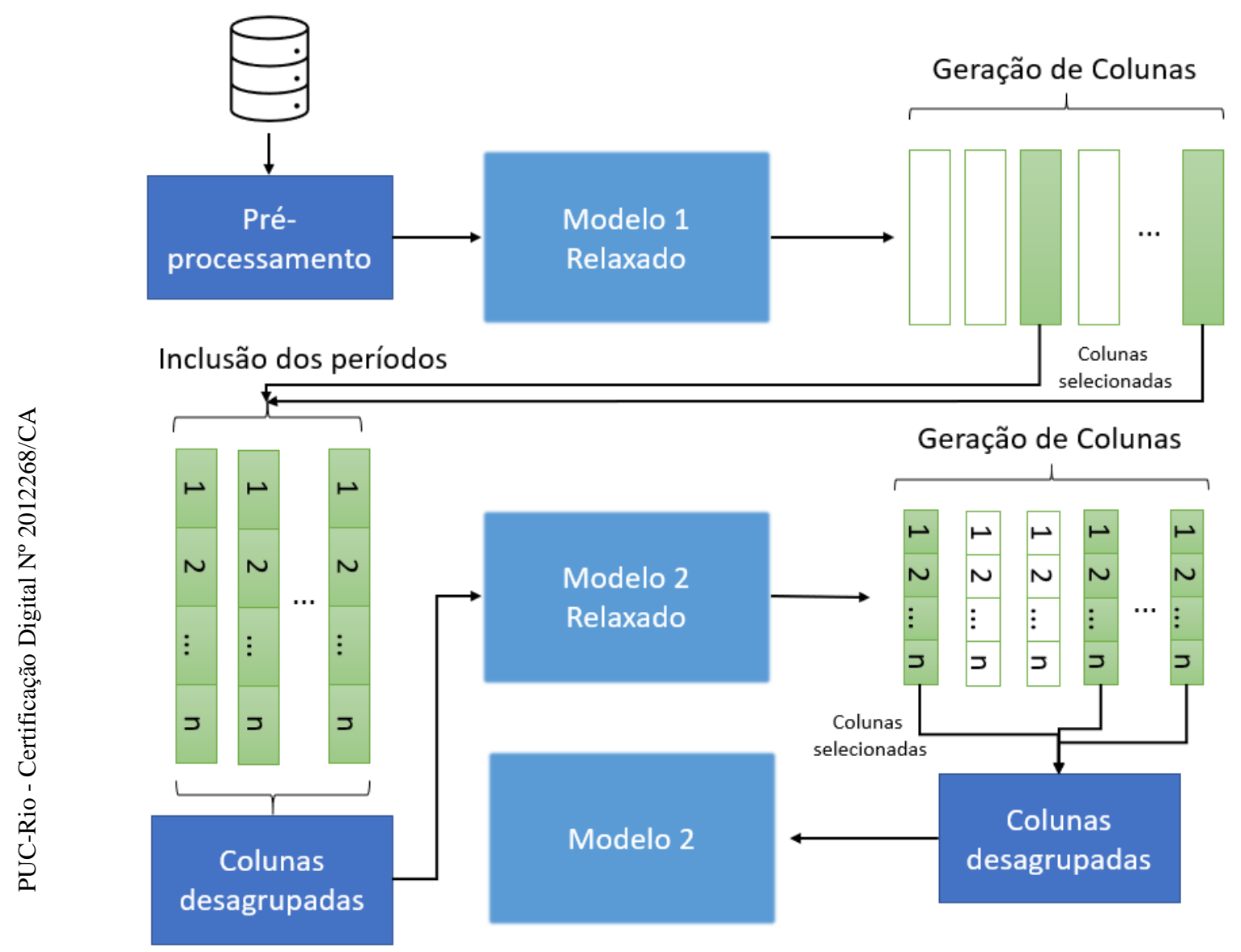

Figura 4.1: Fluxograma de solução e da heurística 3 etapas

Enquanto a Figura 4.1 identifica a heurística 3 etapas, a Figura 4.2 mostra as etapas da heurística 2 etapas. A heurística 2 etapas utiliza a solução a partir da solução encontrada pelo Modelo 1, adicionando os períodos nas variáveis de decisão e otimiza o modelo. Assim, é uma simplificação da heurística 3 etapas. 
A heurística 2 etapas, conforme visualizada na Figura 4.2 apresenta passos semelhantes ao apresentado pela heurística 3 etapas, com a diferenciação que não utiliza as etapas 8 e 9, assim, as variáveis de decisão das colunas obtidas a partir de MAI são utilizadas para a otimização do MAIM. ${ }^{1}$

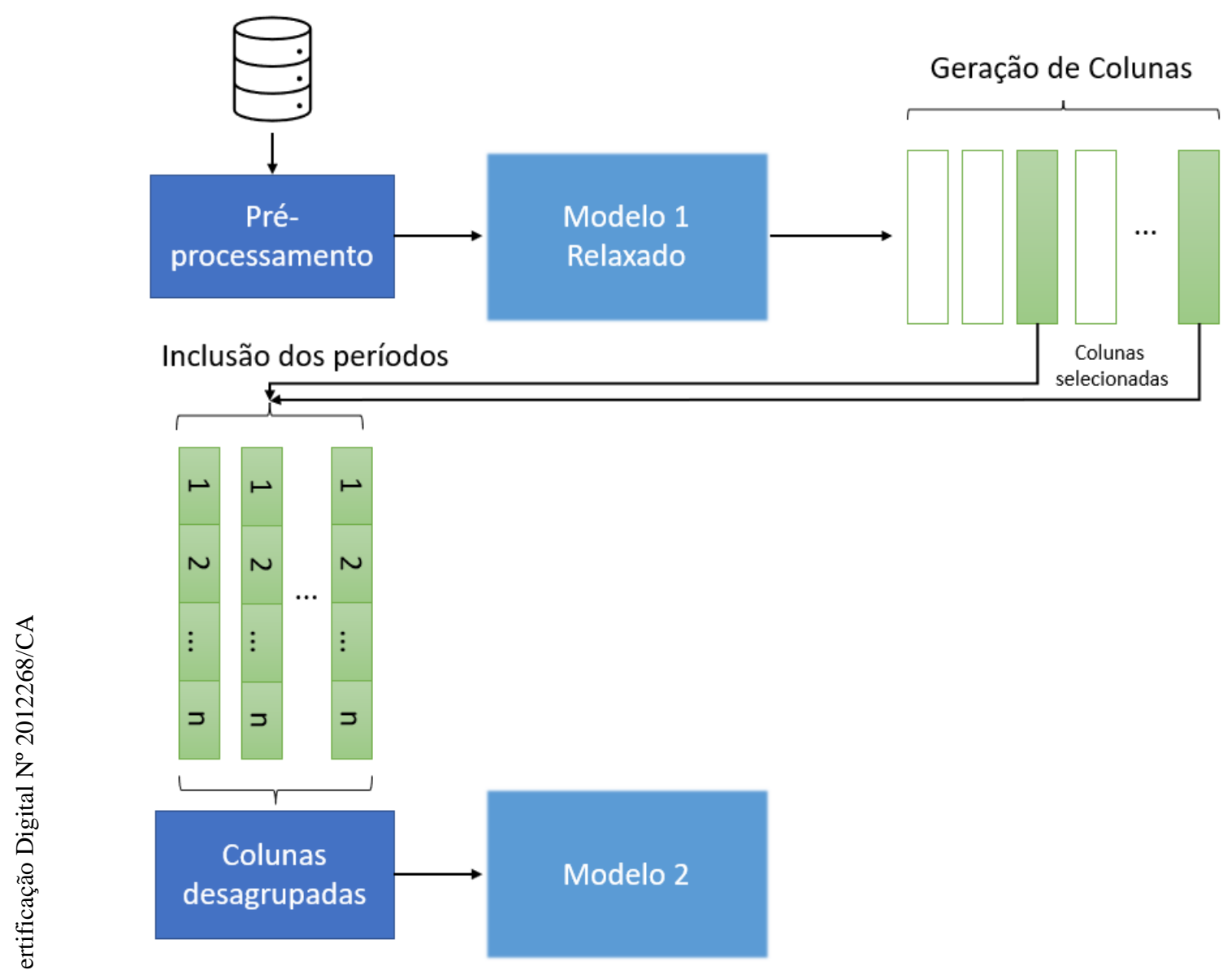

Figura 4.2: Fluxograma de solução e da heurística 2 etapas

A Figura 4.3 apresenta detalhamento da etapa da heurística 3 etapas do MAI apresentado na Figura 4.1.

O Modelo Mestre Restrito da Figura 4.3 é a relaxação do modelo - modelo sem restrição das variáveis inteiras - ele é solucionado e o dual - preço sombra - é utilizado como entrada para o modelo de pricing que gerará uma ou mais colunas com as variáveis que formam as colunas com a maior soma do preço sombra. O modelo de pricing pode ser um modelo de programação inteira, mas

\footnotetext{
${ }^{1}$ Para a utilização das variáveis de decisão do MAI no MAIM é necessário incluir o índice do período na variável de decisão $A M_{i, m}$. Assim, é criada uma variável para cada período, conforme Figura 4.2
} 


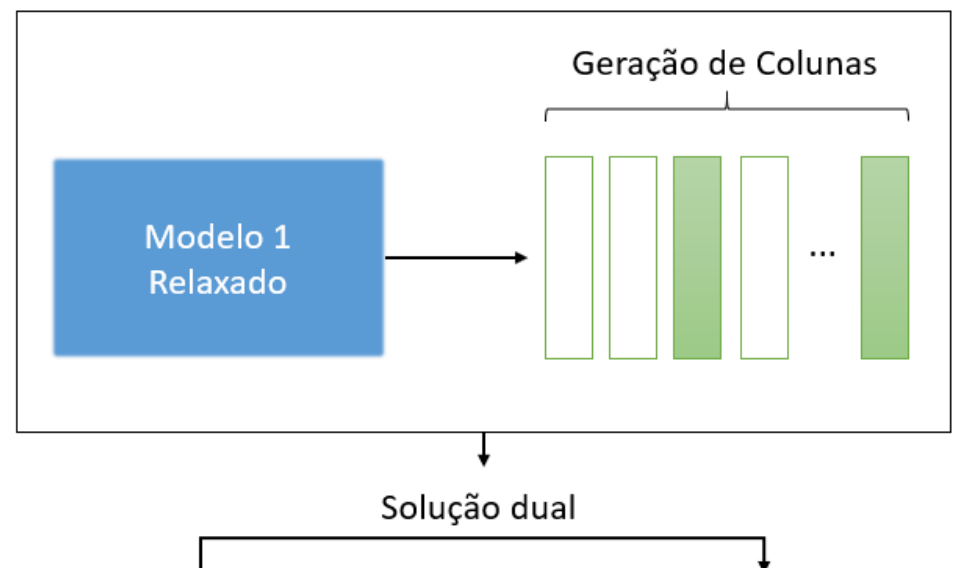

Modelo Mestre

Restrito

Simplex

Modelo Pricing

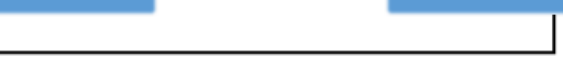

Geração de uma ou mais colunas

Figura 4.3: Detalhamento da heurística 3 etapas

para redução do custo computacional essa etapa foi realizada com a utilização de programação dinâmica. O ciclo deve ser realizado enquanto existir um custo reduzido negativo, ou ainda com algum critério de parada; o segundo caso não garante que a solução final tenha um valor ótimo.

A implementação da programação dinâmica é uma adaptação de um problema de alocação de itens em uma mochila apresentada por Dasgupta et al. (2006), a Equação 4-24 apresenta o algorítimo base, onde $K(w, j)$ representa o valor máximo alcançável usando uma mochila com capacidade $w$ e itens 1 até $j$.

$$
K(w, j)=\max \left\{K\left(w-w_{j}, j-1\right)+v_{j}, K(w, j-1)\right\}
$$

O Algoritmo 1 apresenta a programação dinâmica do problema da mochila sem repetição apresentado por Dasgupta et al. (2006), uma adaptação desse algoritmo foi implementado para as heurísticas, conforme apresentado na Figura 4.1 no Apêndice D. 


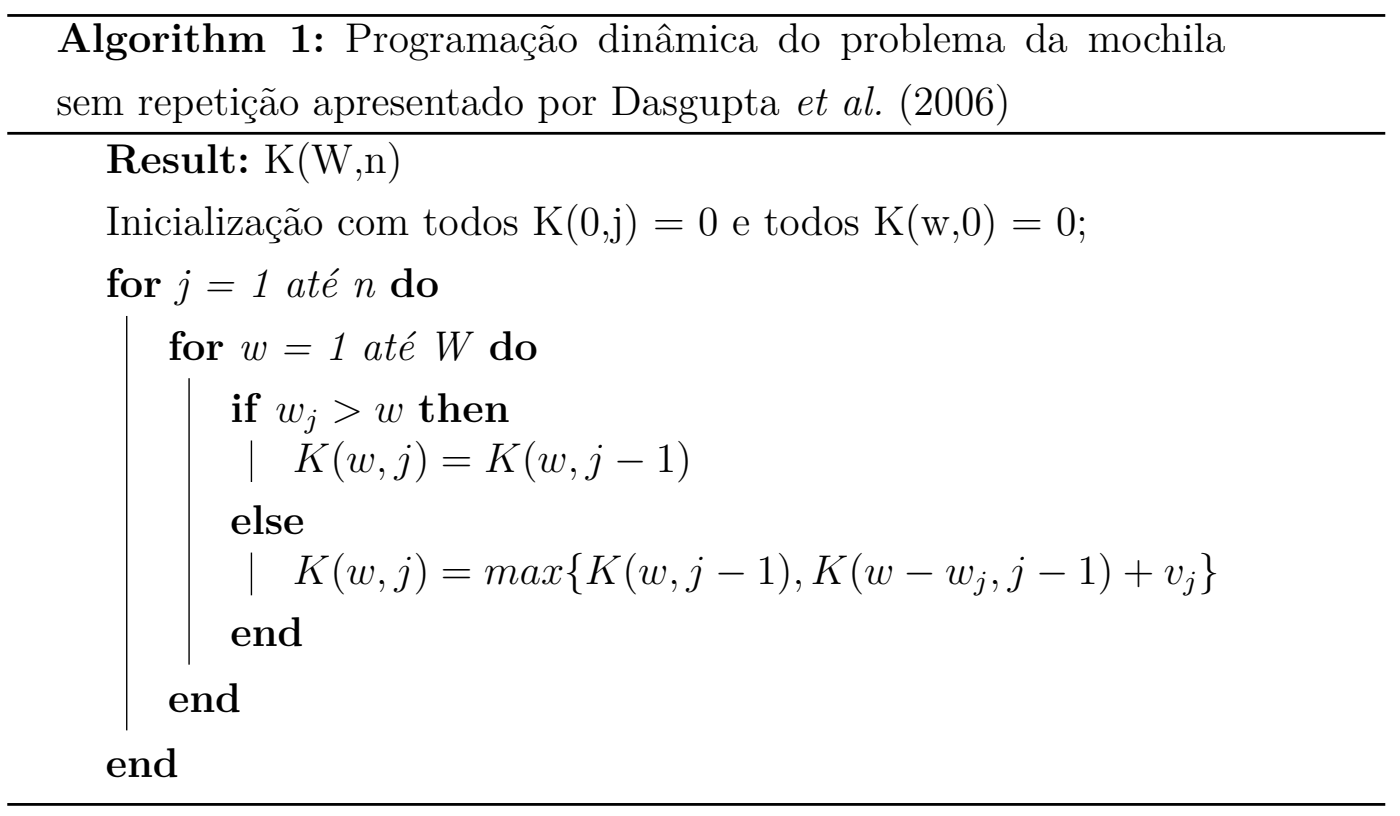

O detalhamento da heurística 3 etapas é apresentada no Apêndice E. 


\section{5 \\ Resultados e discussões}

Nesse capítulo apresenta-se os resultados obtidos com os modelos matemáticos. Todos os modelos e instâncias foram executados em um computador com o sistema operacional Windows 10 com processador Intel Core i7-8550U @ 1.80GHZ e 16 GB de memória RAM.

\section{1}

\section{Implementação dos modelos}

Os modelos foram implementados utilizando o software Julia (1.6.0), com o pacote de otimização JuMP (0.21.6) (DUNNING et al., 2017); e os pacotes dos solvers Gurobi e CPLEX. Além disso foram utilizados os pacotes auxiliares: CSV, para abertura e criação de arquivos .CSV, e o pacote DataFrames, para estruturação dos dados contidos no arquivo .CSV.

O MAI também foi implementado em Julia e no LINGO 19.0. Foram utilizadas licenças de estudante ilimitadas nos solvers CPLEX, Gurobi e no LINGO.

\section{2}

\section{Instâncias}

Para ser possível determinar as especificidades das instâncias, foram criados métricas e indicadores para apontar as características das instâncias e mensuração das soluções encontradas.

Em relação às instâncias, é possível identificar a quantidade de inspetores, capacitações existentes, origens, destinos, missões, períodos e total de períodos de missão - sendo o somatório do produto entre tamanho da equipe e a duração da missão.

Detalhamento das colunas da Tabela 5.1:

1. instância - nome da instância, as instâncias C são alocações reais e as A e B são adaptações das C com retirada na quantidade de missões - e consequentemente redução de habilitações únicas, destinos e dos conjuntos derivados;

2. $|\mathrm{I}|$ - quantidade de inspetores que podem realizar ao menos uma missão; 
3. $|\mathrm{C}|$ - quantidade de habilitações únicas nas missões;

4. $|\mathrm{O}|$ - quantidade de origens;

5. $|\mathrm{D}|$ - quantidade de destinos;

6. $|\mathrm{M}|$ - quantidade de missões;

7. quantidade de períodos de missão - somatório das missões do produto da quantidade de períodos e o tamanho da equipe necessária para realização da inspeção;

8. alocação em viagens - total de arcos de colaborador com os destinos em que ele pode realizar pelo menos uma missão. Não será criada a variável de deslocamento do inspetor $x$ se ele não possuir nenhuma atividade para a qual seja habilitado no destino $y$. Sem essa condicional, o tamanho desse conjunto seria $|\mathrm{I}| *|\mathrm{D}|$;

9. arco de missões - total de missões que os colaboradores podem realizar. Não será criada a variável de alocação do inspetor $x$ se ele não possuir habilitação para realizar a missão $y$. Sem essa condicional, o tamanho desse conjunto seria $|\mathrm{I}| *|\mathrm{M}|$, ou ainda $|\mathrm{I}| *|\mathrm{M}| *|\mathrm{D}|$, se a criação da variável for feita de modo equivocado.

Com as colunas 8 e 9, é possível verificar a esparsidade dos conjuntos de deslocamento e de alocação dos colaboradores. O modelo da literatura considerava esses conjuntos como denso, e, assim, já existe um ganho ao realizar essa condição na criação de variáveis - impedindo alocações inviáveis (SILVA, 2018).

As quantidades das colunas 8 e 9 são referentes ao MAI, que não possui períodos; ao incluir o período como um conjunto, os valores das colunas devem ser multiplicados pelo número total de períodos. Cada período representa 12 horas.

A Tabela 5.1 apresenta as instâncias utilizadas. As instâncias C1, C2 e C3 são os arquivos recebidos da ANAC com os parâmetros reais da alocação. A partir desses dados, foram geradas as instâncias A1, A2, A3, B1, B2 e B3 a partir da remoção de colaboradores, missões e/ou de períodos das instâncias C.

Informações adicionais sobre as instâncias, com as combinações válidas, quantidade de inspeções e de colaboradores por missão, assim como duração, equipe e oferta são apresentadas nos Apêndices F e H. 
Tabela 5.1: Características das instâncias utilizadas

\begin{tabular}{cccccccccc} 
Instâncias & $|\mathrm{I}|$ & $|\mathrm{C}|$ & $|\mathrm{O}|$ & $|\mathrm{D}|$ & $|\mathrm{M}|$ & Qtd períodos de missão & Alocação em viagens & Arco de missões \\
\hline A1 & 38 & 7 & 3 & 8 & 14 & 51 & 146 & 182 \\
A2 & 151 & 19 & 3 & 16 & 44 & 203 & 1.787 & 4.078 \\
A3 & 126 & 24 & 15 & 16 & 48 & 212 & 712 & 2.046 \\
\hline B1 & 38 & 7 & 3 & 9 & 20 & 130 & 177 & 280 \\
B2 & 151 & 21 & 3 & 19 & 66 & 300 & 2.237 & 6.045 \\
B3 & 126 & 24 & 15 & 18 & 62 & 260 & 759 & 2.460 \\
\hline C1 & 41 & 8 & 3 & 11 & 23 & 146 & 2.83 & 10.866 \\
C2 & 151 & 23 & 3 & 22 & 118 & 808 & 1.022 & 5.263 \\
C3 & 126 & 26 & 15 & 21 & 123 & 481 & &
\end{tabular}

\section{3}

\section{Pré-processamento de dados}

Os parâmetros do problema foram disponibilizados via planilha no Excel - com os dados necessários para a otimização do problema. É sabido que o problema apresentado possui conjuntos que podem ser representados em uma matriz esparsa. Foi realizada etapa de pré-processamento dos dados para definição das alocações viáveis, identificando as alocações que cada colaborador poderia realizar em todos os destinos. Essa etapa visou reduzir a quantidade de condicionais necessárias na modelagem matemática.

No Apêndice H, é apresentado o resultado do pré-processamento da instância C2.

\section{4}

\section{Modelo 1 - MAI}

O MAI possui uma formulação matemática simplificada do problema, não determinando o período em que as atividades devem ser realizadas. Essa simplificação reduz o tempo de solução do problema, portanto a solução gerada não necessariamente será viável no problema real. A partir da solução do modelo, é necessária a definição manual do período em que a atividade será realizada. Dahmen et al. (2020) apresentaram essa metodologia.

\subsection{1}

\section{Execução}

Na Tabela 5.2 apresenta-se a solução ótima, o tempo de solução do MAI: os tempos da modelagem em JuMP com os solvers CPLEX e Gurobi, assim como implementação realizada no LINGO. Todas instâncias em todos os modelos encontraram a solução ótima. Os tempos podem ser comparados com o tempo disponível de modelo da literatura no Lingo, apresentado por ANAC (2019a) e por Couto (2020). 
Os tempos encontrados indicam que o modelo no Lingo é em torno de 2 25 vezes mais rápido do que o modelo disponível na literatura, e a implementação no JuMP é em torno de 13 424 vezes mais rápida do que a literatura, dependendo da instância observada. Em nenhum caso o tempo de resolução do modelo da literatura foi menor do que o tempo do Lingo, CPLEX ou do Gurobi. Além disso, na média, o tempo de solução do Gurobi é menor do que o CPLEX para o problema analisado, com uma pequena diferença.

Tabela 5.2: Tempo de solução em segundos das instâncias utilizadas

\begin{tabular}{cccccccc} 
Instância & Ótimo & Variáveis & Restrições & CPLEX & Gurobi & LINGO & Literatura \\
\hline A1 & 11.588 & 328 & 527 & 0,05 & 0,02 & 1,07 & 8,47 \\
A2 & 13.421 & 5.865 & 7.848 & 0,28 & 0,13 & 2,21 & 9,03 \\
A3 & 16.510 & 2.758 & 3.645 & 0,12 & 0,04 & 0,75 & 18,86 \\
B1 & 11.714 & 457 & 693 & 0,13 & 0,02 & 0,93 & 7,9 \\
B2 & 18.505 & 8.682 & 10.737 & 0,43 & 0,13 & 6,17 & 13,71 \\
B3 & 20.343 & 3.219 & 4.167 & 0,14 & 0,06 & 0,95 & 23,08 \\
C1 & 12.144 & 527 & 795 & 0,1 & 0,03 & 1,5 & 2,37 \\
C2 & 27.100 & 14.243 & 17.422 & 3,58 & 2,6 & 11,57 & 34,97 \\
C3 & 26.353 & 6.717 & 8.055 & 0,42 & 0,18 & 2,67 & 43,52
\end{tabular}

A Tabela 5.1 apresentou as principais características das instâncias, e na Tabela 5.2 é possível visualizar o tamanho do problema em relação à quantidade de variáveis e de restrições.

Em relação aos tempos apresentados na Tabela 5.2, é preciso destacar que o modelo proposto e o modelo da literatura foram implementados no Lingo, o que torna justa a comparação do tempo de solução. Os tempos do CPLEX e do Gurobi foram implementados em Julia com a utilização do pacote JuMP, assim, existem diferenças no tempo que cada software considera. No LINGO, o tempo considera a importação, criação do modelo e resolução; em Julia, é considerado apenas o tempo de resolução do problema. Dependendo da instância, essas etapas são realizadas em um ou em poucos segundos para as instâncias maiores, com um tempo total um pouco menor do que o tempo do Lingo.

\section{4 .2}

\section{Benefícios e limitações do MAI}

O tempo de solução do MAI é baixo, mas podem existir limitações na aplicação da solução no problema real. Como existem atividades que necessitam de mais de um colaborador para serem realizadas, ocorre a possibilidade de não existir uma solução viável em que as duas ou mais pessoas alocadas para uma missão possuam um período em comum para a realização da inspeção. 
Um exemplo simplificado dessa inviabilidade é demonstrado nas Figuras 5.1 e 5.2: alocação de dois inspetores, cinco atividades que devem ser feitas em dupla e três períodos; para simplificação, foi desconsiderado o tempo de deslocamento. Nessa situação, são escalados dois inspetores, o A foi atribuído para realizar as missões M1, M2 e M3, o B foi atribuído para as missões M3, M4 e M5. Já que todas as missões devem ser feitas em duplas, as missões M1, M2, M4 e M5 serão feitas em dupla com outros inspetores não apresentados na imagem.

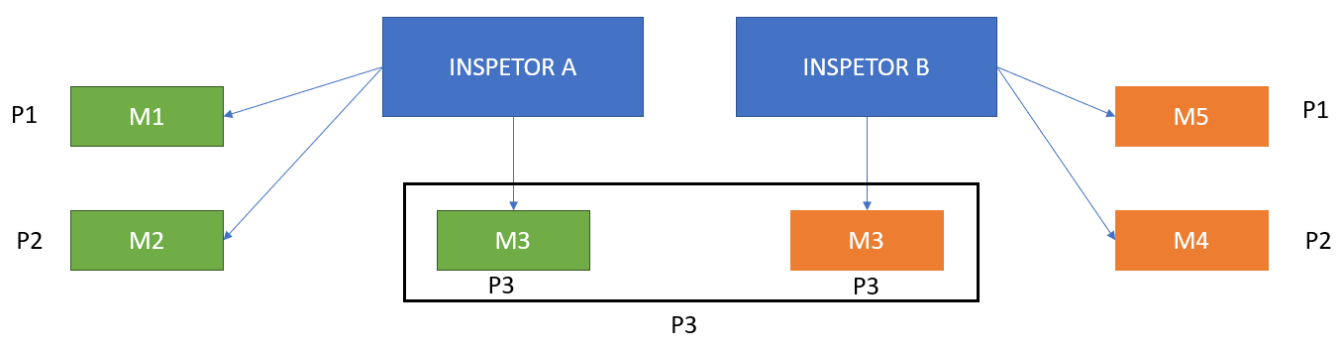

Figura 5.1: Exemplo de solução viável

Considerando que o MAI não determina o período em que cada atividade é realizada, é preciso que posteriormente a solução determine o período em que a atividade será efetuada. Na Figura 5.1, o inspetor A realiza as atividades M1 e M2, respectivamente, nos períodos 1 e 2, o inspetor B realiza M5 e M4, respectivamente, nos períodos 1 e 2; dessa forma é possível que a M3 seja alocada no período 3. Todavia, na Figura 5.2, supondo que as missões M1, M2, M5 e M4 devam ocorrer, respectivamente, nos períodos 1, 3, 2 e 3, não existirá um período em comum para que os inspetores A e B realizem a M3. Nesse exemplo, o inspetor A está livre no período 2 enquanto o inspetor B está livre no período 1, tornando essa uma solução inviável do modelo.

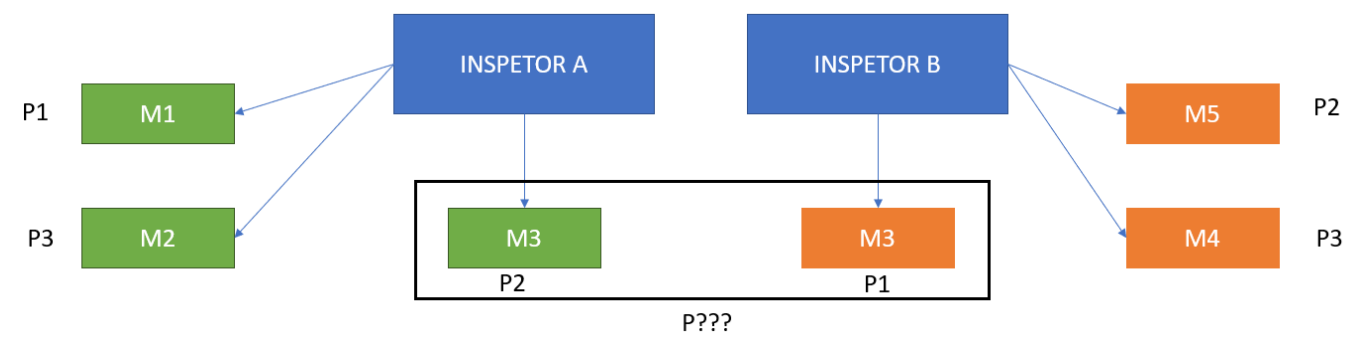

Figura 5.2: Exemplo de solução inviável a partir da solução do MAI 
Assim, a solução apresentada pelo MAI requer a definição do período em que as missões sejam realizadas e existe a possibilidade de que não exista uma combinação viável da solução apresentada por esse problema. O MAIM, além de possuir outras vantagens, é uma alternativa para solucionar esse problema.

\section{5}

\section{Modelo 2 - MAIM}

O MAIM, além de seguir as regras de alocação do MAI, atende a outros aspectos, como a inclusão de uma ajuda de custo dos períodos entre o início e fim das viagens.

\subsection{1}

\section{Execução}

Esse modelo foi implementado e solucionado em Julia com o pacote JuMP e o solver Gurobi, esse solver obteve o melhor desempenho no MAI. Foi definido um limite no tempo de execução de 3.600 segundos - 1 hora.

O modelo matemático utiliza o fluxo apresentado na Figura 4.1 para a criação de colunas, com o objetivo de reduzir a quantidade de variáveis e, com isso, diminuir o tempo computacional necessário para a solução do problema. As instâncias A possuem 14 períodos; as B, 21 períodos; e as C, 28 períodos.

Dessa forma, as instâncias são solucionadas três vezes. A primeira vez, com o modelo completo. Na segunda vez, são geradas colunas a partir do MAI, são incluídos os períodos e o modelo é solucionado com essas variáveis. A terceira vez gera as colunas a partir do MAI, as colunas recebem o período e são geradas novas colunas a partir do MAIM Relaxado, e as colunas selecionadas são utilizadas para resolução do problema. O fluxograma completo encontra-se na Figura 4.1.

A Tabela 5.3 apresenta o tempo de execução consolidado; MI é a melhor solução inteira, dado que esse é um problema de minimização; BB é o Best Bound, garante que não exista nenhuma solução inteira menor do que esse valor, para os dados de entrada utilizados. As três primeiras colunas possuem o tempo de solução e resultado obtido quando o MAIM é executado sem a utilização de heurística. Assim, o resultado dessas colunas permite a utilização de todas as alocações viáveis.

As duas próximas colunas indicam o tempo e MI quando o MAIM é utilizado com a heurística parcial, ou seja, as colunas geradas a partir do MAI Relaxado são enviadas para o MAIM sem passar antes pela heurística do MAIM Relaxado (Figura 4.1). 
Por fim, as duas últimas colunas apresentam o tempo e MI quando o MAIM é solucionado seguindo o fluxograma completo apresentado da Figura 4.1 .

Tabela 5.3: Tempo de solução do Modelo 2

\begin{tabular}{cccccccc} 
& \multicolumn{3}{c}{ Modelo 2 } & \multicolumn{3}{c}{ Modelo 2 - Heurística 2 etapas } & \multicolumn{2}{c}{ Modelo 2 - Heurística 3 etapas } \\
\hline Instância & TEMPO & MI & BB & TEMPO & MI & TEMPO & MI \\
\hline A1 & 3.600 & 14.861 & 11.882 & 1,91 & 14.962 & 20,31 & 15.625 \\
A2 & 3.600 & - & 2.517 & 3.600 & 24.979 & 3.600 & 25.956 \\
A3 & 3.600 & 32.443 & 11.044 & 3.600 & 31.001 & 3.600 & 31.106 \\
B1 & 3.600 & 14.549 & 6.215 & 85 & 14.933 & 34 & 14.883 \\
B2 & 3.600 & - & 1.906 & 3.600 & - & 3.600 & - \\
B3 & 3.600 & - & - & 3.600 & 42.456 & 3.600 & 41.566 \\
C1 & 3.600 & 17.136 & 4.685 & 3.600 & 17.371 & 3.600 & 17.371 \\
C2 & - & - & - & 3.600 & - & 3.600 & - \\
C3 & - & - & - & 3.600 & - & 3.600 & -
\end{tabular}

Utilizando todas as variáveis (Modelo 2), apenas as instâncias A1, A3, B1 e C1 obtiveram uma solução viável. As instâncias A2 e B2 apresentam BB, mas não uma solução viável.

Com os resultados obtidos, é possível verificar que dada a complexidade é inviável a solução desse modelo sem a utilização de alguma técnica para redução de variáveis de decisão. Como esperado, seis das nove instâncias não encontraram uma solução viável no MAIM sem a heurística, enquanto que, com a heurística, apenas três instâncias não encontraram uma solução viável.

A Tabela 5.4 apresenta as instâncias com a melhor solução inteira encontrada e a melhor solução inteira estimada. A estimação utiliza a solução encontrada do MAI (Tabela 5.2), multiplicando-se o $C E$, que é a ajuda de custo do inspetor (Equação 4-7), pela a quantidade de períodos de missão (Tabela 5.1). Assim, a melhor solução inteira estimada é o resultado ótimo do MAI acrescido da ajuda de custo inclusa apenas no MAIM. O GAP estimado é calculado a partir BB estimado.

Tabela 5.4: Best bound e GAP estimados

\begin{tabular}{cccc}
\hline & & Heurística 2 etapas & Heurística 3 etapas \\
\hline Instância & BB estimado & GAP Estimado & GAP Estimado \\
\hline A1 & 14.138 & $5,5 \%$ & $9,5 \%$ \\
A2 & 23.571 & $5,6 \%$ & $9,2 \%$ \\
A3 & 27.110 & $12,6 \%$ & $12,8 \%$ \\
B1 & 14.964 & $-0,2 \%$ & $-0,5 \%$ \\
B2 & 33.505 & - & - \\
B3 & 33.343 & $21,5 \%$ & $19,8 \%$ \\
C1 & 15.794 & $9,1 \%$ & $9,1 \%$ \\
C2 & 67.500 & - & - \\
C3 & 50.403 & - & -
\end{tabular}


A melhor solução inteira estimada é conservadora, pois não leva em consideração a ajuda de custo concedida ao colaborador em deslocamento, ou quando o inspetor está em um destino aguardando a chegada de outro colaborador para realizar determinada missão. Esse segundo caso deve ocorrer somente em casos especiais, quando é mais econômico o inspetor aguardar no destino a chegada de outro inspetor até então indisponível no período anterior.

Das nove instâncias, não foram obtidos valores de uma solução inteira em três casos. Uma solução possível nessa situação é dividir a alocação em períodos menores, dado que em instâncias menores o modelo foi capaz de apresentar solução inteira.

Com a utilização da heurística, foi possível obter soluções viáveis para algumas das instâncias, em maior quantidade de soluções do que o modelo completo. Todavia, uma vez que o método não é exato, não é possível garantir que não exista alguma outra solução com um custo menor.

O GAP estimado utiliza um MI (melhor solução inteira) estimado a partir da solução no MAI. O GAP da instância A1 é negativo, pois as funções objetivo do MAI e do MAIM são diferentes. Assim, no MAIM, pode ser preferível alocar um inspetor que tenha um custo de deslocamento maior, desde que ele tenha um tempo de deslocamento menor. Quando isso ocorre, será pago um valor no deslocamento, mas haverá uma economia no valor de ajuda de custo.

Em relação aos resultados da instância A2 com o MAIM, a heurística parcial possui GAP estimado de 5,6\%. O MAI encontrou o ótimo da instância A2 com um resultado de 13.421, isso indica que o solver teve dificuldade em encontrar uma melhor solução inteira para essa instância, dado que seria impossível existir uma solução melhor do que 13.421. O GAP estimado é uma aproximação da melhor solução inteira e utiliza como base a solução do MAI com a inclusão da ajuda de custo dos períodos em que os colaboradores serão alocados nas inspeções, sem considerar os períodos de deslocamento - quando o inspetor também deve receber a ajuda de custo. A melhor solução inteira estimada é de $23.571(13.421+50 * 203)$, com GAP estimado de 5,6\%, assim, é possível afirmar que a instância A2 está próxima do valor ótimo.

Com a heurística, foram obtidas soluções viáveis em quase todas as instâncias, assim, é possível observar que o GAP indica proximidade da solução ótima.

As instâncias A e B possuem, respectivamente, 14 e 21 períodos. Para o tempo limitado tiveram um pequeno GAP as instâncias A1, A3 e B1, e a instância A1 obteve o ótimo. Embora não tenham sidos obtida soluções para as instâncias $\mathrm{C} 2$ e C3, é possível utilizar uma técnica de divisão do problema inicial. Uma solução para esse problema é separar os 28 períodos em dois ou 
mais subproblemas, dividindo-se as instâncias maiores em problemas menores. As instâncias A representam aproximadamente $40 \%$ do tamanho das instâncias C, enquanto as B representam aproximadamente $50 \%$ do tamanho das C. Desse modo, subdividir o problema maior é uma possível solução para abordar as maiores instâncias.

A melhora da solução da instância A3 em relação ao tempo é apresentada na Figura 5.3. Em tempo menor de 5 minutos, tanto a estratégia de heurística parcial quanto a completa já possuem um solução viável, o que o modelo completo só encontra após 15 minutos.

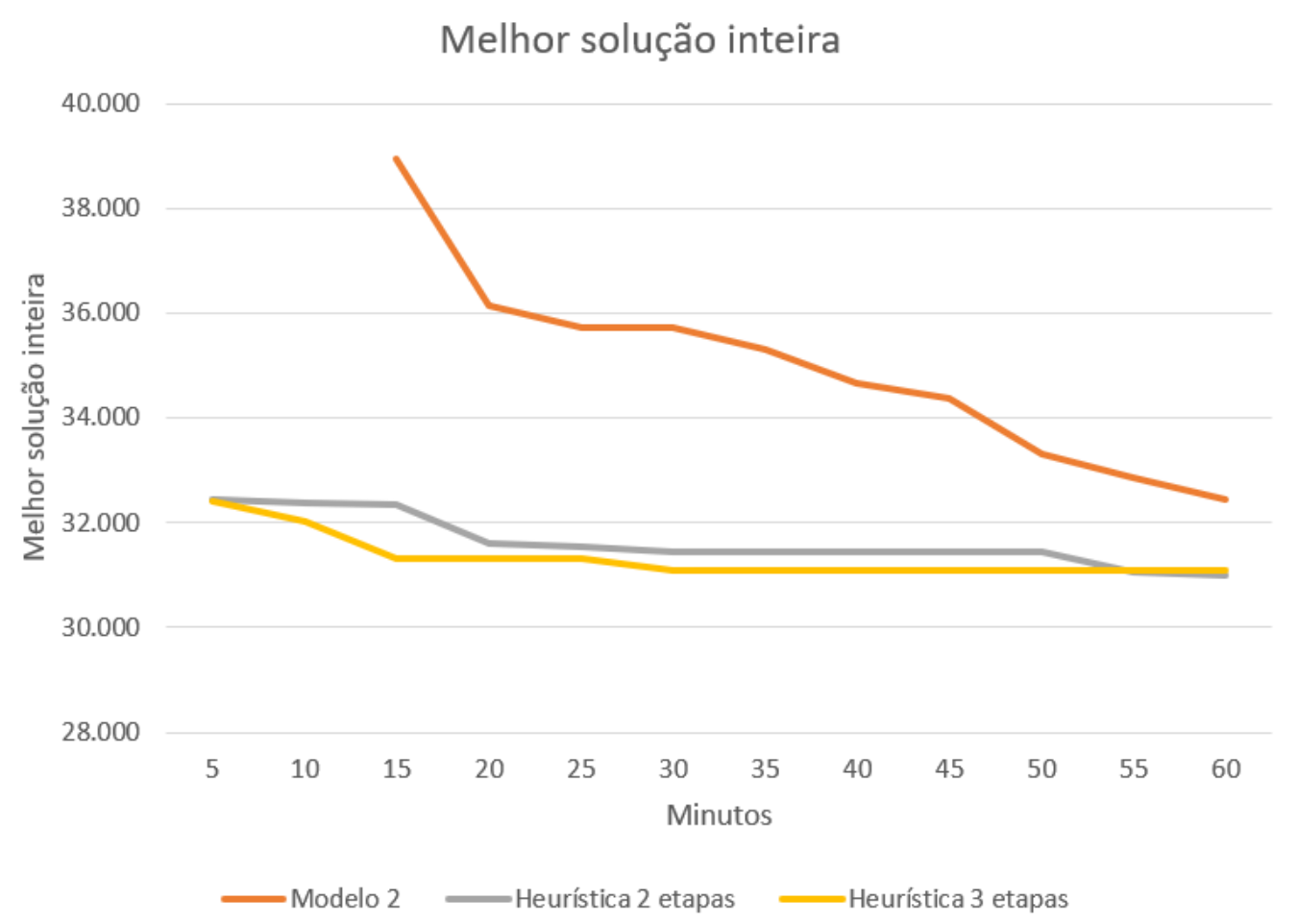

Figura 5.3: Valor da função objetivo em relação ao tempo da instância A3

Ainda que exista um GAP no tempo de solução estabelecido, a solução obtida pode ser utilizada para a alocação dos inspetores nas atividades de inspeção.

A Tabela 5.5 apresenta a redução de variáveis com a heurística. A Alocação em viagens são as variáveis de deslocamento dos colaboradores, indicam o inspetor, período e o arco que pode ser realizado. O Arco de missões apresenta a quantidade de alocações geradas a partir da heurística, do arco de alocação em missões, indicando possíveis alocações do colaborador, período e missão. 
A redução de variáveis com a utilização da heurística é significativa, em alguns casos, conforme demonstrado na Tabela 5.5, a redução na quantidade de variáveis foi de até $95 \%$. Uma consequência da redução de colunas é a redução na quantidade de inspetores que poderão ser alocados, dado que os que possuem um custo maior não serão incluídos. O Apêndice F possui informações adicionais sobre as combinações viáveis e da heurística.

Tabela 5.5: Redução de variáveis com a geração de colunas

\begin{tabular}{cccc} 
Instâncias & Inspetores & Alocação em viagens & Arco de missões \\
\hline A1 & $66 \%$ & $86 \%$ & $87 \%$ \\
A2 & $69 \%$ & $93 \%$ & $95 \%$ \\
A3 & $60 \%$ & $81 \%$ & $89 \%$ \\
B1 & $61 \%$ & $88 \%$ & $90 \%$ \\
B2 & $70 \%$ & $94 \%$ & $95 \%$ \\
B3 & $47 \%$ & $82 \%$ & $92 \%$ \\
C1 & $51 \%$ & $86 \%$ & $89 \%$ \\
C2 & $38 \%$ & $88 \%$ & $94 \%$ \\
C3 & $43 \%$ & $85 \%$ & $92 \%$
\end{tabular}

Com os resultados da Tabela 5.5 é possível observar que, com a utilização da heurística, existe redução significativa na quantidade de inspetores, variáveis de alocação em viagens e de arco de missões. 


\section{6 \\ Conclusões}

No processo de alocação de inspetores qualificados é necessário respeitar as regras existentes, todavia, deve-se ter o objetivo de minimizar o custo da operação dessa atividade. Assim, foi realizada uma RSL para compreender as características desse tipo de problema e elaborados dois modelos matemáticos.

Com a realização da Revisão Sistemática da Literatura, identificou-se a falta de estudos que abordem sobre Safety Oversight System aplicados à alocação de colaboradores de inspeção qualificados. A dissertação de mestrado concluiu que o processo pode ser otimizado com a utilização de um modelo MILP. Além dos ganhos na redução de custos, a solução gerada respeita as restrições estabelecidas, e retorna solução em um tempo menor do que modelos disponíveis na literatura.

O MAIM apresenta uma formulação com características adicionais, como a definição da realização do período em que a atividade será realizada e a ajuda de custo que deve ser paga ao inspetor, o que não era considerado anteriormente. Para a solução, foi apresentada heurística para redução de variáveis com a utilização de programação dinâmica.

Assim, os modelos apresentados podem ser utilizados como ferramentas de apoio à decisão para a alocação de inspetores, considerando as habilitações de cada colaborador, a habilitação necessária para a realização das atividades de inspeção e tamanho da equipe, o local onde o inspetor está localizado, local da atividade e os custos de transporte. Os resultados do MAI tiveram um tempo de solução menor em Julia, com a utilização do pacote JuMP, do que com a implementação no LINGO.

O MAI obteve redução no tempo de solução, sendo em algumas instâncias de 2 até 25 vezes mais rápido do que o tempo encontrado com o modelo base da literatura, considerando a implementação no JuMP. O ganho é proveniente da criação somente das variáveis que efetivamente podem ser realizadas. Assim, o modelo proposto resulta em desempenho melhor do que o modelo da literatura. 
Para o MAIM, foi implementado heurística, em que foi possível reduzir em até 95\% a quantidade de variáveis de decisão e encontrar uma solução viável que não seria possível sem esta redução de variáveis. Com a heurística, foi encontrada uma solução em seis das nove instâncias, enquanto que a resolução do modelo sem a heurística obteve a solução em somente três instâncias.

O problema foi aplicado no setor aéreo, em uma agência fiscalizadora, ainda assim não existe impedimento para a aplicação em outros modais de transporte ou ainda em outras atividades de inspeção. A utilização do modelo proposto em outras aplicações pode ocorrer uma vez que problemas de alocação de equipe de manutenção possuem muitas similaridades ao problema apresentado.

Assim, a dissertação apresentou o MAI com desempenho melhor do que o modelo da literatura; o MAIM leva em consideração aspectos adicionais ao problema; e é utilizada técnica para redução de variáveis para a resolução do MAIM, o que proporciona a obtenção de solução viável em um maior número de instâncias.

\section{1}

\section{Sugestões para trabalhos futuros}

O modelo elaborado parte da premissa de existirem atividades de inspeção que devem ocorrer na próxima quinzena ou no próximo mês. Nesse sentido, a solução apresentada possui maior benefício no nível operacional do problema.

Estudos futuros podem realizar novas propostas da definição das inspeções que devem ocorrer no decorrer do ano, beneficiando-se do preço flutuante das passagens aéreas e da alocação de missões em meses específicos. Já que os inspetores deslocam-se para determinado local, podem realizar diversas atividades de inspeção, o que não seria possível realizar na mesma viagem se as missões fossem alocadas em meses diferentes.

Sugere-se pesquisa para otimizar a quantidade de centros da ANAC, definindo se o fechamento de determinado centro e realocação desses inspetores traria benefício, considerando os custos de tal operação de realocação dos colaboradores.

Os modelos sugeridos possuem objetivo estratégico e podem utilizar técnicas que considerem a incerteza, como por exemplo a utilização de modelos estocásticos ou robustos, uma vez que existe incerteza dos preços futuros das passagens aéreas e da quantidade de missões demandada em cada destino. 
Como uma proposta para trabalho futuro, pode ser realizada RSL com o mesmo enfoque em relação ao tema realizado, todavia verificando alguma outra técnica de solução, como, por exemplo, geração de colunas, algoritmos com técnica de heurística ou de meta-heurística, uma vez que podem existir outras formas de solução para esse tipo de problema. 


\section{Referências}

ANAC. ANAC amplia ações para a distribuição de vacinas contra a Covid-19. [S.l.: s.n.], 2021. Disponível em: <https : //www . anac.gov.br/ noticias/2021/anac-amplia-acoes-para-a-distribuicao-de-vacinascontra-a-covid-19>.

Dados do $2^{\mathrm{o}}$ tri revelam impacto de mais de 6 bilhões nas aéreas brasileiras. [S.l.: s.n.], 2020. Disponível em: <https : //www . anac . gov . br/noticias/2020/dados-do-2o-tri-revelam-impacto-de-maisde-6-bilhoes-nas-aereas-brasileiras $>$.

Mercado aéreo em 2019: maior número de passageiros transportados da série histórica. [S.l.: s.n.], 2020. Disponível em: <https : //www . anac . gov . br/noticias /2020/mercado-aereo-registra-maiornumero-de-passageiros-transportados-da-serie-historica>.

Plano estratégico 2020 - 2026. [S.l.: s.n.], 2020. p. 1-32. Disponível em: <https://www.gov.br/anac/pt-br/acesso-a-informacao/acoese-programas/arquivos/Plano_20202026.pdf $>$.

Projeto Safety Oversight, A04 - Relatório técnico de resultados do modelo inicial. [S.l.: s.n.], 2019. p. 153.

PSO-BR 2019-2022: programa brasileiro para a segurança operacional da aviação civil, p. 24, 2019. Disponível em: <https : //www . anac . gov . br / assuntos / paginas - tematicas / gerenciamento-da-segurancaoperacional/arquivos/pso-br.pdf $>$.

ANOSHKINA, Y.; MEISEL, F. Technician teaming and routing with service, cost- and fairness-objectives. Computers and Industrial Engineering, Elsevier, v. 135, June 2018, p. 868-880, 2019. ISSN 03608352. DOI: 10.1016/ j.cie. 2019.05.016. Disponível em: <https://doi.org/10.1016/j.cie. 2019.05.016>.

ANOSHKINA, Y.; MEISEL, F. Interday routing and scheduling of multiskilled teams with consistency consideration and intraday rescheduling. EURO Journal on Transportation and Logistics, Elsevier Ltd, v. 9, n. 3, p. 100012, 2020. ISSN 21924384. DOI: 10.1016/j.ejtl.2020.100012. Disponível em: <https://doi.org/10.1016/j.ejtl.2020.100012>. 
ANWAR, Z.; BIBI, N.; AHSAN, A. Expertise based skill management model for effective project resource allocation under stress in software industry of Pakistan. In: 2013 6th International Conference on Information Management, Innovation Management and Industrial Engineering. [S.l.]: IEEE, nov. 2013. v. 1, p. 509-513. ISBN 978-1-4799-0245-3. DOI: 10 . 1109 / ICIII . 2013. 6702986. Disponível em: <http : / / ieeexplore . ieee . org / document / $6702986 />$.

ANZANELLO, M. J.; FOGLIATTO, F. S. Learning curve models and applications: Literature review and research directions. International Journal of Industrial Ergonomics, Elsevier Ltd, v. 41, n. 5, p. 573-583, 2011. ISSN 01698141. DOI: 10.1016/j . ergon . 2011 .05 .001. Disponível em: <http: //dx.doi.org/10.1016/j.ergon.2011.05.001>.

ARAÚJO, R. F. N. d. Gestão da qualidade aplicada à vigilância continuada da segurança da aviação civil : o caso brasileiro Quality management applied to the continued vigilance of civil aviation safety : The Brazilian case. v. 11, n. 1, p. 8, 2015. Disponível em: <http ://conexaosipaer .com. br/index . $\mathrm{php} / \mathrm{sipaer/article/download/468/492>.}$

ARIA, M.; CUCCURULLO, C. bibliometrix: An R-tool for comprehensive science mapping analysis. Journal of Informetrics, Elsevier Ltd, v. 11, n. 4, p. 959-975, 2017. ISSN 18755879. DOI: 10 . $1016 /$ j · joi . 2017.08 .007$. Disponível em: <https://doi.org/10.1016/j.joi.2017.08.007>.

BRASIL. Lei $\mathrm{n}^{\mathrm{o}}$ 11.182, de 27 de setembro de 2005. Diário Oficial da União. [S.l.]: Diário Oficial da República Federativa do Brasil, 2005. Disponível em: <http : / /www · planalto gov . br/ccivil_03/_ato20042006/2005/Lei/L11182.htm $>$.

CAMPBELL, G. M. A two-stage stochastic program for scheduling and allocating cross-trained workers. Journal of the Operational Research Society, Nature Publishing Group, v. 62, n. 6, p. 1038-1047, 2011. ISSN 14769360. DOI: 10.1057/jors. 2010.16. Disponível em: <http://dx.doi . org/10.1057/jors. 2010.16>.

CASTILLO-SALAZAR, J. A.; LANDA-SILVA, D.; QU, R. Workforce scheduling and routing problems: literature survey and computational study. Annals of Operations Research, Springer US, v. 239, n. 1, p. 39-67, 2016. ISSN 15729338. DOI: 10 . 1007 / s10479-014-1687-2. Disponível em: <http : //dx.doi.org/10.1007/s10479-014-1687-2>. 
CHAKER, B.; AMMAR, M. H.; DHOUIB, D. A Framework for Multi-Skills Inspectors Scheduling with Client Preferences in Service Industry: Real Case. In: 2019 International Colloquium on Logistics and Supply Chain Management (LOGISTIQUA). [S.1.]: IEEE, jun. 2019. p. 1-6. ISBN 978-1-7281-4679-9. DOI: 10 . 1109 / LOGISTIQUA . 2019 . 8907243. Disponível em: <https : / / ieeexplore. ieee.org/document/8907243/>.

COUTO, L. G. G. Viabilidade da Utilização de Softwares em Programação Matemática Inteira: Análise de um problema de grande porte nos Softwares AIMMS e LINGO. [S.l.: s.n.], 2020. p. 91. Disponível em: <https : / / bdm . unb . br / bitstream/10483/27659/1/2020_ LorrannaGabrieleGoncalvesCouto_tcc.pdf $>$.

CUEVAS, R. et al. A mixed integer programming approach to multi-skilled workforce scheduling. Journal of Scheduling, Springer US, v. 19, n. 1, p. 91-106, fev. 2016. ISSN 1094-6136. DOI: 10 . 1007/s10951-015-0450-0. Disponível em: <http ://link.springer .com/10 .1007/s10951-015-0450$0>$.

DAHMEN, S. et al. A two-stage solution approach for personalized multidepartment multi-day shift scheduling. European Journal of Operational Research, Elsevier B.V., v. 280, n. 3, p. 1051-1063, 2020. ISSN 03772217. DOI: $10.1016 /$ j.ejor.2019.07.068.

DASGUPTA, S.; PAPADIMITRIOU, C. H.; VAZIRANI, U. . Algorithms, Dynamic programming. [S.l.: s.n.], 2006. p. 318. ISBN 0073523402. Disponível em: <http://www . cse. ucsd.edu/ dasgupta/mcgrawhill/\%5Cnhttp: //beust . com/algorithms . pdf\%5Cnhttp : / www . e-booksdirectory . com/ details . php? ebook=1050\%5Cnhttp: / / algorithmics . lsi. upc . edu/docs / Dasgupta-Papadimitriou-Vazirani.pdf $>$.

DIAS, M. c. b. Pesquisa operacional em organizações públicas brasileiras. [S.l.: s.n.], 2019.

DOAN, M. P. et al. Solving a real bi-objective skilled agent assignment problem in the service-to-business domain, considering both economic efficiency and agent satisfaction. IFAC-PapersOnLine, Elsevier Ltd, v. 52, n. 13, p. 20262031, 2019. ISSN 24058963. DOI: 10 . $1016 / \mathrm{j}$. ifacol . 2019 . 11 . 503. Disponível em: <https://doi.org/10.1016/j.ifacol.2019.11.503>.

DUNNING, I.; HUCHETTE, J.; LUBIN, M. JuMP: A Modeling Language for Mathematical Optimization. SIAM Review, v. 59, n. 2, p. 295-320, jan. 2017. ISSN 0036-1445. DOI: 10.1137/15M1020575. Disponível em: <https: //epubs.siam.org/doi/10.1137/15M1020575>. 
FIRAT, M.; HURKENS, C. A. J. An improved MIP-based approach for a multi-skill workforce scheduling problem. Journal of Scheduling, v. 15, n. 3, p. 363-380, jun. 2012. ISSN 1094-6136. DOI: 10.1007/s10951-011-0245-x. Disponível em: <http://link .springer .com/10 .1007/s10951-011-0245$\mathrm{x}>$.

FORD, L. R.; FULKERSON, D. R. A Suggested Computation for Maximal Multi-Commodity Network Flows. Management Science, v. 5, n. 1, p. 97 101, out. 1958. ISSN 0025-1909. DOI: 10.1287/mnsc.5.1.97. Disponível em: <http://pubsonline.informs.org/doi/abs/10.1287/mnsc.5.1.97>.

FREITAS JÚNIOR, L. S. P. d. Modelo de transbordo para problemas de designação de inspetores: um estudo de caso na Agência Nacional de Aviação Civil. [S.l.: s.n.], 2017. p. 53. Disponível em: <https://bdm. unb . br/bitstream/10483/18936/1/2017_LauroSilveiraPedreiradeFreitasJ\% C3\%BAnior .pdf $>$.

GILMORE, P. C.; GOMORY, R. E. A linear programming approach to the cutting-stock problem. Operations research, p. 849-859, 1691.

GOMAR, J. E.; HAAS, C. T.; MORTON, D. P. Assignment and Allocation Optimization of Partially Multiskilled Workforce. Journal of Construction Engineering and Management, v. 128, n. 2, p. 103-109, abr. 2002. ISSN 0733-9364. DOI: 10 . 1061/ (ASCE) 0733-9364 (2002) 128:2(103). Disponível em: <http : / / ascelibrary . org / doi / 10 . 1061 /\%28ASCE $\% 290733-9364 \%$ $282002 \% 29128 \% 3 \mathrm{~A} 2 \% 28103 \% 29>$.

GOPALAN, R. The aircraft maintenance base location problem. European Journal of Operational Research, Elsevier B.V., v. 236, n. 2, p. 634-642, 2014. ISSN 03772217. DOI: 10.1016/j . ejor. 2014.01 .007. Disponível em: <http://dx.doi.org/10.1016/j.ejor.2014.01.007>.

GUASTAROBA, G.; CÔTÉ, J. F.; COELhO, L. C. The Multi-Period Workforce Scheduling and Routing Problem. Omega (United Kingdom), Elsevier Ltd, v. 102, p. 102302, 2021. ISSN 03050483. DOI: $10.1016 / \mathrm{j}$. omega . 2020 . 102302. Disponível em: <https ://doi .org/10 .1016/j .omega. 2020. $102302>$.

HANSEN, M.; MCANDREWS, C. Challenges of Measuring Performance for FAA's Safety Oversight System. Transportation Research Record: Journal of the Transportation Research Board, v. 1937, n. 1937, p. 3136, jan. 2005. ISSN 0361-1981. DOI: 10 . 3141/1937-05. Disponível em: $<$ http://trrjournalonline.trb.org/doi/10.3141/1937-05>. 
HEIMERL, C.; KOLISCH, R. Work assignment to and qualification of multiskilled human resources under knowledge depreciation and company skill level targets. International Journal of Production Research, v. 48, n. 13, p. 3759-3781, 2010. ISSN 00207543. DOI: 10.1080/00207540902852785.

HOSSEINIAN, A. H.; BARADARAN, V. An evolutionary algorithm based on a hybrid multi-attribute decision making method for the multi-mode multi-skilled resource-constrained project scheduling problem. Journal of Optimization in Industrial Engineering, v. 12, n. 2, p. 155-178, 2019. ISSN 24233935. DOI: 10.22094/JOIE.2018.556347.1531.

ICAO. Safety Oversight Manual: Part A: The Establishment and Management of a State's Safety Oversight System, p. 48, 2006. Disponível em: <https : //www.icao.int/WACAF/AFIRAN08_Doc/9734_parta_cons_en.pdf >.

KARAM, A.; ATTIA, E. A.; DUQUENNE, P. A MILP model for an integrated project scheduling and multi-skilled workforce allocation with flexible working hours. IFAC-PapersOnLine, Elsevier B.V., v. 50, n. 1, p. 13964-13969, 2017. ISSN 24058963. DOI: 10 .1016/j . ifacol . 2017 . 08 . 2221. Disponível em: <https://doi.org/10.1016/j.ifacol.2017.08.2221>.

KIERMAIER, F.; FREY, M.; BARD, J. F. The flexible break assignment problem for large tour scheduling problems with an application to airport ground handlers. Journal of Scheduling, Springer US, v. 23, n. 2, p. 177209, 2020. ISSN 10991425. DOI: 10.1007/s10951-019-00635-5. Disponível em: <https://doi.org/10.1007/s10951-019-00635-5>.

KOVACS, A. A. et al. Adaptive large neighborhood search for service technician routing and scheduling problems. Journal of Scheduling, v. 15, n. 5, p. 579-600, 2012. ISSN 10946136. DOI: 10.1007/s10951-011-0246-9.

KUO, Y.-H.; LEUNG, J. M.; YANO, C. A. Scheduling of Multi-skilled Staff Across Multiple Locations. Production and Operations Management, v. 23, n. 4, p. 626-644, abr. 2014. ISSN 10591478. DOI: 10.1111/poms. 12184. Disponível em: <http://doi.wiley.com/10.1111/poms.12184>.

LAZZERINI, B.; PISTOLESI, F. Multiobjective Personnel Assignment Exploiting Workers' Sensitivity to Risk. IEEE Transactions on Systems, Man, and Cybernetics: Systems, IEEE, v. 48, n. 8, p. 1267-1282, 2018. ISSN 21682232. DOI: 10.1109/TSMC. 2017.2665349.

LI, Q. et al. Multi-skill project scheduling with skill evolution and cooperation effectiveness. Engineering, Construction and Architectural Management, v. 27, n. 8, p. 2023-2045, 2019. ISSN 09699988. DOI: 10.1108/ECAM06-2019-0294. 
LOPES, T. F. ANÁLISE DE SENSIBILIDADE EM MODELOS DE PROGRAMAÇÃO LINEAR COM SOLUÇÃO DEGENERADA: Revisão sistemática e estudo aplicado na Agência de Aviação Civil. [S.l.: s.n.], 2019. p. 89. Disponível em: <https ://bdm . unb.br/bitstream/ 10483/25820/1/2019_ThaisFerreiraLopes_tcc.pdf $>$.

LYU, Z.; YU, A. J. Consultant assignment and routing problem with priority matching. Computers and Industrial Engineering, Elsevier Ltd, v. 151, October 2020, p. 106921, 2021. ISSN 03608352. DOI: 10.1016/j . cie. 2020. 106921. Disponível em: <https://doi.org/10.1016/j.cie.2020.106921>. MAGHSOUDLOU, H.; AFSHAR-NADJAFI, B.; AKHAVAN NIAKI, S. T. Multi-skilled project scheduling with level-dependent rework risk; three multiobjective mechanisms based on cuckoo search. Applied Soft Computing Journal, Elsevier B.V., v. 54, p. 46-61, 2017. ISSN 15684946. DOI: 10.1016/ j . asoc . 2017.01 .024. Disponível em: <http: //dx . doi .org/10.1016/j . asoc. $2017.01 .024>$.

MOHER, D. et al. Preferred reporting items for systematic review and metaanalysis protocols (PRISMA-P) 2015 statement. Systematic Reviews, v. 4, n. 1, p. 1, dez. 2015. ISSN 2046-4053. DOI: 10 . 1186/2046-4053-4-1. Disponível em: <https : / / systematicreviewsjournal biomedcentral . com/articles/10.1186/2046-4053-4-1>.

NEMBHARD, D. A.; UZUMERI, M. V. An individual-based description of learning within an organization. IEEE Transactions on Engineering Management, v. 47, n. 3, p. 370-378, 2000. ISSN 00189391. DOI: 10.1109/ 17.865905 .

PARASKEVOPOULOS, D. C. et al. Resource constrained routing and scheduling: Review and research prospects. European Journal of Operational Research, Elsevier B.V., v. 263, n. 3, p. 737-754, 2017. ISSN 03772217. DOI: 10.1016/j.ejor.2017.05.035. Disponível em: <http://dx.doi.org/10. 1016/j.ejor.2017.05.035>.

PEREIRA, D. L.; ALVES, J. C.; MOREIRA, M. C. d. O. A multiperiod workforce scheduling and routing problem with dependent tasks. Computers and Operations Research, Elsevier Ltd, v. 118, p. 104930, 2020. ISSN 03050548. DOI: 10 . 1016/ j . cor . 2020 . 104930. Disponível em: <https : //doi.org/10.1016/j.cor.2020.104930>. 
PINHEIRO, R. D. S. Modelo matemático para apoio a decisão no processo de designação de inspetores em missões de fiscalização na ANAC. [S.l.: s.n.], 2018. p. 83. Disponível em: <https : //bdm . unb . br / bitstream/10483/24560/1/2018_RayleneDosSantosPinheiro_tcc.pdf >.

POUR, A. G.; NAJI-AZIMI, Z.; SALARI, M. Sample average approximation method for a new stochastic personnel assignment problem. Computers and Industrial Engineering, Elsevier Ltd, v. 113, p. 135-143, 2017. ISSN 03608352. DOI: 10 . 1016/j . cie. 2017 . 09 . 006. Disponível em: <https : //doi.org/10.1016/j.cie.2017.09.006>.

QIN, S.; LIU, S.; KUANG, H. Piecewise Linear Model for Multiskilled Workforce Scheduling Problems considering Learning Effect and Project Quality. Mathematical Problems in Engineering, v. 2016, 2016. ISSN 15635147. DOI: $10.1155 / 2016 / 3728934$.

REIS, S. A. d.; CELESTINO, V. R. R. Um modelo matemático para alocação de pessoas na gestão da capacidade em serviços públicos. In: p. 14. Disponível em: <https : / / simpep . feb . unesp . br/abrir_arquivo_pdf . php? tipo= artigo\&evento $=13 \& \operatorname{art}=540 \& \mathrm{cad}=20192 \mathrm{\& opcao}=$ com_id $>$.

RESTREPO, M. I.; GENDRON, B.; ROUSSEAU, L. M. Branch-and-price for personalized multiactivity tour scheduling. INFORMS Journal on Computing, v. 28, n. 2, p. 334-350, 2016. ISSN 15265528. DOI: 10.1287/ijoc. 2015.0683.

SAFAEI, N.; BANJEVIC, D.; JARDINE, A. K. Multi-threaded simulated annealing for a bi-objective maintenance scheduling problem. International Journal of Production Research, v. 50, n. 1, p. 63-80, 2012. ISSN 00207543. DOI: 10.1080/00207543.2011.571444.

SILVA, M. A. D. Escalamento de Inspetores de Aviação Civil no Brasil: Formalização do Problema e Metodologia de Resolução. 2018. f. 110. Tese (Doutorado). Disponível em: <https : //repositorio-aberto.up.pt/ bitstream/10216/115992/2/291403.pdf $>$.

SILVA JUNIOR, H. S. d. Estudo Comparativo de Meta-Heurísticas: Otimização do Modelo de Alocação na Agência Nacional de Aviação Civil. [S.l.: s.n.], 2021. p. 44.

SOLANO CHARRIS, E. L.; MONTOYA-TORRES, J. R.; GUERRERORUEDA, W. A decision support system for technician routing with time windows: A case study of a Colombian public utility company. Academia Revista Latinoamericana de Administracion, v. 32, n. 2, p. 138-158, 2019. ISSN 20565127. DOI: 10.1108/ARLA-04-2017-0101. 
THOMÉ, A. M. T.; SCAVARDA, L. F.; SCAVARDA, A. J. Conducting systematic literature review in operations management. Production Planning \& Control, v. 27, n. 5, p. 408-420, abr. 2016. ISSN 0953-7287. DOI: 10.1080/ 09537287.2015.1129464. Disponível em: <https://www.tandfonline.com/ doi/full/10.1080/09537287.2015.1129464>.

VALLS, V.; PÉREZ, Á.; QUINTANILLA, S. Skilled workforce scheduling in Service Centres. European Journal of Operational Research, v. 193, n. 3, p. 791-804, 2009. ISSN 03772217. DOI: 10.1016/j.ejor.2007.11.008.

VAN DEN BERGH, J. et al. Personnel scheduling: A literature review. European Journal of Operational Research, Elsevier B.V., v. 226, n. 3, p. 367-385, 2013. ISSN 03772217. DOI: 10.1016/j . ejor. 2012 .11.029. Disponível em: <http://dx.doi.org/10.1016/j. ejor.2012.11.029>.

WAN, L.; BARD, J. F. Weekly staff scheduling with workstation group restrictions. Journal of the Operational Research Society, v. 58, n. 8, p. 1030-1046, ago. 2007. ISSN 0160-5682. DOI: $10.1057 /$ palgrave.jors . 2602215. Disponível em: <https : //www . tandfonline . com/doi/full/10 . 1057/palgrave. jors. 2602215>.

ZABIHI, S. et al. Multi-objective teaching-learning-based meta-heuristic algorithms to solve multi-skilled project scheduling problem. Computers and Industrial Engineering, Elsevier, v. 136, July, p. 195-211, 2019. ISSN 03608352. DOI: $10.1016 /$ j . cie. 2019 . 07 .032. Disponível em: <https : //doi.org/10.1016/j.cie.2019.07.032>.

ZAMORANO, E.; STOLLETZ, R. Branch-and-price approaches for the Multiperiod Technician Routing and Scheduling Problem. European Journal of Operational Research, Elsevier B.V., v. 257, n. 1, p. 55-68, 2017. ISSN 03772217. DOI: $10.1016 / \mathrm{j}$. ejor . 2016 .06 .058. Disponível em: <http: //dx.doi.org/10.1016/j.ejor.2016.06.058>. 


\section{A}

\section{Classificação dos artigos selecionados da RSL}

Tabela A.1: Dados coletados dos artigos selecionados e modelos propostos

\begin{tabular}{cccc}
\hline Autores & Ano & Contexto & Classe \\
\hline Guastaroba et al. $(2021)$ & 2021 & Manutenção de serviços elétricos & MILP \\
Lyu e Yu $(2021)$ & 2021 & Alocação de consultores & MILP \\
Anoshkina e Meisel (2020) & 2020 & Colaboradores qualificados & MILP \\
Pereira et al. $(2020)$ & 2020 & Colaboradores com atividades dependentes & MILP \\
Kiermaier et al. $(2020)$ & 2020 & Colaboradores com descansos & MILP \\
Dahmen et al. $(2020)$ & 2020 & Colaboradores entre departamentos & MILP \\
Li et al. $(2019)$ & 2019 & Colaboradores qualificados com aprendizagem & MINLP \\
Zabihi et al. $(2019)$ & 2019 & Colaboradores qualificados com aprendizagem & MILP \\
Doan et al. $(2019)$ & 2019 & Colaboradores qualificados com eficiência e satisfação & MILP
\end{tabular}




$\begin{array}{cccc}\text { Hosseinian e Baradaran (2019) } & 2019 & \text { Colaboradores qualificados em atividades multi-skill } & \text { MILP } \\ \text { Solano Charris } \text { et al. }(2019) & 2019 & \text { Colaboradores qualificados com janelas de tempo } & \text { MILP } \\ \text { Lazzerini e Pistolesi (2018) } & 2018 & \text { Colaboradores em atividades com risco } & \text { MILP } \\ \text { Pour et al. }(2017) & 2017 & \text { Colaboradores qualificados com demanda incerta } & \text { MILP } \\ \text { Karam } \text { et al. }(2017) & 2017 & \text { Colaboradores qualificados com aprendizagem e variação na disponibilidade } & \text { MILP } \\ \text { Maghsoudlou } \text { et } \text { al. }(2017) & 2017 & \text { Colaboradores qualificados com risco de retrabalho } & \text { MILP } \\ \text { Qin } \text { et al. }(2016) & 2016 & \text { Colaboradores qualificados com aprendizagem } & \text { MILP }\end{array}$

Tabela A.2: Dados coletados dos artigos selecionados

\begin{tabular}{|c|c|c|c|c|c|c|c|}
\hline Autores & Implementação & Solver & Multi-Períodos & Multi-Origens & $\begin{array}{c}\text { Multi- } \\
\text { Destinos }\end{array}$ & Skills & Grupos \\
\hline Guastaroba et al. (2021) & - & CPLEX & $\checkmark$ & & $\checkmark$ & $\checkmark$ & Ambos \\
\hline Anoshkina e Meisel (2020) & JAVA & CPLEX & $\checkmark$ & & $\checkmark$ & $\checkmark$ & Ambos \\
\hline Pereira et al. (2020) & Python 3 & CPLEX & $\checkmark$ & & $\checkmark$ & $\checkmark$ & Grupos \\
\hline Li et al. (2019) & MATLAB & CPLEX & $\checkmark$ & & $\checkmark$ & $\checkmark$ & Ambos \\
\hline Zabihi et al. (2019) & - & - & $\checkmark$ & & & $\checkmark$ & Ambos \\
\hline Doan et al. (2019) & CPLEX Studio & CPLEX & & & $\checkmark$ & $\checkmark$ & Ambos \\
\hline
\end{tabular}




\begin{tabular}{|c|c|c|c|c|c|c|c|}
\hline Anoshkina e Meisel (2019) & - & CPLEX & $\checkmark$ & & $\checkmark$ & $\checkmark$ & Ambos \\
\hline $\begin{array}{l}\text { Hosseinian e Baradaran } \\
\qquad(2019)\end{array}$ & GAMS & - & $\checkmark$ & & $\checkmark$ & $\checkmark$ & Ambos \\
\hline Solano Charris et al. (2019) & Excel & Solver & $\checkmark$ & & $\checkmark$ & & Ambos \\
\hline Lazzerini e Pistolesi (2018) & - & - & & & $\checkmark$ & & Individual \\
\hline Pour et al. (2017) & - & CPLEX & $\checkmark$ & & $\checkmark$ & $\checkmark$ & Individual \\
\hline Karam et al. (2017) & - & CPLEX & $\checkmark$ & & $\checkmark$ & $\checkmark$ & Ambos \\
\hline Qin et al. (2016) & LINGO & $\begin{array}{l}\text { LINGO e } \\
\text { CPLEX }\end{array}$ & $\checkmark$ & & $\checkmark$ & $\checkmark$ & Individual \\
\hline Safaei et al. (2012) & LINGO & LINGO & $\checkmark$ & & $\checkmark$ & $\checkmark$ & Ambos \\
\hline Lim-Apo (2021) - 1 & $\begin{array}{l}\text { JuMP e } \\
\text { LINGO }\end{array}$ & $\begin{array}{c}\text { CPLEX, Gurobi } \\
\text { e LINGO }\end{array}$ & & $\checkmark$ & $\checkmark$ & $\checkmark$ & Ambos \\
\hline
\end{tabular}


B

\section{Planilha com os dados após pré-processamento}

\begin{tabular}{|c|c|c|c|c|c|c|c|c|c|c|c|c|c|c|c|c|c|c|c|}
\hline MISSAC & TIVIDAD & DESTINC & OURAC: & QUIPE & \multicolumn{2}{|c|}{ PESSOA DISPONIBILIDADE } & \multicolumn{2}{|c|}{ ORIGENS DESTINOS } & \multicolumn{2}{|c|}{ ORIGEM DESTINO } & \multirow{2}{*}{$\begin{array}{c}\text { CUSTO } \\
0\end{array}$} & \multirow{2}{*}{$\frac{\text { TEMPO }}{0}$} & \multicolumn{3}{|c|}{ PESSOA ORIGEM DESTINO } & \multicolumn{3}{|c|}{ PESSOA ORIGEM MISSAO } & \multirow{2}{*}{$\begin{array}{c}\text { DESTINO } \\
\text { SBBBR }\end{array}$} \\
\hline 1 & AT688 & SBIZ & 0,5 & 2 & P1 & 20 & $\mathrm{DF}$ & SBBR & DF & SBBR & & & P1 & DF & SBBR & P1 & DF & 10 & \\
\hline 2 & AT688 & SBRP & 0,5 & 2 & P2 & 20 & RJ & SBCF & DF & SBGR & 295 & 0,5 & P1 & DF & SBCF & P1 & DF & 31 & SBBR \\
\hline 3 & AT688 & SBGO & 0.5 & 2 & P4 & 20 & SP & SBCG & DF & SBRE & 3055 & 0,5 & P1 & $\mathrm{DF}$ & SBCG & P1 & DF & 85 & SBBR \\
\hline 4 & AT688 & SBRJ & 0,5 & 2 & P5 & 20 & & SBCT & DF & SBCF & 337,5 & 0,5 & P1 & DF & SBCT & P1 & DF & 86 & SBBR \\
\hline 5 & AT688 & SBSP & 0,5 & 2 & P6 & 20 & & SBEG & DF & SBLO & 344 & 0,5 & P1 & DF & SBEG & P1 & DF & 87 & $\begin{array}{ll}\text { SBDBR } \\
\text { SBBR }\end{array}$ \\
\hline 6 & $\begin{array}{l}\text { Alab8 } \\
\text { AT688 }\end{array}$ & SBKP & 0,5 & 2 & $\begin{array}{l}\text { P7 } \\
\text { P7 } 10\end{array}$ & 20 & & $\begin{array}{l}\text { SBEG } \\
\text { SBFL }\end{array}$ & $\begin{array}{l}\text { DF } \\
\text { DF }\end{array}$ & SBGO & $\begin{array}{l}344 \\
375\end{array}$ & 0,5 & $\begin{array}{ll}P 1 \\
\text { P1 }\end{array}$ & 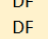 & $\begin{array}{l}\text { SBEG } \\
\text { SBFL }\end{array}$ & P1 & $\begin{array}{l}\mathrm{DF} \\
\mathrm{DF}\end{array}$ & 88 & $\begin{array}{l}\text { SBBK } \\
\text { SBBR }\end{array}$ \\
\hline 7 & AT688 & SBSL & 0,5 & 2 & P8 & 20 & & SBGL & DF & SBCT & 443 & 0,5 & P1 & DF & SBGL & P1 & DF & 89 & SBBR \\
\hline 8 & AT688 & SBSM & 0,5 & 2 & P9 & 20 & & SBGO & DF & SBCG & 474 & 0,5 & P1 & DF & SBGO & $\mathrm{P} 1$ & DF & 90 & SBBR \\
\hline 9 & AT688 & SBFL & 0,5 & 2 & P10 & 20 & & SBGR & DF & SBRP & 492 & 0,5 & P1 & DF & SBGR & P1 & DF & 91 & SBBR \\
\hline 10 & AT688 & SBBR & 0,5 & 2 & P11 & 20 & & SBIZ & $\mathrm{DF}$ & SBFL & 560,5 & 0.5 & P1 & $\mathrm{DF}$ & SBI & P1 & DF & 36 & SBCF \\
\hline 11 & AT688 & SBKP & 0,5 & 2 & P12 & 20 & & SBJP & DF & SBSN & 563,5 & 1 & P1 & DF & SBKP & P1 & DF & 39 & SBCF \\
\hline 12 & AT688 & SBRP & 0,5 & 2 & P13 & 20 & & SBKP & DF & SBSL & 583 & 1 & P1 & DF & SBLO & P1 & DF & 115 & SBCF \\
\hline 13 & AT688 & SBGO & 0,5 & 2 & P14 & 20 & & SBLO & DF & SBPA & 604,5 & 0,5 & P1 & DF & & P1 & DF & 116 & SBCF \\
\hline 14 & AT688 & SBEG & 0,5 & 2 & P15 & 20 & & SBPA & DF & SBIZ & 609 & 0,5 & P1 & DF & SBR & P1 & DF & 107 & SBCG \\
\hline 15 & AT688 & SBGO & 0,5 & 2 & P16 & 20 & & SBRF & DF & SBKP & 616 & 0,5 & P1 & DF & SBRP & P1 & $\begin{array}{l}\text { DF } \\
\text { D }\end{array}$ & 108 & SBCG \\
\hline 16 & AT688 & SBSP & 0,5 & 2 & P17 & 20 & & SBR & DF & SBEG & 636,5 & 0,5 & P1 & DF & SBSJ & P1 & DF & 109 & SBCG \\
\hline 17 & AT116 & SBGR & 5 & 4 & P18 & 20 & & SBRP & DF & SBJP & 647 & 0,5 & P1 & DF & SBSL & P1 & DF & 110 & SBCG \\
\hline 18 & AT117 & SBBR & 1 & 2 & P19 & 20 & & SBSS & DF & SBSJ & 727 & 1 & P1 & DF & SBSM & P1 & DF & 111 & SBCG \\
\hline 19 & AT118 & SBKP & 2 & 1 & P20 & 20 & & SBSL & DF & SBSM & 759 & 0,5 & P1 & DF & SBSP & P1 & DF & 112 & SBCG \\
\hline 20 & AT689 & SBSP & 0,5 & 2 & P22 & 20 & & SBSM & DF & SBGL & 834,5 & 0,5 & P2 & SP & SBBR & P1 & DF & 113 & SBCG \\
\hline 21 & AT356 & SBSP & 1 & 1 & P23 & 20 & & SBSN & DF & SBSP & 834,5 & 0,5 & P2 & SP & SBCF & P1 & DF & 114 & SBCG \\
\hline $\begin{array}{l}21 \\
22\end{array}$ & AT357 & SBSKP & $\begin{array}{l}1 \\
3\end{array}$ & $\begin{array}{l}1 \\
2\end{array}$ & P24 & 20 & & $\begin{array}{l}\text { SBSN } \\
\text { SBSP }\end{array}$ & $\begin{array}{l}\text { DF } \\
\text { DF }\end{array}$ & $\begin{array}{l}\text { SBSP } \\
\text { SBRJ }\end{array}$ & $\begin{array}{l}833,5 \\
1204,5\end{array}$ & $\begin{array}{l}0,5 \\
0,5\end{array}$ & P2 & $S P$ & $\begin{array}{l}\text { SBCF } \\
\text { SBCG }\end{array}$ & $\begin{array}{l}\text { P1 } \\
\text { P1 }\end{array}$ & $\begin{array}{l}\text { DF } \\
\text { DF }\end{array}$ & $\begin{array}{l}114 \\
33\end{array}$ & SBCT \\
\hline 23 & AT358 & SBKP & 3 & 2 & $\begin{array}{l}\text { P25 } \\
\text {. }\end{array}$ & 20 & & & RJ & SBRJ & 0 & 0 & P2 & SP & & P1 & DF & 40 & SBCT \\
\hline 24 & AT4 & SBSF & 4 & 2 & P2 & 20 & & & RJ & SBG & 0 & 0 & $\mathrm{P} 2$ & SP & SBE & P1 & DF & 14 & SBEG \\
\hline 25 & ATE & SBS & 2 & 2 & & 20 & & & R & SB & 136 & 0,5 & P2 & SP & & P1 & DF & $\begin{array}{l}29 \\
29\end{array}$ & SBEG \\
\hline 26 & AT687 & SBGR & 2 & 2 & P28 & 20 & & & RJ & SBCF & 222 & 0,5 & P2 & SP & SB & P1 & DF & 9 & SBFL \\
\hline 27 & AT689 & SBJP & 0,5 & 2 & P29 & 20 & & & RJ & SBGR & 333 & 0,5 & P2 & SP & SBGO & P1 & DF & 81 & SBFL \\
\hline 28 & AT1 & SBSJ & 2 & 1 & P30 & 20 & & & RJ & SBLO & 358 & 0,5 & P2 & SP & SBGR & P1 & DF & 82 & SBFL \\
\hline
\end{tabular}

Figura B.1: Planilha com os dados após pré-processamento 


\section{C}

\section{Mapa com alocação dos inspetores no território brasileiro}

A Figura C.1 apresenta os arcos de alocação possíveis entre as origens e destinos; nesse exemplo as origens são o Distrito Federal, Rio de Janeiro e São Paulo; os destinos são 22 aeroportos distribuídos em 15 estados e no Distrito Federal. Considera a existência de três origens e 22 destinos, existem 66 arcos possíveis. Em azul estão as ligações possíveis e em vermelho é apresentada uma possível solução para o problema. A solução apresentada apresenta um exemplo simplificado da solução do modelo, uma vez que o modelo determina o colaborador que realizará as atividades, e não somente a origem do colaborador que atende a demanda.

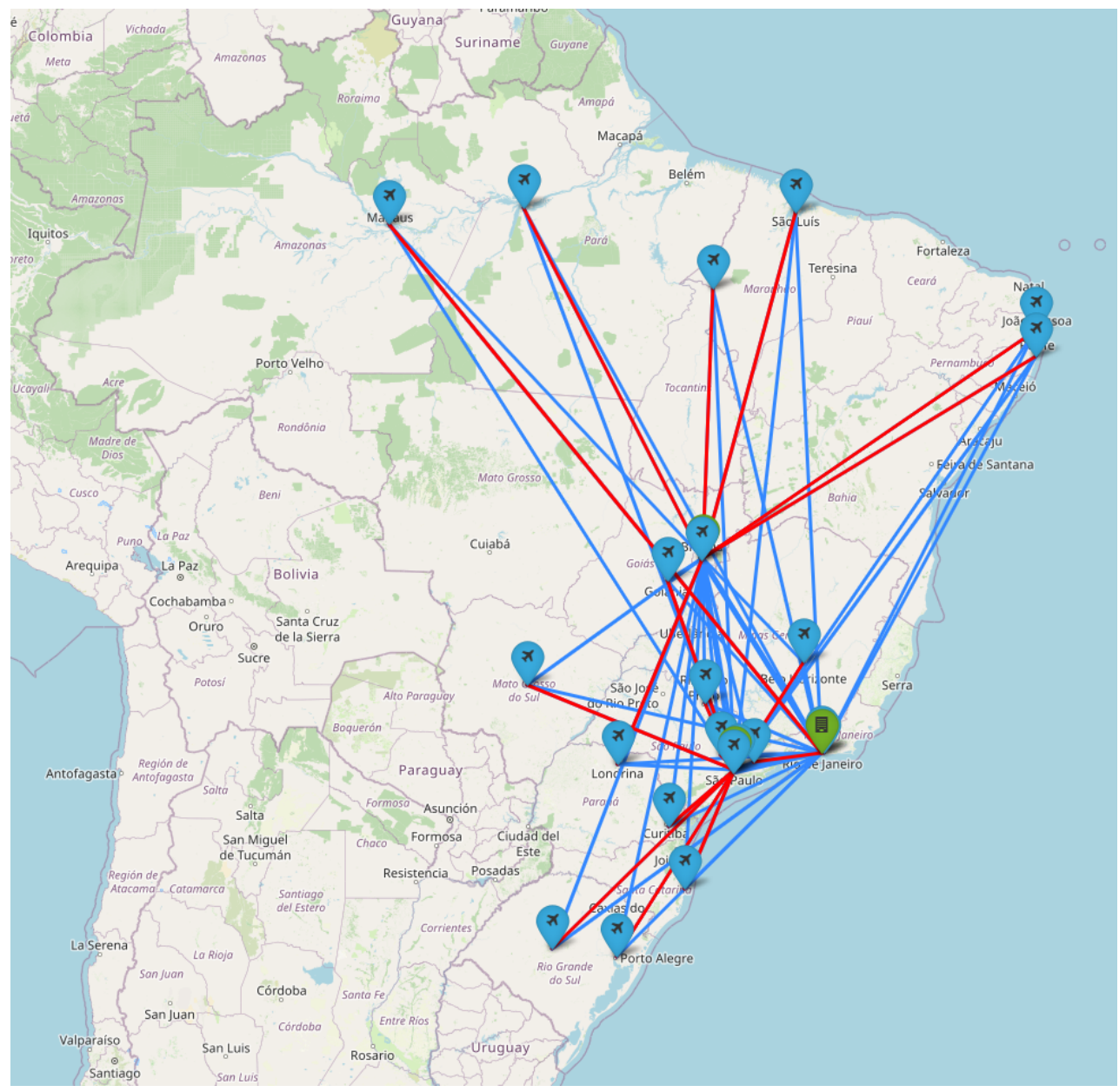

Figura C.1: Mapa com os arcos possíveis e possível solução 
D

\section{Programação dinâmica para criação de colunas}

A implementação da programação dinâmica apresentada na D.2 é uma adaptação de um problema de alocação de itens em uma mochila apresentada por Dasgupta et al. (2006), na Equação 4-24 e no Algoritmo 1.

Onde $w$ é a capacidade da mochila, $I$ é uma lista com os itens disponíveis, $w$ é o peso de cada item e $v$ é o benefício ao carregar cada item na mochila. No exemplo apresentado, considerando $W=10, I=[1,2,3,4], w=[6,3,4,2] \mathrm{e}$ $v=[30,14,16,9]$, devem ser carregados os itens 1 e 3 , com um beneficio de 46 unidades. Essa combinação tem um peso de 10 e respeita o $W$ da mochila, que também é 10 .

A Figura D.1 apresenta a matriz que o procedimento cria. A partir desse resultado é possível descobrir o valor da mochila ótimo e posteriormente a combinação dos itens da mochila a serem incluídos.

No exemplo, a mochila possui capacidade $(w)$ de 10, o que é representado pelas linhas da Figura D.1, os itens $(I)$ são representados pelas colunas. É acrescentado um linha com peso 0 e uma coluna para item 0 .

O processo inicia com valores de 0 para a coluna item 0 , assim como para a linha peso 0. É feito um for para os itens 1 ao 4 e para o peso 1 ao 10 . Se o peso do item for maior do que o peso indicado pela linha, o valor da célula será o valor da célula da esquerda. Caso contrario, é atribuído o máximo entre o valor da célula da esquerda ou o valor da célula da esquerda da linha de peso atual menos o peso do item somado o benefício do item. A lógica desse procedimento foi apresentada no Algoritmo 1.

Na Figura D.1, o valor da célula da coluna da direita da última linha é o valor ótimo da mochila, ou seja, é o maior benefício que se pode ter em uma combinação dos itens disponíveis. Todavia, é preciso realizar um procedimento para descobrir os itens que devem ser carregados.

Para isso, o procedimento inicia no canto inferior direito e deve chegar no canto superior esquerdo. No canto inferior direito inicia o processo, se ao valor da célula da esquerda (46) for igual o valor da célula atual (46) foram iguais então o item dessa coluna não é levado. Assim, agora na coluna do item 


\begin{tabular}{|c|c|c|c|c|c|}
\hline & ITEM 0 & ITEM 1 & ITEM 2 & ITEM 3 & ITEM 4 \\
\hline PESO 0 & 0 & 0 & 0 & 0 & 0 \\
\hline PESO 1 & 0 & 0 & 0 & 0 & 0 \\
\hline PESO 2 & 0 & 0 & 0 & 0 & 9 \\
\hline PESO 3 & 0 & 0 & 14 & 14 & 14 \\
\hline PESO 4 & 0 & 0 & 14 & 16 & 16 \\
\hline PESO 5 & 0 & 0 & 14 & 16 & 23 \\
\hline PESO 6 & 0 & 304 & 30 & 30 & 30 \\
\hline PESO 7 & 0 & 30 & 30 & 30 & 30 \\
\hline PESO 8 & 0 & 30 & 30 & 30 & 39 \\
\hline PESO 9 & 0 & 30 & 44 & 44 & 44 \\
\hline PESO 10 & 0 & 30 & 44 & 46 & -46 \\
\hline
\end{tabular}

Figura D.1: Matriz da programação dinâmica

3 na linha de peso 10 e a coluna da esquerda é diferente, nesse caso, esse item é levado e deve-se subtrair da linha o peso do item $3(10-4)=6$, e ir para essa linha, na coluna da esquerda. O procedimento deve ser realizado até chegar na célula superior da esquerda.

Utilizando como referência as setas indicadas na Figura D.1, é possível observar que, quando a seta está na vertical, o item da origem não é carregado; e, quando a seta está na diagonal, o item da origem é carregado. Assim, compõem essa mochila os itens 1 e 3 . A soma dos pesos desses itens é 10 $(6+4)$ e o benefício desses itens é de $46(30+16)$.

Esse código foi utilizado no modelo de Pricing apresentado na Figura 4.3 , poderia ter sido utilizado um modelo matemático Inteiro para essa etapa, todavia, o custo computacional da programação dinâmica é significativamente menor em relação ao modelo inteiro. 


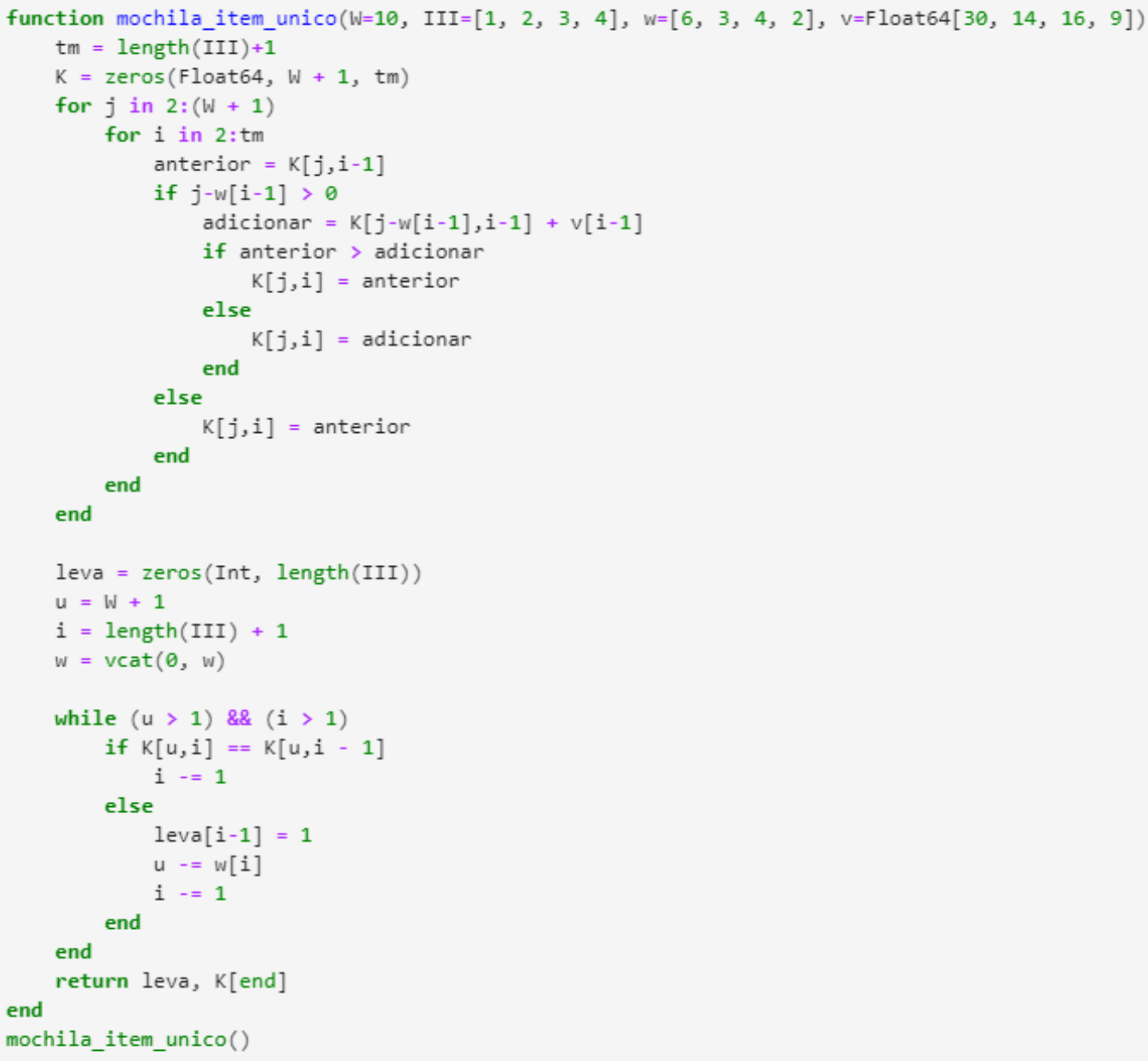

$([1,0,1,0], 46.0)$

Figura D.2: Código da programação dinâmica implementado em Julia 


\section{E \\ Heurística - processo de seleção de variáveis}

O processo de resolução do Modelo MAIM foi apresentado na Figura 4.1. Serão apresentadas considerações para a resolução do fluxograma.

O MAI é solucionado com relaxação das variáveis inteiras para a heurística. Foram feitas as seguintes considerações:

1. a heurística, proposta pelo autor, levou em consideração aspectos da geração de colunas. A variável reduzida é a variável de alocação dos inspetores na missão. Entretanto, poderiam ser utilizadas outras variáveis para essa redução - outra alternativa seria utilizar a variável que determina quando a atividade deve ocorrer, que não existe no MAI, que poderia ser incluída, uma vez que existe no MAIM;

2. como não existe garantia de que as colunas do MAI gerem uma solução viável no MAIM, o Modelo 1 Relaxado permite que o colaborador utilize até $75 \%$ de sua disponibilidade, essa regra foi utilizada nas instâncias, exceto nas A1, B1 e C1, onde todas as inspeções exigem apenas 1 colaborador;

3. o benefício do item é o valor absoluto do preço sombra da alocação do inspetor nas missões, foi acrescentada uma pequena perturbação no preço sombra para reduzir a chance de empates;

4. o problema possui alta simetria, dado que muitas pessoas possuem as mesmas habilitações. Em cada rodada, para cada nível de peso é permitido que exista somente uma alocação para cada valor de preço sombra. Caso existam duas alocações que possuem o peso 5 e preço sombra de 100, o valor do preço sombra será alterado para 0 nessa rodada. Isso é realizado para evitar que seja criada uma coluna atendendo somente a uma missão;

5. para a geração de colunas, no momento inicial foram geradas $n$ colunas com 10 itens em cada uma, essa é a primeira etapa para iniciar a heurística; 
6. para o peso do item, uma alternativa inicial seria atribuir o mesmo peso para todos os itens, o que é uma opção viável. Se isso for realizado, não seria necessária a programação dinâmica, uma vez que bastaria uma simples ordenação e seleção dos $n$ maiores valores do preço sombra. Todavia, nessa etapa foi feito outro procedimento, que busca indiretamente distribuir atividades de inspeção para inspetores que possuem menos atividades. A capacidade do peso dos itens foi atribuída em 50 e o peso dos itens é a normalização entre 5 e 8, levando em consideração a quantidade de habilitações que o inspetor possui. Por exemplo, supondo que existam colaboradores com 10 habilitações até colaboradores com 20, os inspetores com 10 inspeções terão peso de 5 e os com 20 terão peso de 8. Os valores podem ser ajustados, se necessário;

7. foi estabelecido um limite de 100 colunas para cada instância;

8. na heurística, é possível acrescentar mais de uma coluna em cada problema de Pricing solucionado. Na solução apresentada, foi utilizada apenas uma coluna em cada rodada, mas o código permite que sejam acrescentadas $n$ colunas, se desejado.

Após a geração das colunas, o MAI é solucionado para reduzir a quantidade de colunas respeitando o valor de custos apresentados na Tabela 5.2, e é incluído o conjunto de períodos nas variáveis; as instâncias A possuem 14 períodos, a B 21 períodos e a C 28 períodos.

A quantidade de variáveis após a realização desse processo é apresentada na Tabela 5.5, a redução é de aproximadamente $90 \%$.

O procedimento realizado anteriormente é realizado agora com a utilização do MAIM, com as mesmas considerações. Ao final o modelo é solucionado relaxado, para descoberta do menor custo, e é solucionado novamente, ainda relaxado, minimizando a quantidade de colunas com o custo obtido da solução anterior. As colunas dessa etapa são selecionadas, e o MAIM é solucionado com as variáveis das colunas selecionadas.

Cada coluna representa um conjunto de variáveis de decisão. No MAIM as colunas são compostas pelas variáveis $A M_{i, m}$, enquanto que no MAIM são compostas pelas variáveis $A M_{i, m, p}$. O tamanho de cada coluna foi exposto na etapa 6 do processo de seleção de variáveis. 
F

\section{Total de variáveis do MAIM}

A Tabela F.1 apresenta o total de combinações, combinações viáveis e quantidade de variáveis a partir da heurística.

Tabela F.1: Variáveis do MAIM

\begin{tabular}{|c|c|c|c|c|c|c|c|}
\hline & \multicolumn{2}{|c|}{ Total de combinações } & \multicolumn{2}{|c|}{ Combinações viáveis } & \multicolumn{3}{|c|}{ Geração de Colunas } \\
\hline Instâncias & Alocação em viagens & Arco de missões & Alocação em viagens & Arco de missões & Inspetores & Alocação em viagens & Arco de missões \\
\hline A1 & 4.256 & 7.448 & 2.044 & 2.548 & 13 & 280 & 322 \\
\hline A2 & 33.824 & 93.016 & 25.018 & 57.092 & 47 & 1.722 & 3.010 \\
\hline A3 & 28.224 & 84.672 & 9.968 & 28.644 & 50 & 1.918 & 3.220 \\
\hline B1 & 7.182 & 15.960 & 3.717 & 5.880 & 15 & 462 & 588 \\
\hline $\mathrm{B} 2$ & 60.249 & 209.286 & 46.977 & 126.945 & 45 & 3.045 & 6.783 \\
\hline B3 & 47.628 & 164.052 & 15.939 & 51.660 & 67 & 2.940 & 3.990 \\
\hline $\mathrm{C} 1$ & 12.628 & 26.404 & 5.684 & 9.072 & 20 & 812 & 1.008 \\
\hline $\mathrm{C} 2$ & 93.016 & 498.904 & 78.876 & 304.248 & 93 & 9.828 & 19.600 \\
\hline C3 & 74.088 & 433.944 & 28.616 & 147.364 & 72 & 4.256 & 11.508 \\
\hline
\end{tabular}




\section{G \\ Identificação das alocações}

Após a solução dos modelos matemáticos, é necessário identificar a alocação dos colaboradores nas atividades de alocação. No caso do Modelo 2, além disso, é preciso identificar o período em que as atividades e os deslocamentos devem ser realizados.

O pacote JuMP permite consulta para identificação dos valores das variáveis de decisão. Assim, foi criada uma função para apresentação dos resultados de forma estruturada.

A seguir é apresentada a solução obtida a partir da função com os dados da alocação da instância A2, que possui 14 períodos. Dessa forma, o inspetor se desloca até o destino, realiza uma ou mais inspeções e retorna para a origem, onde pode realizar o mesmo processo em outro destino - ou até no mesmo aeroporto, em algum período posterior.

É importante destacar que, caso a missão exija mais de um colaborador para a realização da inspeção, o modelo irá alocar a quantidade de pessoas exigidas no mesmo período.

Essa função permite a validação da solução e pode ser utilizado pelo tomador de decisão para realizar a alocação dos inspetores.

As Figuras G.1 e G.2 apresentam parte da solução obtida, que respeita a ordem de alocação. Nos casos em que o colaborador reside próximo ao aeroporto, ele pode realizar a inspeção no mesmo período em que realiza a primeira inspeção. Isso ocorre no primeiro caso da Figura G.1, em que o colaborador $\mathrm{P} 4$ reside em SP, vai para SBGR no período 2, já inicia a inspeção 7 no período 1 , posteriormente retornando para SP.

$\mathrm{Na}$ Figura G.2, existem exemplos em que os inspetores realizam mais de uma inspeção em um mesmo deslocamento. Como não existe custo nos deslocamentos para os aeroportos próximos, o modelo pode alocar a mesma pessoa em períodos de tempos diferentes. O colaborador P138 foi alocado entre o período 1 e 3 , depois no 6 e 7, e, por fim, entre os períodos 9 e 11, isso ocorre pois é mais econômico o colaborador voltar para casa, realizando uma viagem de ida e volta, do que esperar no destino o início da próxima inspeção, caso em que ele receberia ajuda de custo. 


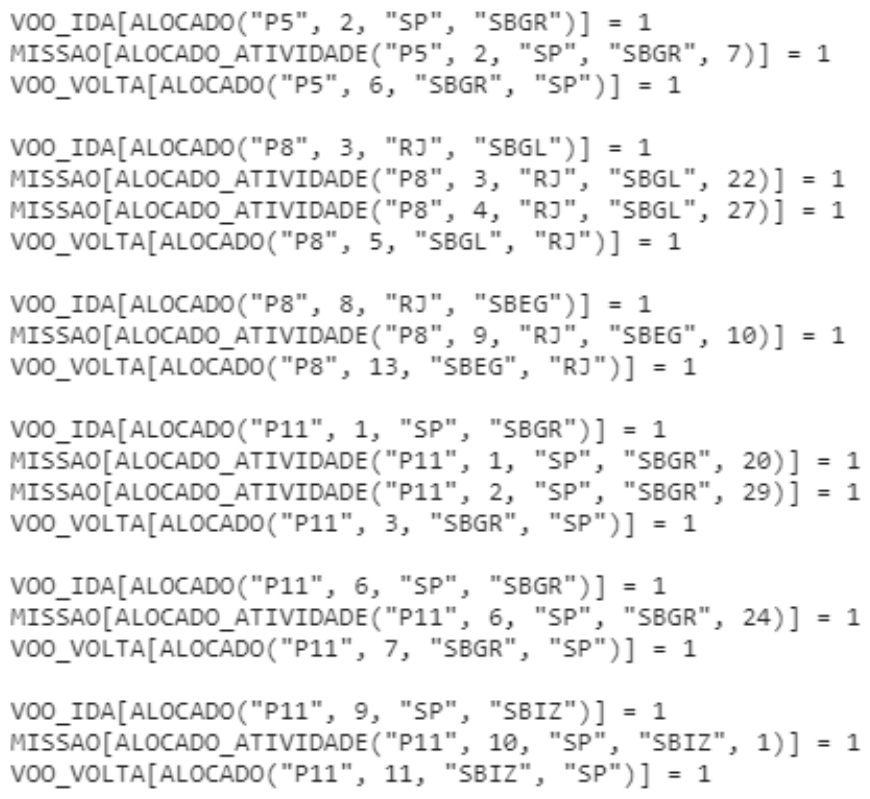

Figura G.1: Parte da solução do MAIM

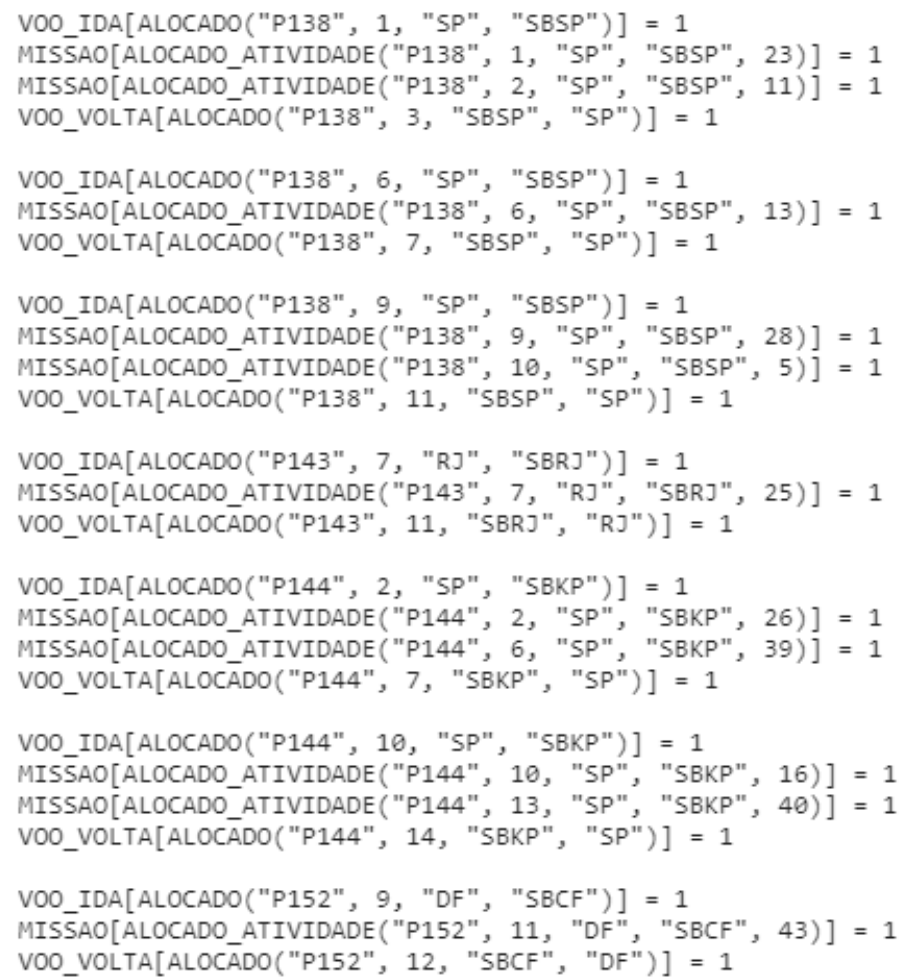

Figura G.2: Parte da solução do MAIM 


\section{H \\ Informações das instâncias}

A seguir são apresentados dados e solução da instância C2, com a utilização do Modelo 1. As análises são aplicáveis para as outras instâncias e para o Modelo 2.

A Tabela H.1 apresenta a demanda de atividades por missão, a duração em períodos, tamanho da equipe necessária. A coluna tempo é calculada a partir da multiplicação da quantidade vezes a duração e equipe. A demanda é a quantidade de inspeções de cada tipo vezes o tamanho da equipe, e, por fim, é apresentada a oferta, ou seja, quantos inspetores são qualificados para realizar tal inspeção.

Tabela H.1: Atividades e inspetores disponíveis

\begin{tabular}{ccccccc}
\hline ATIVIDADE & QUANTIDADE & DURAÇÃO & EQUIPE & TEMPO & DEMANDA & OFERTA \\
\hline AT688 & 24 & 1 & 2 & 48 & 48 & 152 \\
AT689 & 8 & 1 & 2 & 16 & 16 & 91 \\
AT116 & 5 & 10 & 4 & 200 & 20 & 91 \\
AT117 & 5 & 2 & 2 & 20 & 10 & 91 \\
AT118 & 4 & 4 & 1 & 16 & 4 & 91 \\
AT356 & 4 & 2 & 1 & 8 & 4 & 91 \\
AT357 & 4 & 6 & 2 & 48 & 8 & 91 \\
AT358 & 4 & 6 & 2 & 48 & 8 & 91 \\
AT473 & 4 & 8 & 2 & 64 & 8 & 91 \\
AT686 & 4 & 4 & 2 & 32 & 8 & 91 \\
AT687 & 4 & 4 & 2 & 32 & 8 & 91 \\
AT1 & 4 & 4 & 1 & 16 & 4 & 73 \\
AT2 & 4 & 4 & 1 & 16 & 4 & 73 \\
AT102 & 4 & 4 & 2 & 32 & 8 & 73 \\
AT103 & 4 & 4 & 2 & 32 & 8 & 73 \\
AT104 & 4 & 2 & 2 & 16 & 8 & 73 \\
AT105 & 4 & 2 & 2 & 16 & 8 & 73 \\
AT106 & 4 & 4 & 2 & 32 & 8 & 73 \\
AT107 & 4 & 4 & 2 & 32 & 8 & 73 \\
AT108 & 4 & 4 & 2 & 32 & 8 & 73 \\
AT109 & 4 & 4 & 2 & 32 & 8 & 73 \\
AT113 & 4 & 1 & 1 & 4 & 4 & 73 \\
AT114 & 4 & 2 & 2 & 16 & 8 & 73
\end{tabular}

A quantidade de inspeções em cada destino é apresentada na Tabela H.2; é possível verificar que, para essa instância, existe grande concentração de inspeções em alguns aeroportos. 
Tabela H.2: Inspeções por destino

\begin{tabular}{ll}
\hline DESTINO & MISSÕES \\
\hline SBKP & 28 \\
SBGR & 13 \\
SBSP & 12 \\
SBBR & 12 \\
SBCG & 8 \\
SBCF & 6 \\
SBPA & 6 \\
SBGO & 5 \\
SBFL & 5 \\
SBCT & 5 \\
SBGL & 4 \\
SBEG & 3 \\
SBRJ & 2 \\
SBIZ & 1 \\
SBSL & 1 \\
SBSM & 1 \\
SBRP & 1 \\
SBJP & 1 \\
SBSJ & 1 \\
SBLO & 1 \\
SBSN & 1 \\
SBRF & 1
\end{tabular}

A Tabela H.3 apresenta a solução do problema, em que um inspetor irá realizar 14 atividades, dois realizarão 11 atividades, e assim por diante. Os modelos não possuem balanceamento de atividades entre os colaboradores.

Em alguns casos, como o apresentado, pode ocorrer de alguns inspetores acumularem grande quantidade de trabalho, uma vez que eles podem maximizar o deslocamento para um destino e realizar diversas inspeções, evitando que outra pessoa também se desloque.

A soma das inspeções atendidas por cada uma das três origens é apresentada na Tabela H.4.

A quantidade de destinos que cada inspetor irá visitar é apresentada na Tabela H.5. 
Tabela H.3: Inspeções por colaborador

\begin{tabular}{cc}
\hline INSPEÇÕES & QUANTIDADE \\
\hline 14 & 1 \\
11 & 2 \\
10 & 1 \\
9 & 2 \\
8 & 4 \\
7 & 1 \\
5 & 4 \\
4 & 4 \\
3 & 10 \\
2 & 14 \\
1 & 29
\end{tabular}

Tabela H.4: Origem do colaborador que atenderá a inspeção

\begin{tabular}{cc}
\hline INSPEÇÕES & QUANTIDADE \\
\hline O1 & 170 \\
O2 & 39 \\
O3 & 17
\end{tabular}

Tabela H.5: Quantidade de destinos que cada inspetor irá visitar

\begin{tabular}{cc}
\hline INSPEÇÕES & QUANTIDADE \\
\hline 1 & 35 \\
2 & 42 \\
3 & 39 \\
4 & 12
\end{tabular}

